Luciana Bertocco de Paiva Haddad

Expressão de marcadores imunoistoquímicos de origem tecidual e de carcinogênese nos adenocarcinomas tipo intestinal e pancreatobiliar da ampola de Vater

Tese apresentada à Faculdade de Medicina da Universidade de São Paulo para obtenção do título de Doutor em Ciências

Área de concentração: Cirurgia do Aparelho Digestivo

Orientador: Prof. Dr. José Jukemura

São Paulo 
Dados Internacionais de Catalogação na Publicação (CIP)

Preparada pela Biblioteca da

Faculdade de Medicina da Universidade de São Paulo

Creprodução autorizada pelo autor

Haddad, Luciana Bertocco de Paiva

Expressão de marcadores imunoistoquímicos de origem tecidual e de carcinogênese nos adenocarcinomas tipo intestinal e pancreatobiliar da ampola de Vater / Luciana Bertocco de Paiva Haddad. -- São Paulo, 2009.

Tese(doutorado)--Faculdade de Medicina da Universidade de São Paulo. Departamento de Gastroenterologia.

Área de concentração: Cirurgia do Aparelho Digestivo.

Orientador: José Jukemura.

Descritores: 1.Ampola hepatopancreática 2.Adenocarcinoma 3.Imunoistoquímica 4.Cirurgia 5.Prognóstico

USP/FM/SBD-342/09 


\section{NORMATIZAÇÃO ADOTADA}

Esta tese está de acordo com as seguintes normas, em vigor no momento desta publicação:

Referências: adaptado de International Committee of Medical Journals Editors (Vancouver)

Universidade de São Paulo. Faculdade de Medicina. Serviço de Biblioteca e Documentação. Guia de apresentação de dissertações, teses e monografias. Elaborado por Anneliese Carneiro da Cunha, Maria Julia de A. L. Freddi, Maria F. Crestana, Marinalva de Souza Aragão, Suely Campos Cardoso, Valéria Vilhena. $2^{\underline{a}}$ Ed. São Paulo: Serviço de Biblioteca e Documentação; 2005.

Abreviatura dos títulos dos periódicos de acordo com List of Journals Indexed in Index Medicus. 
a minha mãe Maria Lúcia por um amor sem medidas

ao meu pai Naief meu caminho, meu espelho aos meus irmão, Naief, Youssef e Mariana grande alegria de minha vida e a Wellington amor da minha vida 


\section{AgRADECIMENTOS}

Ao Dr. Wellington Andraus, pela contribuição essencial para a elaboração desta tese, direta ou indiretamente, e pelo amor e companheirismo em todos os momentos

Ao Prof. Dr. José Jukemura, mestre e amigo, que diariamente me ensina a arte de ser médico, pela orientação sabia e confiança depositada.

À Dra. Rosely Patzina pela sua irrestrita colaboração e inestimável ajuda na análise dos estudos histológicos e demais etapas desta tese.

Ao Prof. Dr. Ivan Cecconello por incentivar a dedicação à pesquisa e abrir espaço para sua realização.

Ao Prof. Dr. Marcel Cerqueira César Machado, pelos seus ensinamentos em minha formação pessoal e profissional.

Ao Prof. Dr. José Eduardo Monteiro da Cunha, pelo apoio e confiança desde meu ingresso no grupo de Pâncreas e Vias Biliares, e pela contribuição no trabalho.

Ao Prof. Dr. Luiz Augusto Carneiro D’Albuquerque pelo estimulo e apoio ao desenvolvimento do trabalho e à pesquisa.

À Dra. Sheila Aparecida Coelho Siqueira, pela supervisão atenciosa na realização do trabalho de imunoistoquímica e pelo apoio.

À biomédica Neila Aparecida de Souza Silva, pela realização técnica das lâminas de estudo imunoistoquímicos, pelo empenho no auxílio de busca por fomentos e disponibilidade.

Ao Dr. Iberê Cauduro Soares, pelo preparação e construção do bloco de tissue microarray.

Aos amigos do Serviço de Cirurgia do Pâncreas e Vias Biliares, Dra. Sônia Penteado, Dr. Emilio Abdo, Dr. André Montagnini, Dr. André Siqueira Matheus, Dr. Marcos Perini e Dr. Emerson Abe pela amizade sincera, convivência harmoniosa, apoio irrestrito, compreensão e auxílio nos momentos de necessidade.

Ao estaticista Demerson Polli, pela revisão das análises estatísticas, pelas discussões matemáticas e médicas, pelo entusiasmo e disponibilidade.

Ao artista Marcos Antonio Retzer, pelas ilustrações e à bibliotecária Marta Rodrigues pelo auxílio no levantamento de artigos. 
Às secretárias Vilma de Jesus Liberio, Mariza Ochner, Maria Cristina Rabello, Myrtes Freire de Lima Graça, Maria Joelice dos Reis Santos e Fabiana Renata Soares Bispo pelo carinho, disponibilidade e paciência.

Aos residentes da Disciplina de Cirurgia do Aparelho Digestivo que com suas dúvidas e buscas pelo conhecimento nos estimulam a nos mantermos aprendizes.

Aos pacientes, meus profundos agradecimentos

E a todos que de uma maneira ou de outra colaboraram para a realização desta tese. 
A ciência permanecerá sempre a satisfação do desejo mais alto da nossa natureza, a curiosidade; fornecerá sempre ao homem o único meio que ele possui de melhorar a própria sorte 


\section{CONTEÚDO}

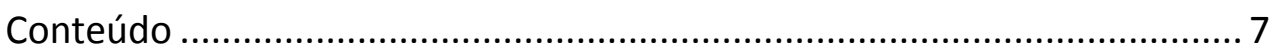

Lista de abreviaturas e símbolos ........................................................... 9

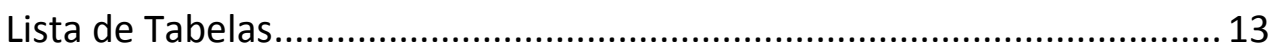

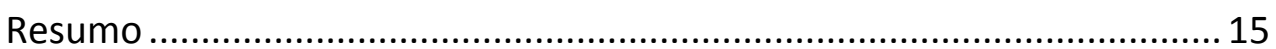

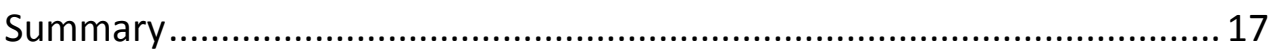

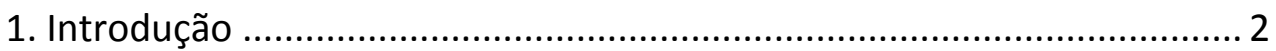

1.1 Marcadores imunoistoquímicos relacionados a origem tecidual ........ 5

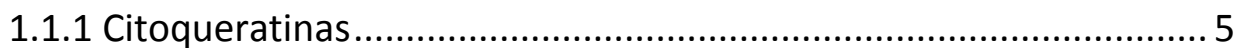

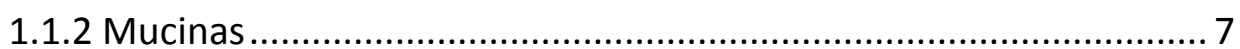

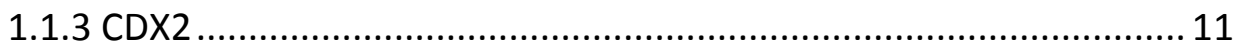

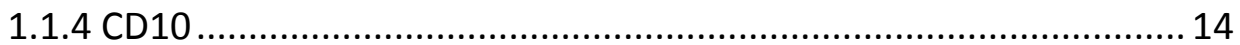

1.2 Marcadores imunoistoquímicos relacionados à carcinogênese ........ 15

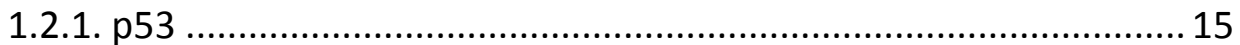

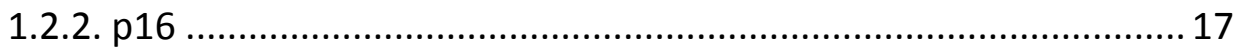

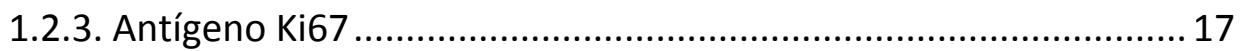

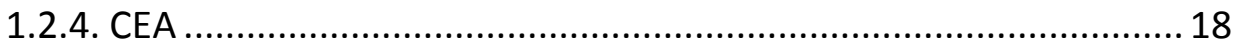

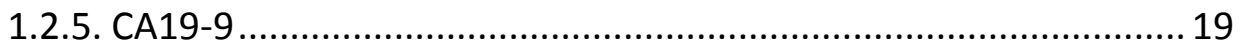

1.2.6. Instabilidade de microssatélites (hMLH1, hMSH2 e hMSH6) ....... 20

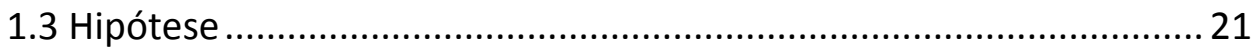

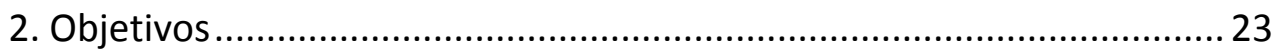

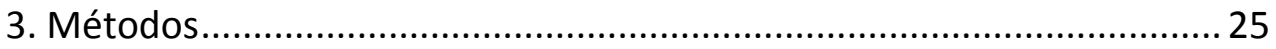

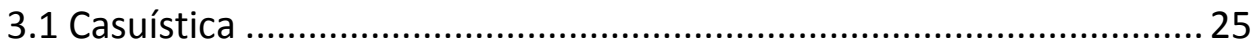

3.2. Características Clínicas e Seguimento de Sobrevivência ................... 26

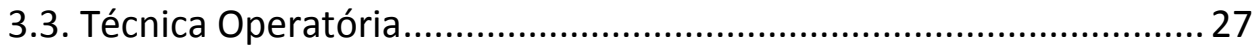

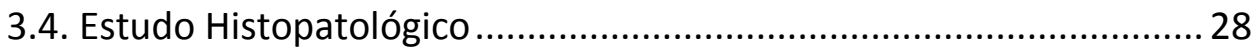

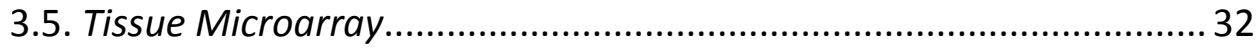

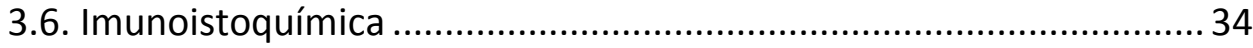

3.7. Análise dos Resultados de Imunoistoquímica ..................................36

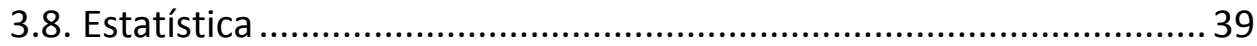

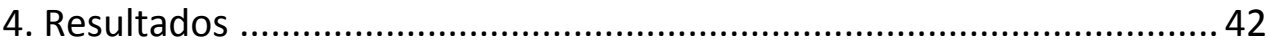

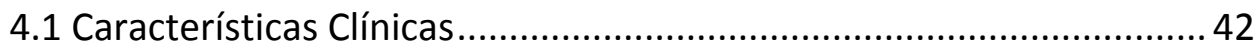


4.2. Características anatomopatológicas

4.3. Expressão imunoistoquímicos para diferenciação do epitélio de

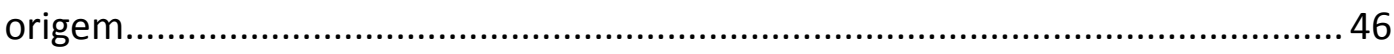

4.4. Marcadores imunoistoquímicos de alterações genéticas .................60 60

4.5. Instabilidade de Microsatélites.........................................................67

4.6. Expressão do CEA e CA 19-9 …....................................................... 72

4.7. Análise da expressão dos marcadores relacionados à carcinogênese com o tipo histológico.... 74

4.8. Fatores associados à recidiva precoce ou longa sobrevivência livre de

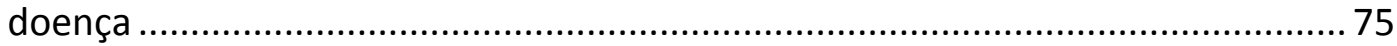

4.9. Análise de Sobrevivência .............................................................. 77

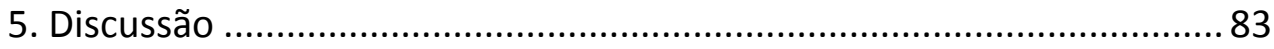

5.1. Casuística e método empregado .................................................. 83

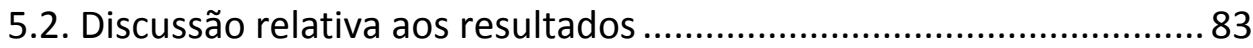

5.2.1 Marcadores imunoistoquímicos para diferenciação do epitélio de

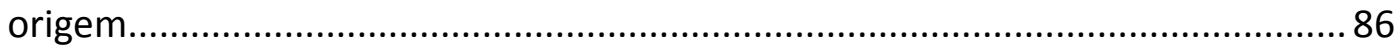

5.2.2 Marcadores imunoistoquímicos relacionados à carcinogênese.... 93

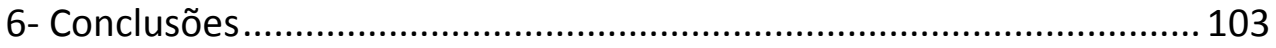

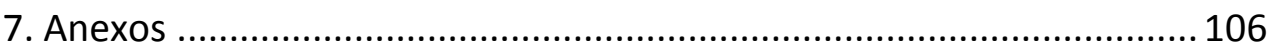

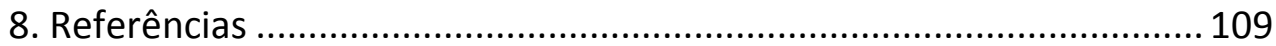

Apêndices 
AAV

$\mathrm{TI}$

TPB

HCFMUSP

TNM

UICC

$H \& E$

TMA

CK7, CK17, CK20

MUC1, MUC2, MUC5AC, MUC6

p53

p16

MMR

IMS

hMLH1

hMSH2 adenocarcinoma da ampola de Vater

tipo intestinal

tipo pancreatobiliar

Hospital das Clínicas da Faculdade de Medicina da Universidade de São Paulo

tumor, linfonodo e metástase a distância

Union Internationale Contra le Cancer

hematoxilina e eosina

arranjo em matriz de amostras teciduais

(tissue microarray)

citoqueratina basais

mucinas

proteína p53

proteína p16

proteínas de reparo do DNA (mismatch repair) hMLH1, hMSH2 e hMSH6

instabilidade de microssatélites

Homo sapiens MutL homolog 1

Homo sapiens MutS homolog 2 
hMSH6

$\%$

$\pm$

$+$

$400 x$

g/dl

$\mathrm{mg} / \mathrm{dl}$
Homo sapiens Muts homolog 6

por cento

mais ou menos

positivo

negativo

aumento de quatrocentas vezes

gramas por decilitro

miligramas por decilitro 


\section{LISTA DE FIGURAS}

Figura 1: Ampola de Vater e os diferente tipos de mucosa que podem

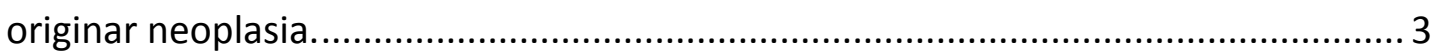

Figura 2: Reconstrução em dupla alça para duodenopancreatectomia........ 28

Figura 3: Adenocarcinoma da ampola de Vater do tipo intestinal, com células de Paneth (H\&E, 400x)

Figura 4: Adenocarcinoma da ampola de Vater do tipo pancreatobiliar, com atipia celular (H\&E, 400x)

Figura 5: Sistema de transferência de cortes histológicos por selos 33

Figura 6: Preparo do bloco de TMA 33

Figura 7: Sensibilidade, especificidade, acurácia e valor preditivo positivo dos marcadores para o tipo intestinal 50

Figura 8: Sensibilidade, especificidade, acurácia e valor preditivo positivo dos marcadores para o tipo pancreatobiliar 50

Figura 9: MUC2 - marcação imunoistoquímica de padrão citoplasmático em AAV tipo intestinal $(400 x)$

Figura 10: CK20 - marcação imunoistoquímica de padrão citoplasmático em AAV tipo intestinal (400x)

Figura 11: CDX2 - marcação imunoistoquímica de padrão citoplasmático em AAV tipo intestinal (400x)

Figura 12: CD10 - marcação imunoistoquímica com padrão de membrana em AAV tipo intestinal (400x)

Figura 13: MUC1 - marcação imunoistoquímica de padrão citoplasmático em AAV tipo pancreatobiliar (400x)

Figura 14: CK7 - marcação imunoistoquímica de padrão citoplasmático e de membrana em AAV tipo pancreatobiliar (400x)

Figura 15: Curva ROC. .58

Figura 17: p16 - marcação imunoistoquímica de padrão citoplasmático em AAV tipo pancreatobiliar (400x). 66

Figura 18: Ki67 - marcação imunoistoquímica de padrão nuclear em AAV tipo pancreatobiliar (400x)

Figura 16: p53 - marcação imunoistoquímica de padrão nuclear em AAV, A tipo intestinal, B tipo pancreatobiliar (400x) 66 
Figura 19: hMLH1 - marcação imunoistoquímica de padrão nuclear em AAV tipo intestinal (400x)

Figura 21: hMSH6 - marcação imunoistoquímica de padrão nuclear em AAV tipo pancreatobiliar (400x) 68

Figura 20: hMSH2 -marcação imunoístoquímica de padrão nuclear em AAV; A, positiva; $B$, negativa frente a controle de tecido não neoplásico positivo (400x) 68

Figura 22: CEA - marcação imunoistoquímica de padrão citoplasmático em AAV tipo intestinal $(400 x)$

Figura 23: CA19-9 - marcação imunoistoquímica de padrão citoplasmático em AAV tipo pancreatobiliar (400x). .73

Figura 24: Curva de sobrevivência em cinco anos em relação ao acometimento linfonodal.. .79

Figura 25: Curva de sobrevivência em cinco anos em relação ao

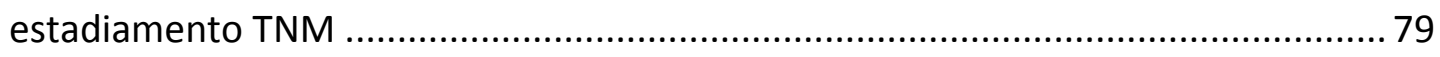

Figura 26: Curva de sobrevivência em cinco anos em relação à invasão linfática...... 80

Figura 27: Curva de sobrevivência em cinco anos em relação ao tipo histológico 80 


\section{LISTA DE TABELAS}

Tabela 1- Relação dos anticorpos utilizados nas reações imunoistoquímicas ........... 36

Tabela 2- Características clínico-cirúrgicas gerais................................................. 43

Tabela 3- Mortalidade e morbidade pós-operatória ................................................ 44

Tabela 4- Características anátomo-patológicas ..................................................... 46

Tabela 5- Estadiamento e classificação TNM ............................................................ 46

Tabela 6- Positividade para marcadores imunoistoquímicos dos tumores tipo intestinal e pancreatobiliar 48

Tabela 7- Sensibilidade, especificidade e acurácia dos marcadores imunoistoquímicos para determinação do tipo histológico

Tabela 8- Modelo linear generalizado para identificar os principais marcadores imunoistoquímicos para determinação do tipo histológico.

Tabela 9- Modelo linear generalizado para identificar os efeitos dos marcadores apontados como significantes para determinação do tipo histológico.

Tabela 10- Modelo linear generalizado para identificar os efeitos dos marcadores MUC2 e CDX2 associados

Tabela 11- Modelo linear generalizado para identificar os efeitos dos marcadores MUC1, MUC2 e CDX2 associados

Tabela 12- Modelo linear generalizado para identificar os efeitos dos marcadores MUC1, CK7, MUC2 e CDX2 associados.

Tabela 13- Marcadores imunoistoquímicos para os tumores tipos incomuns .57

Tabela 14- Análise da probabilidade de ser tipo pancreatobiliar dos tumores incomuns, segundo análise GLM

Tabela 15- Comparação da classificação histológica com a classificação imunoistoquímica dos AAV

Tabela 16- Relação entre imunoexpressão do p53 e características clínicas e anatomopatológicas..

Tabela 17- Relação entre imunoexpressão do p16 e características clínicas e anatomopatológicas.

Tabela 18- Relação entre imunoexpressão do Ki67 e características clínicas e anatomopatológicas. 
Tabela 19- Frequência das diversas possibilidades de perfis de expressão de proteínas MMR

Tabela 20- Relação entre expressão de hMLH1 e características clínicas e anatomopatológicas.

Tabela 21- Relação entre expressão de hMSH2 e características clínicas e

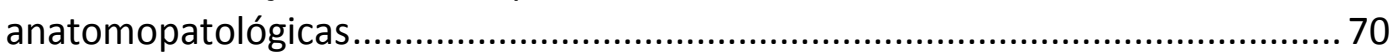

Tabela 22- Relação entre expressão de hMSH6 e características clínicas e

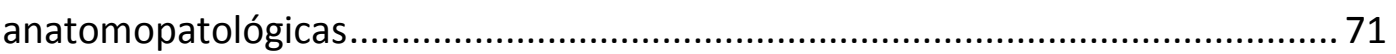

Tabela 23- Relação entre a imunoexpressão do CEA e demais marcadores

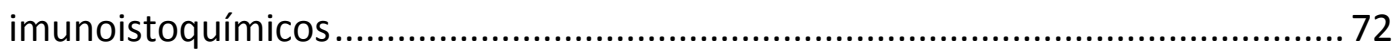

Tabela 24- Expressão dos marcadores relacionados à carcinogênese e o tipo histológico e classificação imunoistoquímica dos AAVs ...................................... 74

Tabela 25- Comparação entre doentes com óbito após menos de 20 meses do tratamento cirúrgico e aqueles com sobrevivência maior que 120 meses, em relação aos critérios clínicos, anatomopatológicos e marcadores

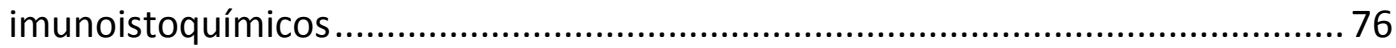

Tabela 26- Fatores relacionados à sobrevivência, em análise univariável ................ 78

Tabela 27- Modelo de risco proporcional com cura ................................................. 81 


\section{RESUMO}

Haddad LBP. Expressão de marcadores imunoistoquímicos de origem tecidual e de carcinogênese nos adenocarcinomas tipo intestinal e pancreatobiliar da ampola de Vater [tese]. São Paulo: Faculdade de Medicina, Universidade de São Paulo; 2009. $119 p$

INTRODUÇÃO: Os adenocarcinomas da ampola de Vater (AAV) são classificados conforme a diferenciação histológica em tipos pancreatobliliar e intestinal, com comportamento biológico e prognóstico diferentes. O objetivo deste estudo foi determinar um painel imuno-histoquímico para a diferenciação do tipo histológico dos AAVs e analisar os fatores relacionados com a sobrevivência desses tumores em uma série de pacientes submetidos à ressecção do tumor com intenção curativa. MÉTODO: Variáveis clínicas e histopatológicas foram analisadas para os tipos intestinal e pancreatobiliar em 97 doentes submetidos à ressecção pancreática por AAV. A expressão de mucinas (MUC1, MUC2, MUC5AC, MUC6), citoqueratinas (CK7, CK17, CK20), CD10, CDX2, p53, p16, Ki67, CEA, CA19-9, hMLH1, hMLH2 e hMSH6 foi avaliada usando técnica de imunoistoquímica. RESULTADOS: Quarenta e três casos foram histologicamente classificados como tipo intestinal, 47 como tipo pancreatobiliar e 7 em outros tipos, de acordo com a classificação de AlboresSaavedra. O tipo intestinal apresentou expressão significativamente maior de MUC2 (74,4\% vs 23,4\%; $p<0,001$ ), CK20 (76,7\% vs $29,8 \%$; $p<0,001$ ), CDX2 ( $86 \%$ vs $21,3 \%$; $p<0,001)$ e CD10 (81,4\% vs $51,1 \% ; p=0,002)$; enquanto MUC1 (53,5\% vs $82,9 \%$; $p=0,001)$ e CK7 $(79,1 \%$ vs $95,7 \% ; p=0,041)$ foram mais expressos nos adenocarcinomas pancreatobiliares. Os marcadores imunoistoquímicos com maior acurácia para determinação do tipo histológico foram CDX2, MUC2 e CK20 (82,2\%, $75,5 \%$ e $73,3 \%$ respectivamente). A positividade para p53, p16, Ki67, CEA e CA19-9 foram $36,1 \%, 30,9 \%, 37,1 \%, 79,4 \%$ e $88,6 \%$, respectivamente, sem qualquer diferença significativa entre os tipos intestinal e pancreatobiliar. A perda de expressão de pelo menos uma das proteínas hMLH1, hMLH2 e hMSH6 ocorreu em 13,4\%, sem diferença entre os tipos histológicos. Em análise univarida, a sobrevivência foi significativamente menor para o tipo histológico pancreaticobiliar ( $p=0,021)$, estadiamentos TNM mais avançados $(p<0,001)$, neoplasias com acometimento linfonodal $(p<0,001)$ e invasão linfática $(p=0,004)$. Em análise multivariada, o acometimento linfonodal $(p<0,001)$ e a invasão linfática $(0,013)$ foram fatores independentes de risco. CONCLUSÃO: A expressão imunoistoquímica de MUC1, MUC2 e CDX2 são úteis para a classificação dos AAVs em tipo intestinal e pancreatobiliar. $O$ tipo intestinal esteve associado a um melhor prognóstico, mas apenas o acometimento linfonodal e a invasão linfática foram fatores independentes de risco. 
Descritores: 1. Ampola hepatopancreática, 2. Adenocarcinoma, 3. Imunoistoquímica, 4. Cirurgia, 5. Prognóstico. 


\section{SUMMARY}

Haddad LBP. Immunohistochemistry expression of tissue origin and carcinogenesis markers in adenocarcinomas of intestinal and pancreaticobiliary types of Vater's ampolla [thesis]. São Paulo: Faculdade de Medicina, Universidade de São Paulo; 2009. $119 p$

The intestinal and pancreatobliliary types of histological Vater's ampulla adenocarcinoma present different biologic behavior and prognosis. The aim of the present study was to determine the best immunohistochemical panel for tumor classification and analyze the survival of these histological types in a series of patients. Clinical and histopathologal variables were analyzed for each pancreatobiliary and intestinal type differentiation in 97 resected ampullary adenocarcinomas. The expression of mucins (MUC1, MUC2, MUC5AC, MUC6), cytokeratins (CK7, CK17, CK20), CD10, CDX2, p53, p16, Ki67, CEA, CA19-9, hMLH1, hMLH2 and hMSH6 was evaluated by using immunohistochemistry. Forty three Vater's ampulla carcinomas were histologically classified into intestinal type, 47 into pancreatobiliary type and 7 into other types, according to Albores-Saavedra classification. The intestinal type had a significantly higher expression of MUC2 (74.4\%vs23.4\%. p<0.001), CK20 (76.7\%vs29.8\%p<0.001), CDX2 (86\%vs21. 3\%. $p<0.001)$ and CD10 (81.4\%vs51.1\%. $p=0.002)$; while MUC1 (53.5\%vs82.9\%. $p=0.001$ ) and CK7 (79.1\%vs95.7\%. $\quad \mathrm{p}=0.041)$ were higher in pancreatobiliary adenocarcinomas. The most accurate markers for the immunohistochemical classification were CDX2, MUC2 and CK20 (82.2\%. 75.5\% and 73.3\% respectively). The positivity of p53, p16, Ki67, CEA and CA19-9 were 36.1\%, 30.6\%, 37.1\%, 79\% and $88 \%$, respectively without any significant difference between intestinal and pancreatobiliary types. Loss of hMLH1, hMLH2 and hMSH6 proteins expression occurred in $13.4 \%$ of Vater's adenocarcinoma, without difference between intestinal and pancreaticobiliary types. Survival was significantly affected by pancreaticobiliary type $(p=0.021)$, tumor grade $(p<0.001)$, nodal status $(p<0.001)$ and lymphatic invasion $(p=0.004)$. Only regional lymph node involvement $(p<0.001)$ and lymphatic invasion $(p=0.013)$ was independent risk factors for survival in a multivariate analysis. In conclusion, the immunohistochemical expression of apomucins MUC1, MUC2 and CDX2 are useful for the classification of ampullary adenocarcinoma in intestinal and pancreaticobiliary types. Intestinal type was associated with a better prognosis, but only lymph node status and lymphatic invasion were independent risk factors.

Keywords: 1. Hepatopancreatic ampulla, 2. Adenocarcinoma, 3. Immunohistochemistry, 4. Surgery, 5. Prognosis. 


\section{Introdução}




\section{INTRODUÇÃO}

A ampola de Vater é formada pela união do ducto biliar comum e do ducto pancreático principal em sua desembocadura, na parede póstero-medial da segunda porção duodenal. É uma estrutura anatômica complexa, composta por fibras musculares e elementos neuronais especiais que regulam, através do esfíncter de Oddi, o fluxo de bile e suco pancreático para o trato digestivo $(1,2)$.

Os componentes da ampola de Vater são a papila duodenal maior, o canal comum, a porção distal do colédoco e a porção distal do ducto pancreático principal. A papila duodenal é uma projeção de mucosa do tipo intestinal através da parede duodenal (3). As demais partes da ampola são revestidas por epitélio simples mucinoso, como dos ductos pancreaticobiliares (4). Conseqüentemente, os tumores ampulares podem se originar de 2 tipos diferentes de epitélio, o que pode refletir em diferentes espectros histomorfológicos destes tumores (5) (Figura 1).

As neoplasias originadas da ampola de Vater são raras. Sua incidência é estimada em 5 a 7 casos por milhão de habitantes ao ano (6). Representam 0,2\% das neoplasias do trato gastrointestinal (7) e 7 a $12 \%$ dos tumores periampulares (8). É a segunda neoplasia mais frequente da região periampular, após os tumores do pâncreas (9). Apesar de pouco comuns, a ocorrência de adenomas e carcinomas nesta localização é mais frequente que em todo o intestino delgado (10). Isto ocorre provavelmente devido a exposição permanente da mucosa da ampola às secreções do fígado, vesícula biliar, pâncreas e duodeno (10). O epitélio da ampola possui 
elementos protetores para essa agressão, como a secreção de muco, além de mecanismos de prevenção do refluxo do duodeno para o ducto pancreático e ducto biliar (11). A perda de fatores protetores pode estar relacionada com a carcinogênese dos adenocarcinomas da ampola de Vater (AAVs).

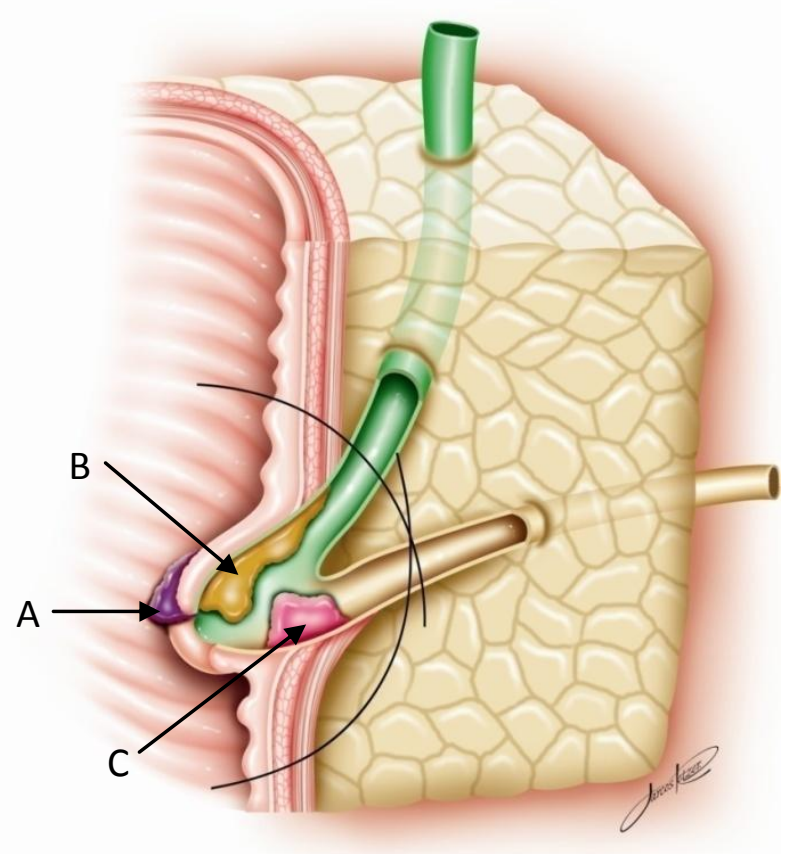

Figura 1: Ampola de Vater e os diferente tipos de mucosa que podem originar neoplasia. A; mucosa tipo intestinal, B; epitélio simples mucinoso biliar, C; epitélio simples mucinoso pancreático

Os pacientes com adenocarcinoma da ampola de Vater (AAV) apresentam manifestações clínicas mais precoces e maior índice de ressecabilidade quando comparados aos demais tumores periampulares(12). A sobrevivência após ressecção é maior que do adenocarcinoma de pâncreas e vias biliares, porém pior que do adenocarcinoma de duodeno (12-18) 
Estudos histopatológicos recentes começaram a elucidar a patogênese dos cânceres da ampola de Vater. Kimura et al (19) foram os primeiros a diferenciar os tipos pancreatobiliar (TPB) e intestinal (TI) para os tumores ampulares. AlboresSaavedra (20) classificou os tumores ampulares em 2 tipos principais, pancreatobiliar e intestinal; e tipos "incomuns", como os carcinomas com células em anel de sinete e os carcinomas indiferenciados. Baseados na classificação de Albores-Saavedra, uma série de estudos moleculares analisaram a histogênese e tumorigênese dos carcinomas ampulares.

O tratamento com intenção curativa dos AAVs é a duodenopancreatectomia ou gastroduodenopancreatectomia, ambas as operações apresentando resultados de sobrevivência semelhantes(21-23). Estas operações cirúrgicas, inicialmente descritas com alta morbimortalidade, atualmente apresentam índices de mortalidade operatória de 1,5 a 2,5\% nos centros especializados, porém ainda com altos índices de complicações pós-operatórias $(9,24)$.

Os fatores mais frequentemente relacionados à melhor sobrevivência nos pacientes com tumores da ampola de Valer são: a ressecabilidade com margens livres e ausência de linfonodos acometidos. Outros fatores como tamanho do tumor, grau de diferenciação histológica, estadiamento TNM, invasão neural e tipo histológico apresentam influência variável entre os diversos estudos $(6,12,13$, 2531)

Estudos iniciais sugerem que o carcinoma de ampola de Vater do tipo intestinal está associado a melhor prognóstico que o tipo pancreatobiliar (32-35). 
Entretanto, apresentam resultados muitas vezes conflitantes, talvez pelo fato de não haver até o momento um critério histomorfológico consistente e confiável para fazer este diagnóstico diferencial $(19,20,32)$.

\subsection{MARCADORES IMUNOISTOQUímicos RELACIONADOS A}

\section{ORIGEM TECIDUAL}

A origem tecidual dos adenocarcinomas ampulares nem sempre pode ser determinada apenas com os aspectos histológicos, principalmente para patologistas pouco familiarizados com esses tumores (33). Atualmente, não há marcador imunoistoquímico capaz de distinguir inequivocamente os tumores da ampola de Vater de origem intestinal daqueles de origem pancreatobiliar. Assim, faz se necessário compor um painel de marcadores com maior precisão para esse fim.

\section{Caracterização dos antígenos}

\subsubsection{Citoqueratinas}

As citoqueratinas foram os primeiros marcadores imunoistoquímicos testados para tumores periampulares. São proteínas de filamentos intermediários entre microfilamentos e microtúbulos, que constituem o citoesqueleto de células 
epiteliais eucarióticas, sendo marcadores amplamente utilizados. Embora geralmente confinados aos epitélios e suas respectivas neoplasias, não são marcadores com alta especificidade, pois aparecem em diferentes tipos de tumores (36).

As citoqueratinas correlacionam-se com diferentes vias de diferenciação epitelial e origem embrionária, permitindo a classificação das células epiteliais em diferentes subtipos. Esta expressão é mantida mesmo durante o processo de transformação tumoral (37). As citoqueratinas 7 (CK7) e 20 (CK20) são as duas mais comumente utilizadas na prática da patologia cirúrgica $(36,38,39)$.

Chu et al analisaram a expressão de citoqueratinas em tecidos não tumorais e verificaram que o CK7 está expresso nas células de ductos biliares e pancreáticos e essencialmente ausente no epitélio gastrointestinal, e o CK20 está expresso no epitélio gástrico foveolar, nos vilos intestinais e no epitélio das criptas (40).

Para determinar a expressão de citoqueratinas nos tumores de origem pancreática, Vang et al estudaram uma centena de casos e verificaram que os cistoadenomas mucinosos pancreáticos expressam CK7 na totalidade dos casos, e CK20 na metade deles (41). A neoplasia intraductal papilífera mucinosa também expressa CK7, porém a expressão do CK20 é pouco frequente, em menos de $20 \%$ casos (41). Os adenocarcinomas pancreáticos e biliares apresentam expressão difusa para CK7; entretanto a expressão de CK20 é variável, desde negativo, ou positividade focal e até multifocal $(42,43)$. 
Os estudos relativos à ampola de Vater são mais recentes, como de Zhou et al (32), que verificaram que nos tecidos normais há expressão do CK7 no canal comum, glândulas periampulares da ampola, e também no ducto pancreático. 0 CK20, ao contrário, está expresso no epitélio da superfície duodenal e na papila duodenal.

A citoqueratina 17 é uma queratina de baixo peso molecular e pertence à família das citoqueratinas tipo 1 (37). Está expressa nos tecidos normais apenas em células basais e mioepiteliais; (40) e nos carcinomas de células escamosas, basais e transicionais ou adenocarcinomas com diferenciação escamosa (37). Estudando a expressão do CK17 em uma série de adenocarcinomas, Miettinen et al encontraram uma frequência de positividade de $90 \%$ em pâncreas e 50\% em colangiocarcinomas (44). Chu et al verificaram a expressão de CK17 em 83\% dos adenocarcinomas pancreáticos e dos AAV do tipo pancreatobiliar; já para os AAV tipo intestinal houve apenas $18 \%$ de expressão desta citoqueratina (3).

\subsubsection{Mucinas}

Um grande avanço para diagnóstico da origem tecidual para diversas neoplasias se deu com a descoberta das mucinas. As mucinas são glicoproteínas filamentosas presentes na interface das células e seu micro-ambiente extracelular, podendo ser secretadas para o lúmen de órgãos com cavitários formando camadas de muco, ou participar de funções celulares como proteínas de membrana $(45,46)$. 
Atualmente 14 glicoproteínas do tipo mucina estão catalogadas na família do gene MUC (MUC1, 2, 3A, 3B, 4, 5AB, 5AC, 6, 7, 8, 11, 12, 13, 15) conforme o Human Genome Organization Gene Nomenclature Committee (47, 48). Originalmente o termo mucina era utilizado para glicoproteínas encontradas no muco secretado pelos enterócitos do trato gastrointestinal, posteriormente, evidenciou-se a produção de glicoproteínas que atuam como proteínas transmembrana nas células epiteliais, com função de mediação de interações entre as células e seu microambiente, e que também foram designadas mucinas. Dessa forma, as mucinas podem estar no centro da patogênese de várias doenças inflamatórias, infecciosas e também de neoplasias e suas metástases $(46,48)$.

As mucinas são classificadas como de membrana ou secretora, e incluídas nas famílias do gene MUC de acordo com a localização cromossômica. A primeira família de mucinas é a secretora. Esta família é composta pelo MUC2, MUC5AC, MUC5AB e MUC6; são formadares de muco e são codificadas pelo gene localizado no cromossomo 11p15. A segunda família é formada pelas mucinas de membrana. Esta família é composta pelas mucinas MUC3A, MUC3B, MUC11 e MUC12 e o gene que as codifica localizada-se no cromossomo 3q13.3. A MUC1, cujo gene localiza-se no cromossomo 1q21, também é uma proteína de membrana, sendo agrupada nesta família. Ainda não se identificou homologia genética para as mucinas MUC7 e MUC8, portando, elas não estão inclusas em nenhuma das famílias (46).

A MUC1, também conhecido como mucina pan-epitelial associada à membrana, tem ampla distribuição no corpo humano. Está presente em glândulas 
mamárias, ductos pancreáticos e superfície foveolar gástrica. A MUC2, mucina secretória intestinal, é expressa em células caliciformes e tumores do trato gastrointestinal inferior. A MUC5AC, mucina gástrica secretória de célula foveolar, e a MUC6, mucina gástrica secretória de glândulas pilóricas, são consideradas as principais mucinas que caracterizam a mucosa gástrica $(45,49)$.

Corfield et al (50) descreveram a distribuição das mucinas no trato gastrointestinal normal. A MUC1 está presente nos ácinos de glândulas salivares, ductos das glândulas submucosas esofágicas, ductos pancreáticos, epitélio foveolar superficial gástrico, nas células caliciformes e enterócitos dos intestinos delgado e grosso. As MUC2, MUC5AC e MUC6 são todas formadoras de gel, responsáveis pela formação das camadas de muco no corpo. A MUC2 é expressa nas células caliciformes dos intestinos delgado e grosso. A MUC5AC é expressa no epitélio foveolar gástrico. A MUC6 é a principal mucina gástrica.

Lee et al (45) estudaram 486 casos de carcinomas de diversos sítios anatômicos do trato gastrointestinal, avaliando entre outros marcadores, as mucinas MUC1, MUC2, MUC5AC e MUC6. A MUC1 foi expressa mais frequentemente nos carcinomas de pâncreas, do ânus e da vesícula biliar. A MUC2 foi frequentemente positiva nos carcinomas de intestino delgado e de cólon, bem como na totalidade dos carcinomas do apêndice cecal. A MUC5AC foi positiva em cerca de 70\% dos carcinomas de pâncreas e de apêndice cecal. A MUC6 não foi expressa nos casos estudados. Observaram ainda que a MUC1 ajuda a distinguir os carcinomas de cólon dos carcinomas de ânus; e que o padrão de positividade da 
MUC1, MUC2 e CK20 é diferente nos carcinomas de duodeno e nos carcinomas do resto do intestino delgado, sendo MUC1+/MUC2-/CK20- no duodeno e MUC1/MUC2+/CK20+ no jejuno e íleo.

A expressão de mucinas foi estudada no pâncreas normal e em diversos tumores pancreáticos por Terada et al (51). O pâncreas normal expressou MUC1, tanto nos ductos quanto nos ácinos, já a MUC2, MUC3 e MUC5/6 não foram expressas em nenhuma célula. Na pancreatite crônica, a MUC1 foi expressa na maioria dos casos, e $40 \%$ deles expressaram MUC5/6. Na neoplasia intraductal papilífera mucinosa houve expressão frequente de MUC1 e MUC5/6, e metade dos casos expressaram MUC3. Finalmente, no adenocarcinoma ductal invasivo houve expressão em quase a totalidade dos casos de MUC1, MUC3 e MUC5/6 (51).

Assim, a MUC1 pode ser considerada apomucina do pâncreas normal, persistindo durante a transformação neoplásica. No pâncreas normal a expressão é apical ou membranosa, diferente do adenocarcinoma, onde há uma expressão citoplasmática difusa (52).

No adenocarcinoma pancreático ductal, além da hiperexpressão de MUC1, verifica-se expressão de MUC6 e MUC5AC, sugerindo presença de metaplasia foveolar gástrica e metaplasia pilórica em fases precoces da carcinogênese, desde os estágios iniciais de neoplasia pancreática intraepitelial (PanIN) até o carcinoma ductal invasivo. Entretanto, a metaplasia intestinal evidenciada pela expressão de MUC2 raramente ocorre $(49,51,53-56)$. 
A expressão de mucinas é útil também na caracterização dos cistoadenomas mucinosos e dos adenomas intraductais papilíferos mucinosos (IPMA) do pâncreas. Enquanto o primeiro expressa MUC1, MUC2 e MUC5AC em cerca de um terço dos casos; nos IPMAs a expressão da MUC1 é pouco freqüente, e quase sempre ocorre expressão do MUC5AC e da MUC2 $(41,52)$.

O uso de um painel de mucinas composto por MUC1, MUC2 e MUC5AC serve para o diagnóstico diferencial de lesões pancreáticas, inclusive à partir de material de biópsias (52).

A expressão de mucinas na ampola de Vater foi estudada em espécimes de cadáveres de indivíduos sem histórico de doença gastrointestinal, comparando com a mucosa duodenal (57). Utilizando análise de mRNA, tanto a ampola de Vater quanto o duodeno normais expressaram MUC1, MUC3, MUC4, MUC5AC, MUC6 e MUC7; já MUC2 e MUC8 foram expressos apenas na mucosa duodenal. Em estudo imunoistoquímico, a ampola de Vater e o duodeno expressaram MUC4, MUC5AC e MUC6 e no duodeno houve expressão de MUC2, MUC7 e MUC8. Assim, essas seriam as mucinas úteis para diferenciação da origem dos carcinomas ampulares.

\subsubsection{CDX2}

Um avanço significativo na identificação dos tumores de origem intestinal ocorreu com a identificação do gene CDX2. Ele é responsável pela transcrição de um fator intestinal específico e regula a expressão de MUC2 (58-60). A proteína CDX2 
regula o desenvolvimento e a diferenciação do intestino delgado e grosso e é expressa no núcleo das células epiteliais de todo o trato intestinal na vida embrionária e pós-natal (59).

O papel deste fator de transcrição na carcinogênese intestinal é complexo e ainda controverso. Estudos bloqueando esse gene em ratos mostraram que a ausência do gene (-/-) é letal ainda na vida intra-uterina e nos heterozigotos (+/-) há desenvolvimento de hamartomas e neoplasias colônicas (61-63). Alguns estudos verificaram a perda de expressão do CDX2 em adenocarcinomas colorretais, com incidência variando de 2 a 10\% dos casos (64-66). Tanto em estudo experimental com linhagens de câncer colorretal (67) quanto na análise de espécimes ressecados de humanos, (68) ficou demonstrado que a perda de expressão do CDX2 está associada aos adenocarcinomas colorretais pouco diferenciados.

No epitélio gástrico, a expressão do CDX2 está associada a uma expressão da mucina intestinal MUC2 e à presença de metaplasia do tipo intestinal (69). Em carcinomas gástricos o CDX2 está expresso em $55 \%$ dos casos, principalmente em tumores com morfologia intestinal (70). Além disso, o CDX2 é encontrado na metaplasia intestinal no esôfago de Barrett, conhecido precursor de adenocarcionoma esofágico (71).

No pâncreas normal, o CDX2 está presente nas células não beta das ilhotas de Langerhans, onde participa da regulação da produção de glucagon (72); e também é detectado em pequena quantidade nos ductos pancreáticos e células acinares (73). Na ampola de Vater verifica-se a expressão do CDX2 na mucosa 
duodenal, porém não há expressão no epitélio do canal comum e dos ductos biliares e pancreáticos (74).

Werling et al (73) realizaram um grande estudo com 476 amostras de carcinomas de diversas localizações para determinar a expressão imunoistoquímica do CDX2. Verificaram que o CDX2 foi expresso de forma uniforme na maioria dos tumores de cólon e duodeno. Uma grande expressão foi verificada também em carcinomas mucinosos de ovário e adenocarcinoma primário da bexiga. Carcinomas gástricos, esofágicos, pancreáticos e de vias biliares mostraram um padrão heterogênio de expressão, a maioria com pequeno número de células coradas. Carcinomas hepatocelulares e carcinóides gastrointestinais não expressaram CDX2, assim como carcinomas genitourinários, de pulmão, coração e pescoço. Concluíram que o CDX2 é o marcador com maior sensibilidade e especificidade para tumores de origem intestinal.

Alguns autores sugeriram que a análise da expressão imunoistoquímica do CDX2 pode ser útil para identificar carcinomas de origem intestinal, principalmente nos casos de metástases com sítio primário não determinado, com sensibilidade e especificidade maiores que $90 \%(73,75)$.

Mais recentemente, Hansel et al (74) verificaram a expressão do CDX2 em 40\% dos adenocarcinomas da ampola de Vater, sendo este um fator independente de melhor prognóstico. O CDX2 não é expresso no tecido normal das vias biliares, já nos adenocarcinomas, o CDX2 foi expresso em $16 \%$ a $42 \%$ dos casos, sendo a expressão um fator independente de melhor sobrevivência $(60,76)$. 


\subsubsection{CD10}

O CD10 é também conhecido como CALLA (antígeno da leucemia linfoblástica aguda comum), uma metaloproteína de $100 \mathrm{Kd}$ da superfície celular envolvida na modulação das respostas celulares a hormônios peptídeos, idêntica à enzima endopeptidase neutra. É expresso por muitos tipos celulares, incluindo algumas linhagens de células epiteliais, assim como células hematopoiéticas, tais como linfócitos e granulócitos $(77,78)$. O CD10 reduz a resposta celular aos hormônios peptídeos e provavelmente está envolvido na proliferação celular mediada por peptídeos, além de controlar a atividade secretória do intestino através de mecanismos endócrinos e parácrinos (79).

A função biológica do CD10 parece ser órgão específica. No pulmão, ele regula o efeito das taquicininas; no rim, regula a ação do hormônio natriurético (80). A perda de expressão do CD10 ocorre em uma série de neoplasias, incluindo câncer renal, gástrico e próstata. Especula-se que a redução de CD10 promova uma proliferação celular mediada por peptídeos devido a um acúmulo importante destes na superfície celular, facilitando o desenvolvimento de neoplasias (80).

O CD10 está expresso na borda em escova das células da mucosa intestinal e nas células dos ductos pancreáticos (81). No pâncreas normal, mais de $80 \%$ das células expressam CD10 (41). Nos cistoadenomas mucinosos do pâncreas a expressão ocorre em $70 \%$ dos casos $(41,81)$, nos carcinomas neuroendócrinos pancreáticos em 50\% (81), e nos IPMN não há expressão (41). No adenocarcinoma 
ductal pancreático a expressão de CD10 é heterogênia e ocorre quase na totalidade dos casos (80).

Não há até o momento nenhum estudo publicado que tenha analisado a expressão do CD10 em AAV.

\subsection{MARCADORES IMUNOISTOQUímicos RELACIONADOS À}

\section{CARCINOGÊNESE}

Considerando as diferentes origens histológicas dos AAVS é provável que os mecanismos envolvidos no desenvolvimento desses tumores sejam diferentes. A utilização de marcadores imunoistoquímicos relacionados à carcinogênese pode de alguma maneira contribuir para a caracterização dos diferentes tipos de AAV.

\subsection{1. p53}

O gene supressor de tumor p53, localizado na banda 13.1 do braço curto do cromossomo 17, é o mais comumente implicado na carcinogênese humana, estando mutado em aproximadamente $50 \%$ de todas as neoplasias malignas (82, 83). Em seres humanos, a proteína p53 selvagem codificada por esse gene inibe a proliferação e a transformação celular nas céluals que apresentam dano no DNA, atuando quando a célula permanece em repouso (fase G1). Além de exercer papel importante na regulação celular, a alteração do p53 tem apresentado implicações 
na síntese e na reparação do DNA, na manutenção da estabilidade genômica, na diferenciação celular e na apoptose (84). Em aproximadamente $80 \%$ dos casos, a mutação do p53 ocorre nos exons 5 - 8, sendo "missense", ou seja, conduz para a substituição de um aminoácido, assim alterando a conformação da proteína (85, 86).

A proteína p53 é uma fosfoproteína de 53 kD que está presente no núcleo de células normais. No entanto, devido à meia-vida curta da proteína p53 do tipo selvagem, em torno de 20 minutos, esta normalmente não é detectada. Mutações de p53 frequentemente aumentam a estabilidade da proteína e, portanto, sua vida média, resultando na possibilidade de caracterização por imunoistoquímica utilizando anticorpos monoclonais anti-p53 $(87,88)$.

O método de detecção da mutação do p53 por imunoistoquímica tem resultados concordantes com a análise sequencial direta na maioria dos casos, e apenas uma pequena parcela de reações positivas à imunoistoquímica se devem a outros mecanismos de estabilização da proteína (89).

A mutação do p53 é detectada em 50 à $70 \%$ dos adenocarcinomas pancreáticos $(90,91)$. Raramente essa mutação é encontrada nos casos de displasia, e nunca na hiperplasia (92), confirmando tratar-se de um fenômeno tardio na tumorigênese. Este marcador pode ser útil para diferenciar tumores bem diferenciados de displasia intensa. 
No AAV a ocorrência de mutação do p53 é menos frequente, variando entre $13 \%$ e $46 \%$, e parece ocorrer principalmente durante a transformação maligna de adenoma em carcinoma (93-97).

\subsection{2. p16}

No ciclo celular normal, a proteína p16 se liga ao complexo ciclina D-CDK4 ou 6, finalizando os processos do "ponto de checagem" G1-S do ciclo celular (98). Anormalidades na expressão do p16 predispõem uma progressão anormal do ciclo celular. Esta proteína é um produto do gene quinase dependente de ciclina 2 (CDKN2), também conhecido como gene supressor tumoral múltiplo número 1 (MTS1), localizado no cromossomo 9p21. É frequente a ocorrência de anormalidades nesse gene em neoplasias humanas como melanoma, leucemias, linfomas, carcinomas de esôfago, pulmão e cabeça e pescoço (99).

A inativação do gene p16 é extremamente frequente no câncer do pâncreas, ocorrendo em quase $100 \%$ dos casos (100). Alterações nesse gene também foram verificadas em $61,8 \%$ dos carcinomas de vesícula biliar, $54,5 \%$ dos colangiocarcinomas e $70,6 \%$ dos carcinomas ampulares (101).

\subsubsection{Antígeno Ki67}

O Ki67 é um antígeno nuclear presente nas fases G1, S, G2 e M do ciclo celular, porém ausente na fase de repouso (G0). Pode ser detectado nas células em proliferação através do uso de anticorpos monoclonais (MIB-1 e MIB-3) pelo 
método da imunoistoquímica e pode ser considerado um marcador de proliferação celular $(83,102)$.

O anticorpo anti-Ki67 MIB1 reconhece duas proteínas com pesos moleculares de 345 e 395kD, que são produto de um gene localizado na banda 25 do braço longo do cromossomo 10. Alguns estudos demonstram que a frequência de positividade do Ki67 é valioso parâmetro para caracterização de tumores malignos $(103,104)$. Acredita-se que, com a ajuda deste anticorpo monoclonal, é possível a rápida e simples determinação da fração de crescimento celular.

No câncer do pâncreas, o Ki67 é detectado com freqüência elevada, sendo que há uma progressão de seus índices partindo da ausência no tecido pancreático normal, com aumento progressivo na hiperplasia ductal, displasia e carcinoma (92).

\subsubsection{CEA}

O antígeno carcinoma embrionário (CEA) é uma glicoproteína localizada na superfície apical dos enterócitos maturos e secretada na superfície luminal do trato gastrointestinal. O CEA é codificado por uma família de 29 genes localizados no cromossomo 19q13;2, dos quais 18 são expressos (105). Sua principal função no indivíduo normal está relacionado à adesão celular. Além do cólon, o CEA está presente no estômago, língua, esôfago, cérvix e próstata. Trata-se de um importante marcador tumoral para diversos carcinomas, principalmente os colorretais. É útil como marcador prognóstico, no estadiamento, avaliação de 
recorrência e resposta ao tratamento destas e outras neoplasias. Pode ser diagnosticado nos tecidos através de imunoistoquímica, utilizando anticorpos monoclonais (106).

\subsubsection{CA19-9}

O CA19-9 é uma glicoproteína que contém o antígeno Sialyl Lewis, usualmente positiva nos carcinomas de pâncreas, vias biliares e colorretais. Esse antígeno é sintetizado por uma série de glicosiltranferases. Há evidências de que ele é responsável pela adesão das células cancerígenas ao endotélio (107). O CA19-9 pode ser detectado por imunoistoquímica nos tecidos e já foi demonstrado correlação entre o grau de expressão tecidual e os níveis séricos desse antígeno em pacientes com câncer pancreático $(108,109)$.

Em pacientes com carcinoma pancreático avançado, os níveis séricos de CA19-9 pré-tratamento têm valor prognóstico em relação à sobrevivência e é útil para avaliação de resposta à terapêutica quimioterápica (110). Porém, esse não é um marcador sensível para diagnóstico de câncer do pâncreas em pacientes assintomáticos uma vez que pode elevar-se em doenças não neoplásicas, como nas icterícias de outras etiologias (111). 


\subsubsection{Instabilidade de microssatélites (hMLH1, hMSH2 e hMSH6)}

A instabilidade de microssatélites (IMS) é um dos eventos mais importantes para o acúmulo de mudanças gênicas que ocasionam a predisposição à carcinogênese humana (112). Microssatélites são regiões genômicas com sequências de DNA curtas de repetições de nucleotídeos, existindo normalmente centenas de milhares destas no genoma humano (113). Durante a replicação de DNA, podem ocorrer mutações em algumas destas regiões resultando na contração ou alongamento do microssatélite conhecida como instabilidade de microssátelites (112).

Geralmente estas anormalidades são corrigidas durante a replicação celular por proteínas de reparo ou “mismatch-repair” (MMR). A observação de um grande número de alterações nas sequências de microssatélites está relacionada a uma deficiência na ação das proteínas de reparo causada por mutações (114).

A instabilidade de microssatélites foi primariamente descrita em pacientes com câncer colorretal hereditário não polipóide (HNPCC), apresentando mutações na linhagem germinativa em genes de reparo de DNA, que são o hMSH2, hMLH1, e hMSH6 $(115,116)$.

Poucos estudos analisaram o papel dessas proteínas de reparo do DNA nos adenocarcinomas da ampola de Vater. A frequência da incidência de instabilidade de microssatélites nesses estudos foi bastante variável (117-120). Park et al não detectaram nenhum caso de IMS na sua análise de 35 casos de ampolas de Vater normais, 22 adenomas e 32 carcinomas (118). A maior série, descrita por Sessa et 
al, com 53 casos de AAV, encontrou uma freqüência de 9,5\% de IMS (120). Todos os casos tratavam-se de adenocarcinomas do tipo intestinal, e houve uma melhor sobrevivência desses doentes. Scarpa et al (119) encontraram 15\% de IMS em sua série, também relacionados com melhor sobrevivência em 5 anos.

\subsection{HIPÓTESE}

Os adenocarcinomas da ampola de Vater tipo intestinal e pancreatobiliar devem expressar de forma diferente os marcadores teciduais de origem tecidual e os marcadores relacionados à diferenciação tumoral e instabilidade de microssatélites.

Além disso, como o tipo histológico influencia a evolução dos doentes após o tratamento cirúrgico curativo, esses marcadores podem influir na sobrevivência desses doentes. 
Objetivos 


\section{OBJETIVOS}

Os objetivos do presente estudo são:

2.1- Realizar um painel imunoistoquímico capaz de determinar a origem tecidual dos adenocarcinomas da ampola de Vater.

2.2- Avaliar a frequência e associação com parâmetros clínicos e anatomopatológicos da expressão imunoistoquímica de marcadores relacionados à carcinogênese (proteína p53, p16, Ki67, CEA, CA19-9, hMLH1, hMSH2 e hMSH6)

2.3- Analisar a diferença da expressão de marcadores relacionados à carcinogênese nos adenocarcinomas da ampola de Vater do tipo intestinal e pancreatobiliar.

2.4- Avaliar a influência de variáveis anatomopatológicas e dos marcadores imunoistoquímicos na sobrevivência dos doentes tratados cirurgicamente por adenocarcinoma da ampola de Vater 
3 Métodos 


\section{MÉTOdOS}

O presente estudo teve aprovação da Comissão de Ética para Análise de Projetos de Pesquisa (CAPPesp, protocolo de pesquisa $n^{\circ} 114 / 06$ ) da Diretoria Clínica do Hospital das Clínicas e da Faculdade de Medicina da Universidade de São Paulo. O projeto foi financiado com Auxílio Pesquisa da Fundação de Amparo à Pesquisa do Estado de São Paulo FAPESP (protocolo 2007/04735-4).

\subsection{Casuística}

Em etapa preliminar, foram investigados todos os 103 pacientes com diagnóstico de carcinoma de ampola de Vater tratados cirurgicamente com intenção curativa no Serviço de Vias Biliares e Pâncreas da Disciplina de Cirurgia do Aparelho Digestivo do Hospital das Clínicas da Faculdade de Medicina da Universidade de São Paulo (HCFMUSP) entre 1985 e 2006. Somente os pacientes dos quais se obtiveram as lâminas e os blocos de parafina do tumor na Divisão de Anatomia Patológica deste Hospital foram incluídos, totalizando 97 doentes.

Os pacientes operados entre 1985 e 2003 foram estudados de maneira retrospectiva e aqueles operados a partir de 2003 foram seguidos prospectivamente através do banco de dados informatizado do serviço. 
O adenocarcinoma ampular foi definido como aquele originado microscopicamente da ampola de Vater. Grandes tumores envolvendo o pâncreas, as vias biliares e/ou o duodeno foram tratados como ampulares quando centrados na ampola de Vater, sendo a definição dada pelo patologista. Outros tumores periampulares de origem biliar, duodenal ou pancreática foram excluídos, assim como os tumores não adenocarcinomas, como por exemplo os neuroendócrinos.

\subsection{Características Clínicas e Seguimento de Sobrevivência}

Os dados de anamnese, exame físico, descrição cirúrgica, achados intraoperatórios, evolução pós-operatória e seguimento foram obtidos a partir da revisão dos prontuários no Serviço de Arquivo do HCFMUSP. A partir do ano de 2003 todos os doentes foram seguidos prospectivamente, com preenchimento sistemático destas informações em base de dados durante a hospitalização. Os resultados de exames laboratoriais e anatomopatológico foram coletados através do sistema informatizado do Hospital.

O seguimento em relação à sobrevivência dos doentes foi feito através de consultas ambulatoriais. Para os pacientes que não mantiveram acompanhamento ambulatorial foram realizados contatos telefônicos com os mesmos ou familiares. Alguns óbitos foram confirmados através dos registros do Serviço de Verificação de Óbitos da Capital (SVOC) da cidade de São Paulo. Estipulamos o tempo de cinco anos de seguimento para o estudo de sobrevivência. 


\subsection{Técnica Operatória}

Todas as operações foram realizadas pela equipe da Divisão de Clínica Cirúrgica II - Serviço de Cirurgia do Pâncreas e Vias Biliares do HCFMUSP, seguindo a padronização cirúrgica do grupo.

A extensão tumoral era avaliada no início do ato operatório após exploração completa da cavidade abdominal, verificando-se presença de doença avançada localmente ou metástases a distância não diagnosticadas pré-operatoriamente. Uma vez confirmada a ressecabilidade, realizava-se operação radical (duodenopancreatectomia ou gastroduodenopancreatectomia) e linfadenectomia regional.

Todos os casos foram reconstruídos com dupla alça (figura 2), conforme técnica descrita no Serviço, utilizando-se uma alça exclusa para a anastomose pancreatojejunal e outra para anastomose hepaticojejunal (121). Nos pacientes operados mais recentemente, deu-se preferência à preservação pilórica, desde que esta opção não comprometa a radicalidade da ressecção. 


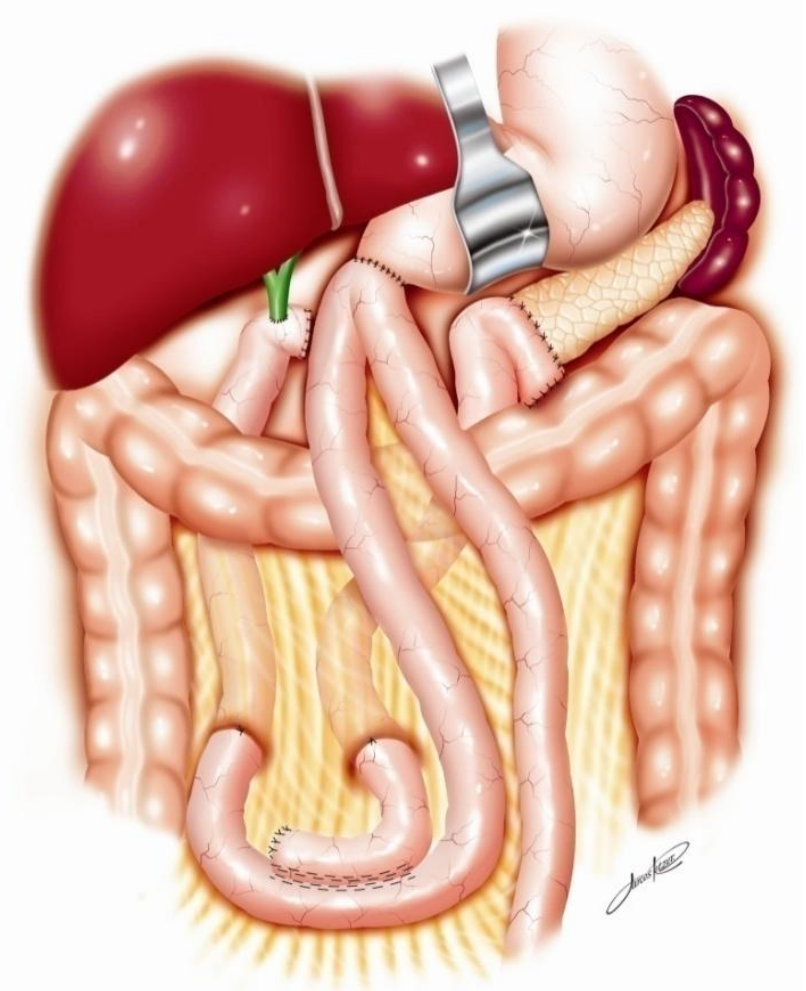

Figura 2: Esquema representativo de técnica cirúrgica para reconstrução de duodenopancreatectomiautilizando dupla alça para anastomose biliar e pancreática.

\subsection{Estudo Histopatológico}

Os relatórios dos exames anatomopatológicos e as lâminas referentes aos tumores de cada paciente foram recuperados no Serviço de Arquivo do Departamento de Patologia do HCFMUSP. As lâminas com coloração de hematoxilina e eosina foram novamente examinadas por dois patologistas experientes do Departamento de Patologia do HCFMUSP que não tinham conhecimento da evolução do paciente.

Caracterizou-se o grau de diferenciação em bem, moderadamente e pouco diferenciado, a condição das margens cirúrgicas, infiltração de estruturas 
adjacentes, a ocorrência e o número de metástases linfonodais e invasão vascular, linfática ou perineural. O tamanho do tumor em seu maior eixo foi recuperado do relatório de exame anatomopatológico original. Os tumores foram estadiados de acordo com a Union Internationale pour le Controle du Cancer (UICC - 2002) (Anexo A).

Dois patologistas experientes classificaram esses adenocarcinomas em tipo intestinal e pancreatobiliar, baseados nas características citológicas e arquiteturais, conforme descrição de Albores-Saavedra (20). Os tumores do tipo intestinal (Figura 3) são histologicamente indistinguíveis dos tumores colorretais. Nos tumores bem diferenciados, verifica-se formação de glândulas tubulares e vilos em estroma desmoplásico mínimo a moderado. Áreas de complexo cribiforme e áreas sólidas podem estar presentes. Em tumores pouco diferenciados predominam as áreas sólidas. As glândulas e áreas cribiformes podem exibir necrose central com células inflamatórias. As células são colunares com núcleo ovais em arranjo pseudoestratificado próximos ao pólo basal. Os núcleos geralmente assemelham-se uns aos outros, e o número de mitoses é variável. Nos tumores bem diferenciados, podem ser vistos borda em escova bem definida em pólo luminal, células caliciformes e mais raramente células de Paneth.

O tipo pancreatobiliar (Figura 4) assemelha-se aos tumores primários do pâncreas e ductos biliares extra-hepáticos. Esses tumores quando bem diferenciados apresentam glândulas simples ou ramificadas em estroma desmoplásico mínimo a moderado. Formações papilares focais ou micropapilares 
podem estar presentes. As células são cubóides ou colunares baixas e geralmente estão dispostas em camada única, sem pseudoestratificação nuclear. Os núcleos são mais arredondados que no tipo intestinal e frequentemente apresentam variação de tamanho e forma. Pode haver um alto grau de pleomorfismo nuclear mesmo na presença de glândulas bem formadas. Nos tumores pouco diferenciados, áreas sólidas ou mesmo células isoladas são encontradas.

Nos casos com padrão histológico misto, a classificação foi daquele tipo histológico mais predominante (122). Outros tipos menos comuns de adenocarcinoma são o carcinoma papilar invasivo, o carcinoma mucinoso (colóide), o adenoescamoso, o carcinoma com células em anel de sinete e o carcinoma de células claras. 


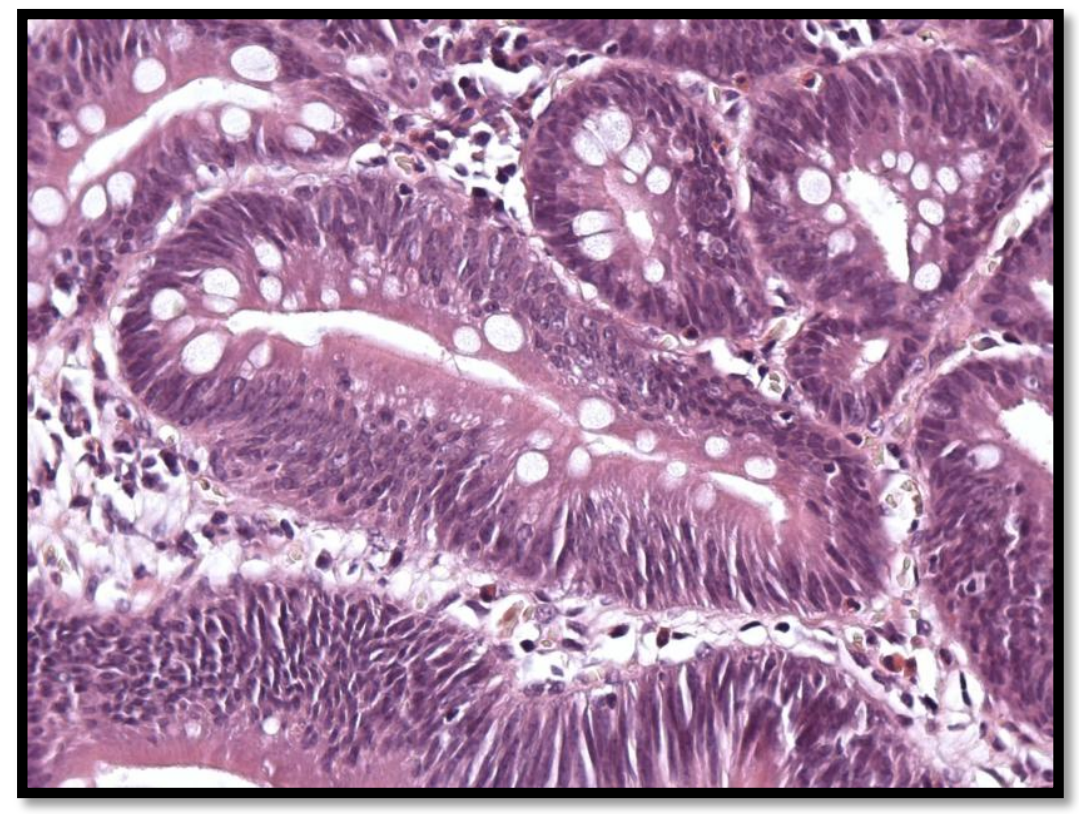

Figura 3: Adenocarcinoma da ampola de Vater do tipo intestinal, com células de Paneth (H\&E, 400x).

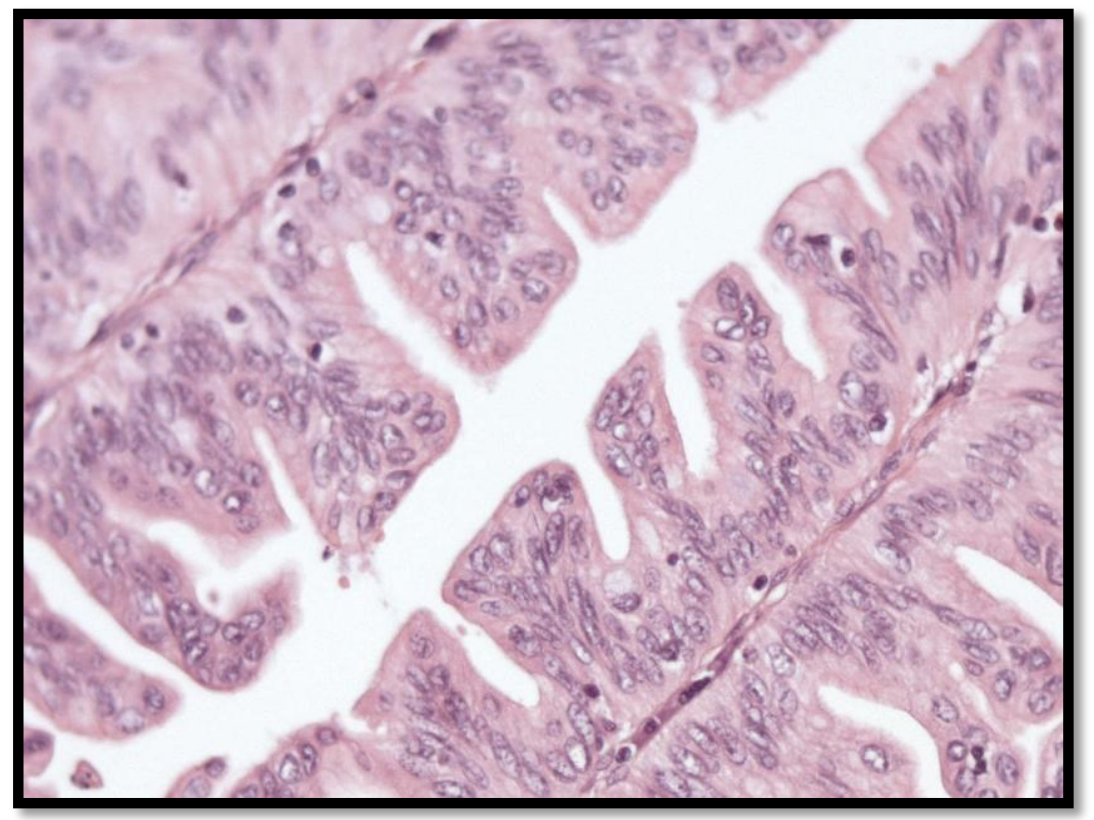

Figura 4: Adenocarcinoma da ampola de Vater do tipo pancreatobiliar, com atipia celular (H\&E, 400x). 


\subsection{Tissue Microarray}

Cortes histológicos representativos dos casos, corados pela hematoxilina e eosina foram revisados pelos patologistas e as áreas de interesse foram selecionadas nas lâminas. Os blocos de parafina contendo os cortes histológicos das peças cirúrgicas foram recuperados no arquivo-blocário da Divisão de Anatomia Patológica do Hospital das Clínicas da Faculdade de Medicina da Universidade de São Paulo. As mesmas áreas foram marcadas nos respectivos blocos de parafina doadores dos tecidos. Cilindros de $1,0 \mathrm{~mm}$ de diâmetro das áreas marcadas nos blocos de parafina doadores foram transportados para um bloco de parafina receptor através de um sistema mecanizado de precisão (Beecher Instruments), com um intervalo de 0,3 mm entre os cilindros (figura 3).

Cada cilindro amostral foi alocado numa posição do bloco receptor definido num sistema cartesiano de coordenadas, e o conjunto das amostras constituiu uma micromatriz tecidual (TMA) com 16 linhas e 13 colunas. No total, o TMA construído contém 208 posições, sendo 194 amostras de 97 casos, com 2 amostras por caso mais 9 amostras de tecidos controle (mucosa duodenal e do ducto pancreatobiliar) e 5 espaços em branco para determinar o posicionamento do TMA. Foram realizados dois blocos de TMA idênticos, adicionais, de forma que estarão disponíveis para análise de 1 a 6 amostras de cada caso distribuídas pelo total de 3 blocos de TMA receptores. Duas amostras por caso foram avaliadas para cada marcador. Uma vez prontos, os blocos de TMA foram cortados em secções histológicas de $3 \mu \mathrm{m}$ (Leica Instruments), em lâminas carregadas positivamente 
(carga elétrica). De cada um dos blocos de TMA foram cortadas 50 lâminas, sendo três delas coradas pela hematoxilina e eosina, e as 47 restantes reservadas aos estudos imunoistoquímicos (figura 4).

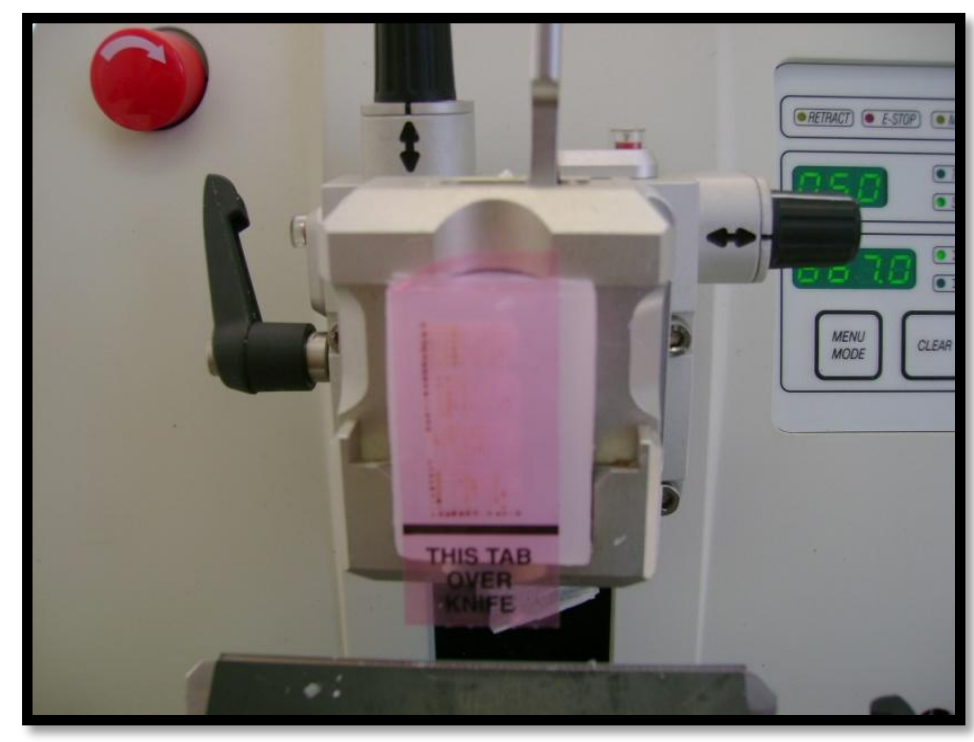

Figura 5: Equipamento que realiza cortes histológicos nos blocos de parafina para realização do TMA.

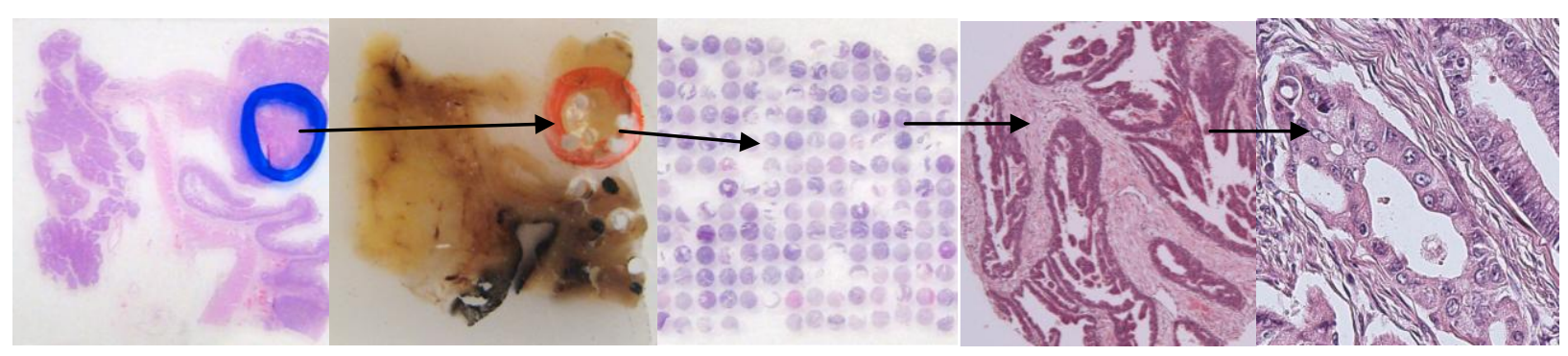

Figura 6: Preparo do bloco de TMA; 1 seleção da área na lâmina de H\&E, 2 seleção da área no bloco de parafina, 3 lâmina de TMA em H\&E, 4 . lâmina de TMA em H\&E aumento 100x, 5 lâmina de TMA em H\&E aumento 400x. 


\subsection{Imunoistoquímica}

Para análise imunoistoquímica os blocos foram seccionados e submetidos à desparafinização a quente com xilol a $60^{\circ} \mathrm{C}$ por trinta minutos e, a seguir, a desparafinização a frio com xilol à temperatura ambiente por 10 minutos. Os cortes histológicos foram hidratados em solução com concentrações decrescentes de etanol e a seguir lavados com água destilada. Para induzir bloqueio da peroxidase endógena, as lâminas foram imersas em água oxigenada a 6\% (20 volumes) por 20 minutos. A seguir, os cortes foram submetidos à recuperação antigênica pelo calor, durante 2 a 5 minutos em panela de pressão, imersos em solução de ácido cítrico 0,01M no pH 6,0 ou solução TRIS/EDTA pH 9,0. Após esta etapa inicial, as lâminas foram lavadas em água corrente, água destilada e com solução salina tamponada com fosfato (PBS), $\mathrm{pH} 7,4$, por um minuto, três vezes.

Cada lâmina foi incubada com o anticorpo primário, específico para o antígeno, diluído em solução de albumina a 1\% em PBS, em câmara úmida, por 18 horas a $4^{\circ} \mathrm{C}$. As lâminas foram então lavadas por 3 vezes em tampão PBS. Os anticorpos utilizados para classificação histológica das neoplasias foram: anticorpo monoclonal para citoqueratina 7 , citoqueratina 17 , citoqueratina 20 , apomucina MUC1 (mammary gland-type apomucin), apomucina MUC2 (apomucin of intestinal goblet cell type), apomucin MUC5AC (apomucin of gastrical foveolar cells type), apomucina MUC6, antígeno CA19-9, antígeno carcinomaembrionário (CEA), CDX2 e CD10. Outros anticorpos monoclonais específicos testados para determinação de 
alterações genéticas foram: proteína p53, anticorpo anti p16, anti KI67, antihMSH2, anti-hMLH1 e anti hMSH6 (Tabela 1).

Após a reação primária as amostras foram incubadas com anticorpo secundário biotinilado (LSAB+, Dako) ou com polímero (Max Polímero, zymed) específico para a espécie animal em que foi produzido o anticorpo primário, em câmara úmida por 1 fora ou 30 minutos, a $37^{\circ} \mathrm{C}$ e posteriormente lavadas com PBS por um minuto, três vezes.

Aplicou-se então o conjugado enzimático polímero peroxidase (Max polímero, Zymed) ou complexo Avidina-biotina-peroxidase (LSAB+, Dako), em câmara úmida a 37 ํ por 30 minutos, seguindo lavagem em tampão PBS, por 3 vezes. Foi realizada a revelação com substrato cromogênico (diaminobenzidina a $60 \%$ em PBS $+1,5 \mathrm{~mL}$ de água oxigenada a 20 volumes) por 3 a 5 minutos e após lavagem com água corrente destilada. Realizou-se contracoloração com hematoxilina de Harrys, Mayer ou Carazzi, e após lavados com água corrente e destilada. Foi então feita desidratação dos cortes com álcool com concentrações crescentes 50\%, 95\% e absoluto) e xilol, por 3 vezes. Foram então montadas as lâminas em Entellan, para análise dos resultados. 
Tabela 1: Relação dos anticorpos utilizados nas reações imunoistoquímicas.

\begin{tabular}{|c|c|c|c|c|}
\hline $\begin{array}{l}\text { Anticorpo } \\
\text { Monoclonal }\end{array}$ & Clone & Marca & Diluição & Código \\
\hline Anti MUC 1 & Ma 695 & Novocastra & 1:1000 & NCL-MUC-1 \\
\hline Anti MUC 2 & Ccp58 & Dako & $1: 50$ & NCL-MUC-2 \\
\hline Anti MUC 5AC & $\mathrm{CLH} 2$ & Novocastra & $1: 200$ & NCL-MUC-5AC \\
\hline Anti MUC 6 & CLH5 & Novocastra & $1: 125$ & NCL-MUC-6 \\
\hline Anti CDX2 & АMT28 & Novocastra & $1: 50$ & NCL-CDX2 \\
\hline Anti CK7 & OV-TL-12/30 & Dako & $1: 25000$ & M 7018 \\
\hline Anti CK17 & E3 & Novocastra & $1: 50$ & NCL-CK17 \\
\hline Anti CK20 & Ks20-8 & Dako & $1: 400$ & M7019 \\
\hline Anti CD10 & $56 C 6$ & Novocastra & $1: 100$ & NCL-CD10-270 \\
\hline Anti p53 & D07 & Dako & $1: 50$ & M7001 \\
\hline Anti p16 & $6 \mathrm{H} 2$ & Novocastra & $1: 100$ & NCP-P16 \\
\hline Anti Ki-67 & KIS5 & Dako & $1: 250$ & PP3.30 \\
\hline Anti CA19-9 & 116-ns-19.9 & Dako & $1: 100$ & M3517 \\
\hline Anti CEA & $11-7$ & Dako & $1: 400$ & M7072 \\
\hline Anti MLH1 & G168-15 & $\mathrm{BD}$ & $1: 200$ & 551092 \\
\hline Anti MSH2 & $\mathrm{MSH} 2$ & Novocastra & $1: 200$ & NCL-MSH2 \\
\hline Anti MSH6 & 44 & $\mathrm{BD}$ & $1: 400$ & 610919 \\
\hline
\end{tabular}

\subsection{Análise dos Resultados de Imunoistoquímica}

A análise do resultado da imunoistoquímica foi realizada por um único patologista experiente (RP). Todos os cortes histológicos foram examinados, usando 
sistema pré-definido de graduação. A reatividade nuclear e citoplasmática foi classificada semiquantitativamente numa escala de 0 a 3 para distribuição (distribuição: 0 = ausência de coloração na amostra corada; 1=células positivas esparsas, menos de $10 \%$ da amostra; 2=várias áreas de positividade, correspondendo a $10 \%$ a $50 \%$ da amostra celular; e 3=quase todas as células uniformemente positivas, ou acima de $50 \%)$.

\section{Análise da imunoexpressão de MUC1, MUC2, MUC5AC, MUC6 e CDX2}

A imunorreatividade para a expressão de mucinas foi definida pela presença de grânulos citoplasmáticos corados. Foi considerada alterada para esses marcadores quando a reatividade da leitura foi maior ou igual a 1 na escala 1, 2 ou 3 para distribuição.

\section{Análise da imunoexpressão das citoqueratinas CK7, CK17, CK20 e do CD10}

A imunorreatividade para a expressão de citoqueratinas e do CD10 foi definida pela presença de grânulos citoplasmáticos ou de membrana corados. Foi considerada alterada para esses marcadores quando a reatividade da leitura foi maior ou igual a 1 na escala 1, 2 ou 3 para distribuição.

\section{Análise da imunoexpressão de p53, p16 e Ki67}

A análise da imunoistoquímica para p53 e Ki67 corresponde à coloração nuclear e para o p16 à coloração citoplasmática. Foi considerada positiva para esses marcadores, quando a intensidade de leitura foi classificada como maior ou igual a 2 na escala 1 a 3 para distribuição. 


\section{Análise da imunoexpressão do CEA e CA19-9}

A análise da imunoistoquímica para o CEA (antígeno carcinoma-embrionário) e para o CA 19-9 corresponde à coloração citoplasmática. Foi considerada positiva para esses marcadores, quando a intensidade de leitura foi classificada como maior ou igual a 1 na escala de 1 a 3 para distribuição.

\section{Análise da imunoexpressão de hMLH1, hMSH2 e hMSH6}

A expressão normal para os marcadores imunoistoquímicos das proteínas de reparo do DNA (MMR) hMLH1, hMSH2 e hMSH6 corresponde à uma coloração nuclear. Os casos foram considerados alterados para a expressão desses marcadores quando houve total ausência de reatividade nuclear para esses marcadores, frente a um controle positivo das amostras de tecido normal do TMA. Controles internos positivos (linfócitos, células epiteliais não neoplásicas e células estromais) encontradas nas mesmas amostras foram utilizadas para validar a ausência de coloração nuclear nas células neoplásicas como verdadeiros negativos.

Todos os casos alterados no TMA foram validados através de reação imunoistoquímica em lâminas com cortes convencionais. Os casos negativos no TMA que resultaram positivos na validação, foram considerados positivos para análise dos resultados. 


\subsection{Estatística}

A análise estatística foi realizada utilizando o programa SPSS ${ }^{\circledR}$ versão 15.0 (Statistical Package for the Social Sciences, Chicago, Illinois, USA). Em todos os testes foi considerada significância estatística valores de $p \leq 0,05$.

O teste Qui-quadrado de Pearson e o teste Exato de Fisher foram utilizados para comparação entre os resultados de variáveis categóricas. Para a comparação entre médias das variáveis contínuas foi utilizado o método de t-Student.

Para analisar os marcadores de origem histológica, foi aplicado o Modelo Linear Generalizado (Generalized Linear Model ou GLM) com distribuição binomial e função de ligação logística para identificar a chance de a origem tecidual ser pancreática. Esse modelo é equivalente a uma regressão logística habitual. Quando o efeito foi protetor (coeficiente negativo), o resultado foi apresentado como chance para origem intestinal.

Para classificar os tumores utilizando os marcadores imunoistoquímicos, foi aplicado o GLM para cada caso, categorizando uma probabilidade de ser tipo pancreatobiliar para cada caso. Para classificar os pacientes por tipo de tumor (intestinal ou pancreatobiliar) foi necessário encontrar um ponto de corte que maximizasse a sensibilidade e especificidade na curva ROC. Com a intenção de estimar uma distribuição de probabilidades para tal ponto de corte, foi adotado uma técnica de re-amostragem ("bootstrap"). A mediana dos pontos de corte obtidos após 5000 re-amostragens foi adotada para classificar os pacientes. 
Calculou-se então a sensibilidade, especificidade e acurácia dessa nova classificação. A análise da intensidade da concordância entre as duas classificações foi feita pelo método Kappa.

Referente à análise de sobrevivência, foi ajustado o modelo de Kaplan-Meier e comparado pelo teste de Log-rank. Os pacientes foram acompanhados a partir da data do procedimento cirúrgico até a data do óbito (evento de interesse) ou último contato ambulatorial ou telefônico no período de cinco anos (censura).

Realizamos então a análise pelo modelo de risco proporcional com cura (proportional hazard with cure, ou modelo de Cox com cura) para determinar as variáveis independentes relacionadas à sobrevivência. 
4. Resultados 


\section{RESULTADOS}

\subsection{Características Clínicas}

Noventa e sete pacientes com neoplasia de papila foram submetidos à ressecção cirúrgica entre janeiro de 1985 a dezembro de 2006. A média etária dos pacientes foi de 59,3 anos, com variação entre 23 a 83 anos. Cinquenta e oito doentes $(59,8 \%)$ eram homens. Cinqüenta e oito por cento dos doentes eram tabagistas e 57,3\% etilistas. Os sintomas pré-operatórios mais freqüentes foram: icterícia $(84,3 \%)$, emagrecimento $(79,6 \%)$ e dor abdominal $(59,8 \%)$. Cinquenta e sete pacientes $(58,8 \%)$ apresentaram perda de peso superior a $10 \%$ do peso habitual (Tabela 2). Dezenove doentes $(19,6 \%)$ foram submetidos à passagem de prótese na via biliar pré-operatoriamente.

Sessenta doentes $(61,9 \%)$ foram submetidos a duodenopancreatectomia com preservação pilórica e 37 (38,1\%) a gastroduodenopancreatectomia, todos os pacientes tiveram reconstrução em dupla alça. O tempo médio do procedimento foi $581 \pm 150,3$ minutos. A transfusão sanguínea intra-operatória foi necessária em 40 doentes $(41,2 \%)$, sendo 0,8 a média de concentrados de hemácias transfundidos. 
Tabela 2: Características clínico-cirúrgicas gerais dos doentes com AAV.

\begin{tabular}{ll}
\hline & $\mathrm{n}=97$ \\
\hline Média etária & $59,3 \pm 12,7$ \\
Sexo & $58(59,8 \%)$ \\
$\quad$ Masculino & $39(40,2 \%)$ \\
$\quad$ Feminino & \\
Sintomas pré-operatórios & $82(84,5 \%)$ \\
$\quad$ Icterícia & $58(59,8 \%)$ \\
$\quad$ Dor abdominal & $57(58,8 \%)$ \\
$\quad$ Perda de peso > 10\% peso habitual & $32(33 \%)$ \\
$\quad$ Náuseas e/ou vômitos & \\
Exames laboratorias pré-operatórios & $11,9 \pm 1,7$ \\
$\quad$ Hemoglobina (g/l) & $7,7 \pm 9,4$ \\
Bilirrubina total (mg/dl) & $3,5 \pm 0,7$ \\
Albumina (g/dl) & \\
Cirurgia realizada & $60(61,9 \%)$ \\
$\quad$ Duodenopancreatectomia & $37(38,1 \%)$ \\
Gastroduodenopancreatectomia &
\end{tabular}

A taxa de complicações pós-operatórias foi de $58,7 \%$, sendo o retardo de esvaziamento gástrico $(29,9 \%)$ e a fístula pancreática $(21,7 \%)$ as mais frequentes (Tabela 3). Ocorreram três óbitos $(3,1 \%)$ relacionados ao procedimento, no 10 , 12 e 14을 dias. Seis doentes foram reoperados, sendo dois por fístulas pancreáticas complicadas, dois para drenagem de coleção, um por coleperitôneo e um por deiscência da aponeurose. O tempo médio de internação foi de 16,8 dias (8-58dias). 
Tabela 3: Mortalidade e morbidade pós-operatória dos doentes com AAV submetidos a duodenopancreatectomia.

\begin{tabular}{lcc}
\hline Mortalidade 30 dias pós-op & 3 & $3,1 \%$ \\
\hline Morbidade total & 57 & $58,7 \%$ \\
Retardo no esvaziamento gástrico & 29 & $29,9 \%$ \\
Fistula pancreática & 21 & $21,7 \%$ \\
Infecção de ferida & 21 & $21,7 \%$ \\
Abcesso intra-abdominal & 4 & $4,1 \%$ \\
Fístula biliar & 3 & $3,1 \%$ \\
Pneumonia & 3 & $3,1 \%$ \\
Trombose venosa profunda & 1 & $1 \%$ \\
\hline
\end{tabular}

\subsection{Características anatomopatológicas}

Todos os espécimes ressecados tratavam-se de adenocarcinomas. As margens foram histologicamente negativas em 96 casos ressecados. Uma paciente teve margem duodenal proximal comprometida (R1), apresentando recidiva precoce da doença e óbito após oito meses de seguimento.

O tamanho médio das lesões foi de $2,4 \mathrm{~cm} \pm 1,36 \mathrm{~cm}$, variando de 0,3 a $8 \mathrm{~cm}$. A média de linfonodos dissecados foi $13,5 \pm 9,8$. Trinta e três pacientes (34\%) apresentaram linfonodos comprometidos pela neoplasia, com mediana de dois linfonodos acometidos por paciente (variação de 1 a 10). Todos os pacientes foram estadiados de acordo com o manual de estadiamento do "American Joint Committee on Cancer" (AJCC) como: estadio IA: 25 pacientes (T1NOMO, T1: limitado 
à ampola de Vater ou esfíncter de Oddi); estadio IB: 19 pacientes (T2NOMO, T2: invadindo a parede duodenal); estadio IIA: 19 pacientes (T3NOMO, T3: invadindo o pâncreas); estadio IIB: 33 pacientes (qualqueT,N1M0, N1: metástases em linfonodos regionais); estadio IV: 1 paciente (qualquer T, qualquer $\mathrm{N}$, presença de metástase). Um total de 22 tumores (22,7\%) eram bem diferenciados [grau (G)1], 63 (64,9\%) moderadamente diferenciados (G2), e 12 (12,4\%) pouco diferenciados (G3) (Tabelas 4 e 5$)$. 
Tabela 4: características anátomo-patológicas dos AAV ressecados.

\begin{tabular}{lll}
\hline & $\mathrm{n}=97$ & \\
\hline Tamanho do tumor $(\mathrm{cm})$ & $0,3-8$ & $2,4 \pm 1,36^{*}$ \\
Linfonodos dissecados & $5-47$ & $13,5 \pm 9,8^{*}$ \\
Linfonodos metastáticos & 33 & $34 \%$ \\
Grau histológico & & \\
$\quad$ Bem diferenciado & 22 & $22,7 \%$ \\
Moderadamente diferenciado & 63 & $64,9 \%$ \\
Pouco diferenciado & 12 & $12,4 \%$ \\
Invasão vascular & 6 & $6,2 \%$ \\
Invasão linfática & 28 & $28,9 \%$ \\
Invasão perineural & 22 & $22,7 \%$ \\
Extensão & & \\
Restrito à papila & 30 & $30,9 \%$ \\
Pâncreas & 33 & $34 \%$ \\
Duodeno & 33 & $34 \%$ \\
Veia porta & 1 & $1,1 \%$ \\
\hline
\end{tabular}

*média e desvio padrão

Tabela 5: Estadiamento e classificação TNMdos AAV.

\begin{tabular}{llll}
\hline Estadio & TNM & N & $\%$ \\
\hline IA & T1, N0, MO & 25 & 25,8 \\
IB & T2, N0, MO & 19 & 19,6 \\
IIA & T3, N0, MO & 19 & 19,6 \\
IIB & Qualquer T, N1, MO & 33 & 34 \\
IV & Qualquer T e N, M1 & 1 & 1 \\
\hline
\end{tabular}

4.3. Expressão imunoistoquímicos para diferenciação do epitélio de origem

Os tumores foram classificados segundo a origem tecidual em tipos intestinal (TI) em 43 casos (44,3\%), tipo pancreatobiliar (TPB) em 47 casos $(48,5 \%)$ e 
outros tipos em 7 casos (7,2\%) (5 adenocarcinomas mucinosos, 1 adenoescamoso e 1 adenocarcinoma de células claras).

A expressão imunoistoquímica do CDX2, MUC1, MUC2, CK7, CK20 e CD10foram significativamente diferentes nos adenocarcinomas TI e TPB (Tabela 6). Os marcadores CDX2, MUC2, CD10 e CK20 são expressos com maior freqüência no TI e os marcadores MUC1 e CK7 são mais expressos no TPB. Particularmente, $86 \%$ dos tumores TI expressaram CDX2, e 93,6\% dos tumores TPB expressaram CK7. Trinta e dois tumores TI (74,4\%) expressaram fortemente o CDX2 (escore 3+).

Quando analisamos a sensibilidade e a especificidade dos marcadores que tiveram significância na determinação do tipo histológico, pudemos notar que os marcadores com maior sensibilidade e especificidade são aqueles que predominam no tipo intestinal. O marcador com maior acurácia foi o $\operatorname{CDX2}(82,2 \%)$, seguido do MUC2 (75,5\%) e CK20 (73,3\%). Os marcadores para o tipo pancreatobiliar, MUC1 e CK7, apresentam boa sensibilidade $(84,8 \%$ e $95,7 \%$, respectivamente), porém, por frequentemente marcarem também os $\mathrm{TI}$, apresentam baixa especificidade $(46,5 \%$ e $20,9 \%$, respectivamente). O marcador com maior valor preditivo positivo para o tipo intestinal foi o $\operatorname{CDX} 2(78,7 \%)$ e para o tipo pancreatobiliar o MUC1 $(62,9 \%)$ (Tabela 7, figuras 5 e 6). 
Tabela 6: Positividade para marcadores imunoistoquímicos dos tumores tipo intestinal e pancreatobiliar.

\begin{tabular}{lcrl}
\hline & $\begin{array}{c}\text { Tipo Intestinal }(\mathrm{n}=43) \\
\mathrm{n}(\%)\end{array}$ & $\begin{array}{c}\text { Tipo Pancreatobiliar }(\mathrm{n}=47) \\
\mathrm{n}(\%)\end{array}$ & \\
\hline MUC1 & $23(53,5 \%)$ & $39(82,9 \%)$ & 0,001 \\
MUC2 & $32(74,4 \%)$ & $11(23,4 \%)$ & $<0,001$ \\
MUC5AC & $29(67,4 \%)$ & $33(70,2 \%)$ & 0,436 \\
MUC6 & $19(44,2 \%)$ & $21(44,7 \%)$ & 0,566 \\
CDX2 & $37(86 \%)$ & $10(21,3 \%)$ & $<0,001$ \\
CK7 & $34(79,1 \%)$ & $44(93,6 \%)$ & 0,041 \\
CK17 & $27(62,8)$ & $37(78,7 \%)$ & 0,096 \\
CK20 & $33(76,7 \%)$ & $14(29,8 \%)$ & $<0,001$ \\
CD10 & $35(81,4 \%)$ & $24(51,1 \%)$ & 0,002 \\
\hline
\end{tabular}

* Teste qui-quadrado de Pearson 
Tabela 7: Sensibilidade, especificidade, acurácia e valor preditivo positivo dos marcadores imunoistoquímicos para determinação do tipo histológico dos AAV.

\begin{tabular}{|c|c|c|}
\hline & Tipo Intestinal & Tipo pancreatobiliar \\
\hline MUC2 & $\begin{array}{l}\text { Sensibilidade: } 74,4 \% \\
\text { Especificidade: } 76,6 \% \\
\text { Acurácia: } 75,5 \% \\
\text { VPP: } 74,4 \%\end{array}$ & \\
\hline CK20 & $\begin{array}{l}\text { Sensibilidade: } 76,7 \% \\
\text { Especificidade: 70,2\% } \\
\text { Acurácia: } 73,3 \% \\
\text { VPP: } 70,2 \%\end{array}$ & \\
\hline CD10 & $\begin{array}{l}\text { Sensibilidade: } 81,4 \% \\
\text { Especificidade: } 48,9 \% \\
\text { Acurácia: } 64,4 \% \\
\text { VPP: } 59,3 \%\end{array}$ & \\
\hline CDX2 & $\begin{array}{l}\text { Sensibilidade: } 86 \% \\
\text { Especificidade: } 78,7 \% \\
\text { Acurácia: } 82,2 \% \\
\text { VPP: } 78,7 \%\end{array}$ & \\
\hline MUC1 & & $\begin{array}{l}\text { Sensibilidade: } 84,8 \% \\
\text { Especificidade: } 46,5 \% \\
\text { Acurácia: } 66,3 \% \\
\text { VPP: } 62,9 \%\end{array}$ \\
\hline CK7 & & $\begin{array}{l}\text { Sensibilidade: } 95,7 \% \\
\text { Especificidade: } 20,9 \% \\
\text { Acurácia: } 59,6 \% \\
\text { VPP: } 56,4 \%\end{array}$ \\
\hline
\end{tabular}

VPP; valor preditivo positivo 


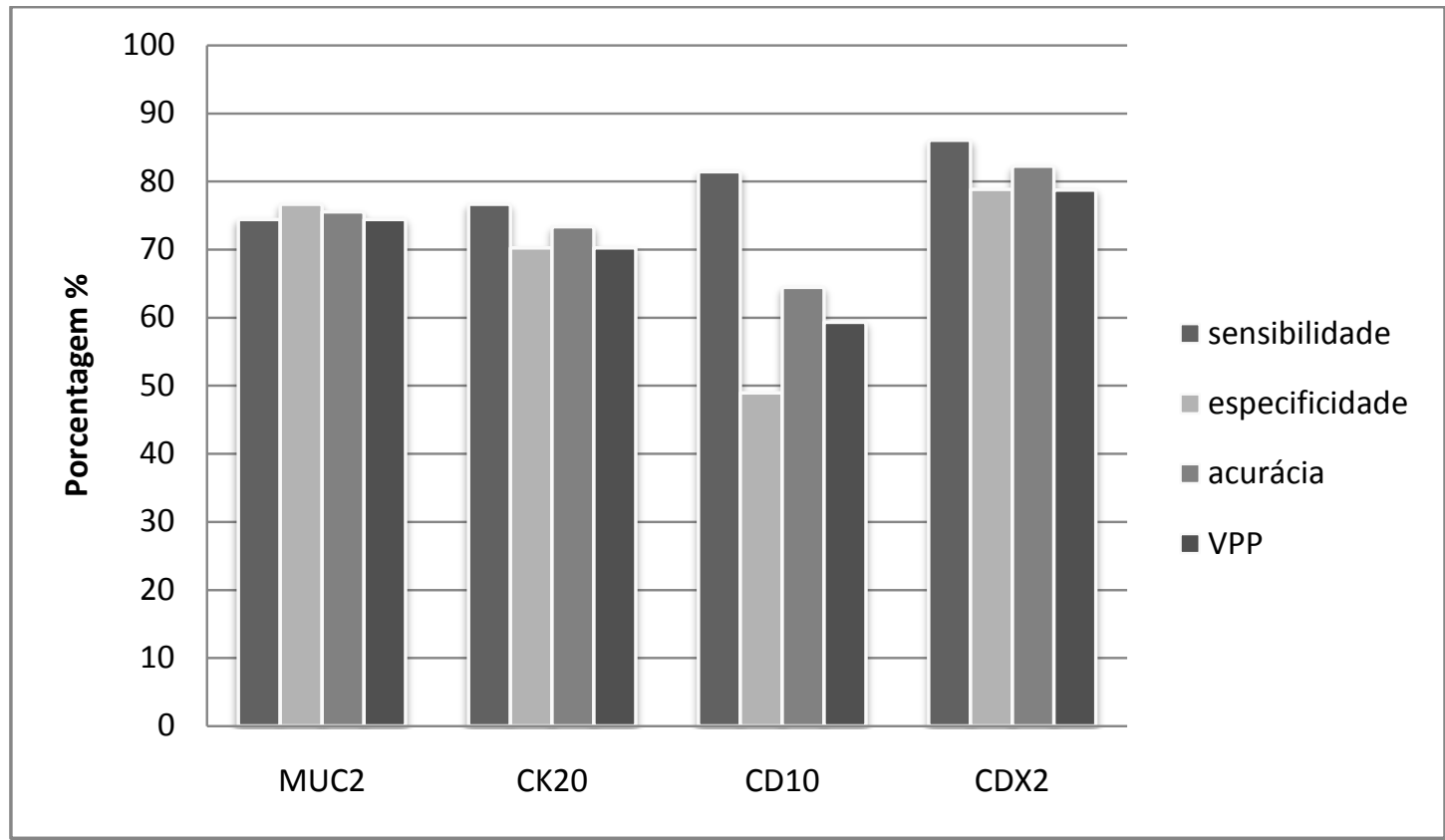

Figura 7: Sensibilidade, especificidade, acurácia e valor preditivo positivo (VPP) dos marcadores para o AAV tipo intestinal.

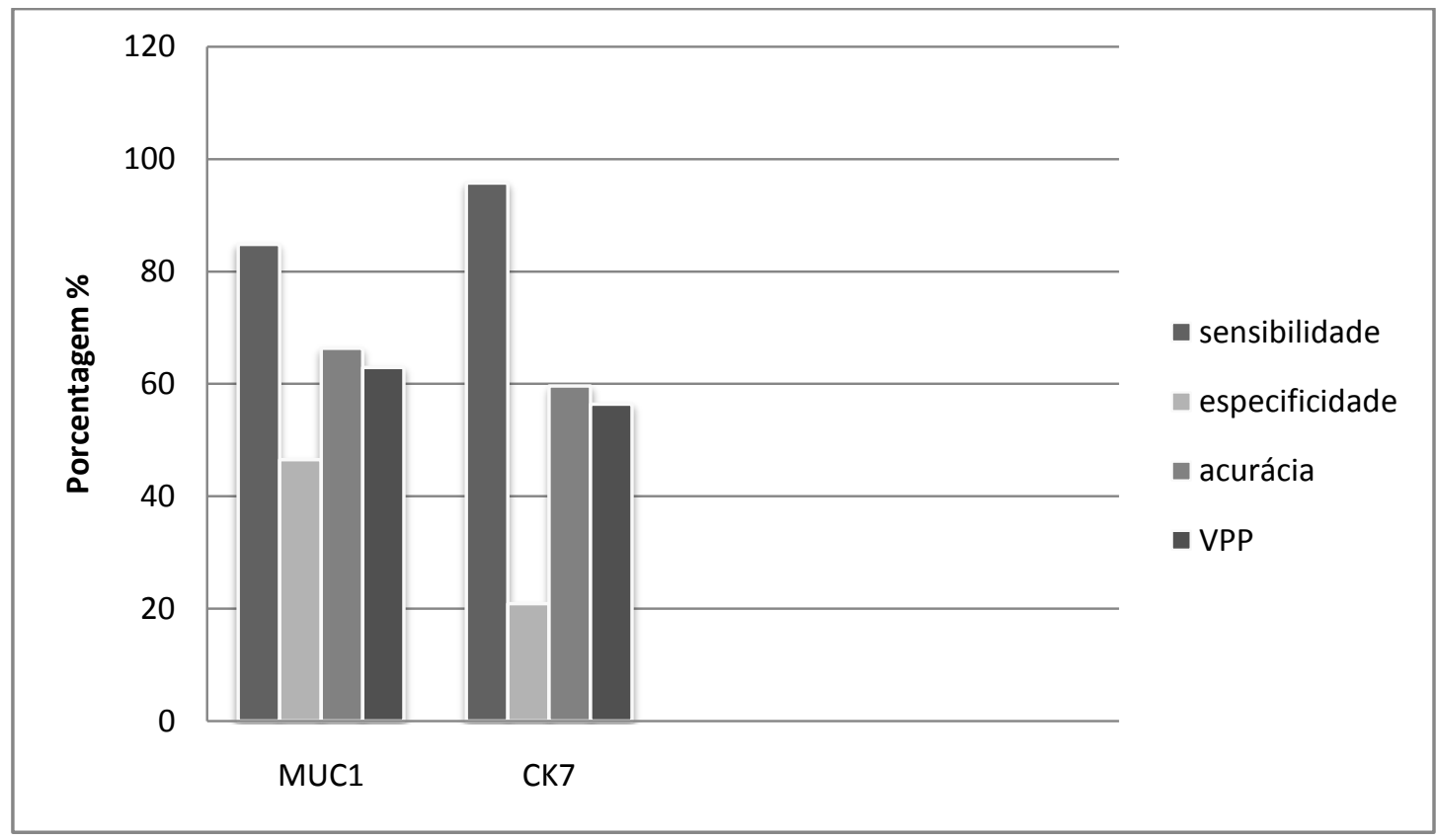

Figura 8: Sensibilidade, especificidade, acurácia e valor preditivo positivo (VPP) dos marcadores para o AAV tipo pancreatobiliar. 


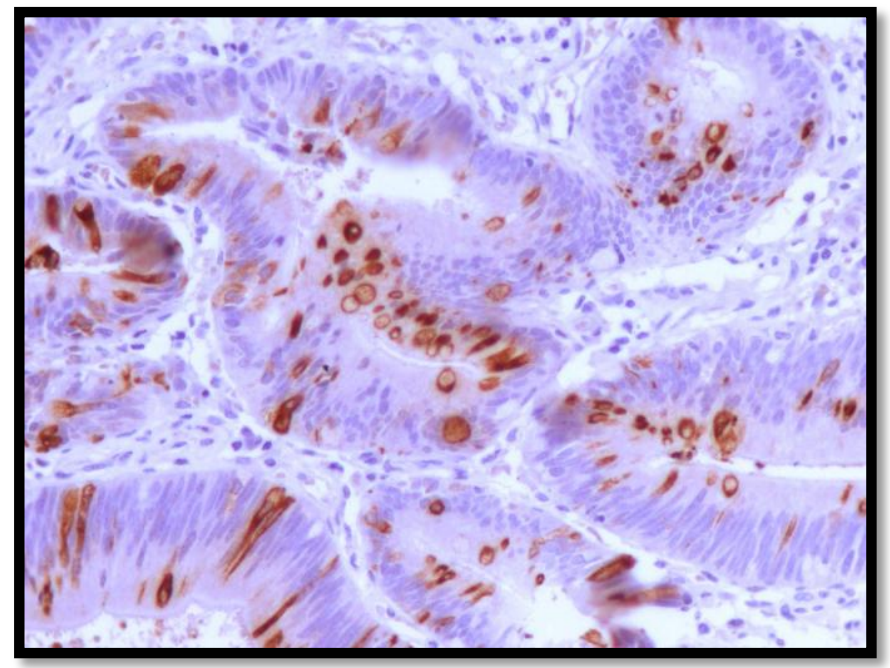

Figura 9: MUC2 - marcação imunoistoquímica de padrão citoplasmático em AAV tipo intestinal $(400 x)$

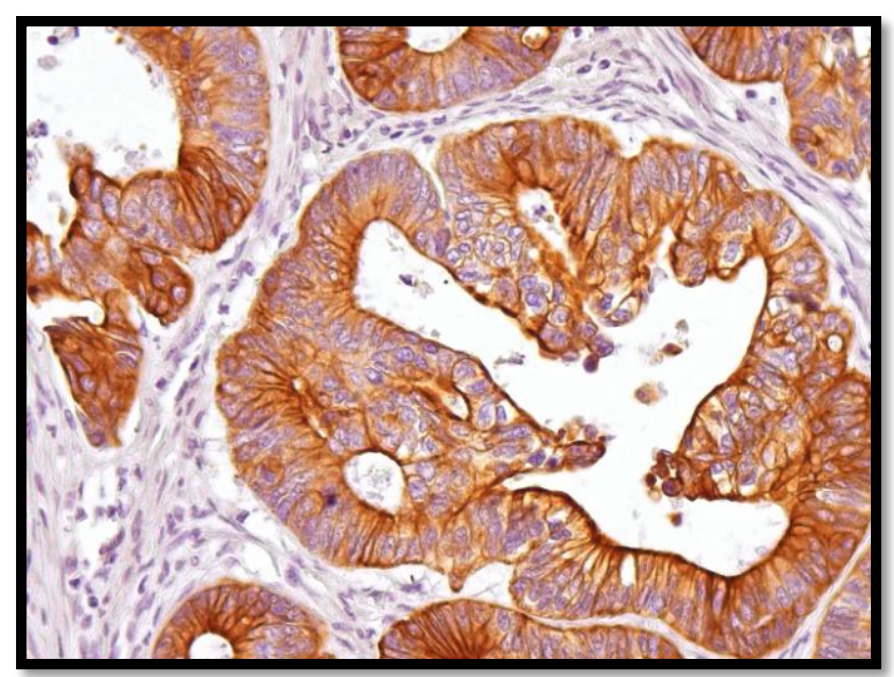

Figura 10: CK20 - marcação imunoistoquímica de padrão citoplasmático em AAV tipo intestinal (400x)

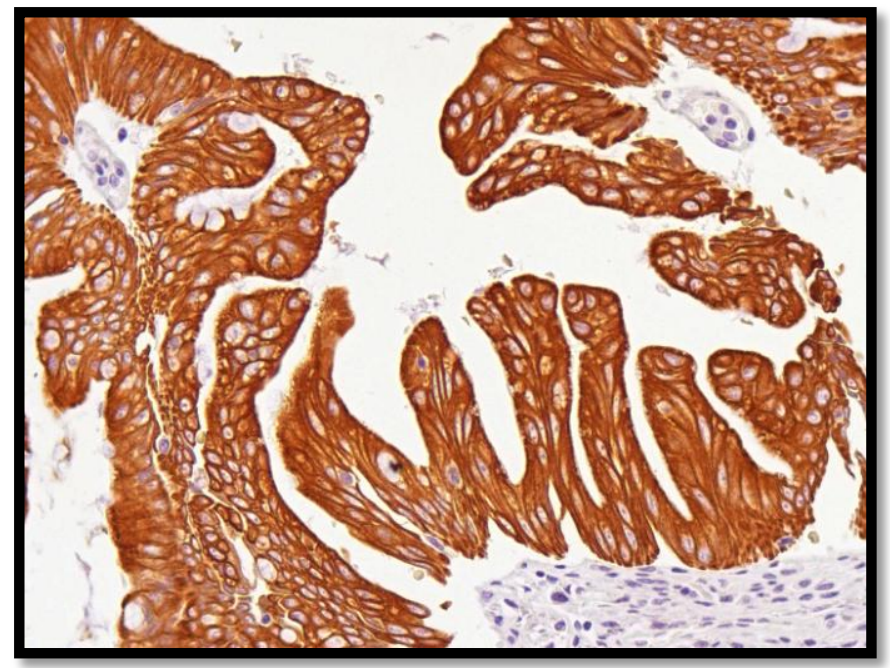

Figura 11: CDX2 - marcação imunoistoquímica de padrão citoplasmático em AAV tipo intestinal (400x) 


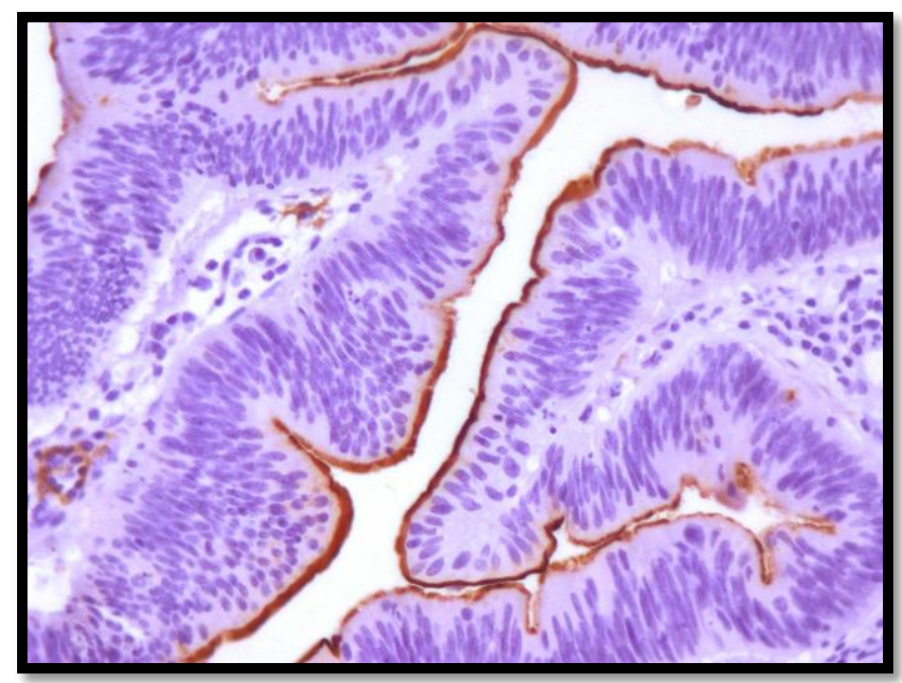

Figura 12: CD10 - marcação imunoistoquímica com padrão de membrana em AAV tipo intestinal (400x)

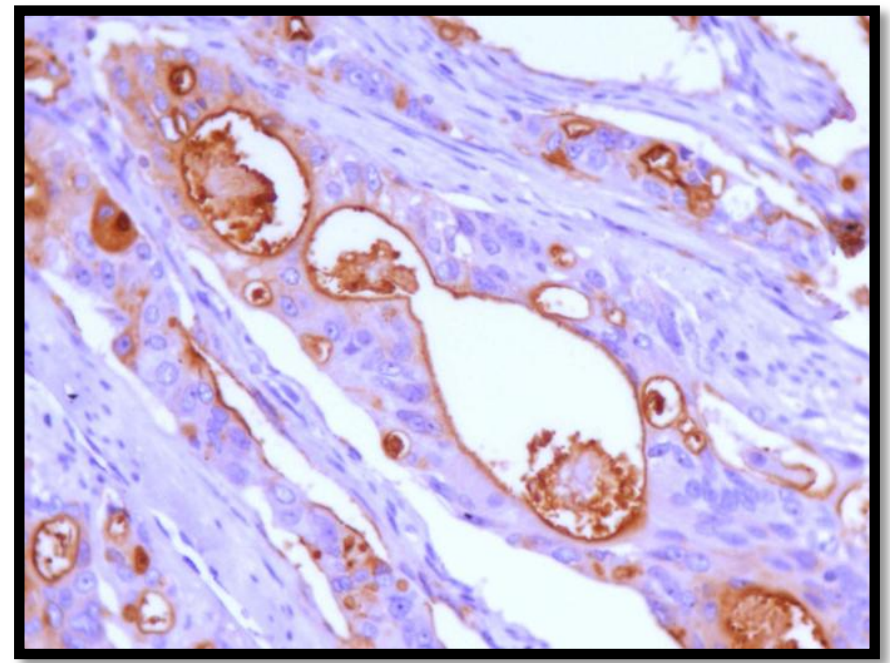

Figura 13: MUC1 - marcação imunoistoquímica de padrão citoplasmático em AAV tipo pancreatobiliar $(400 x)$

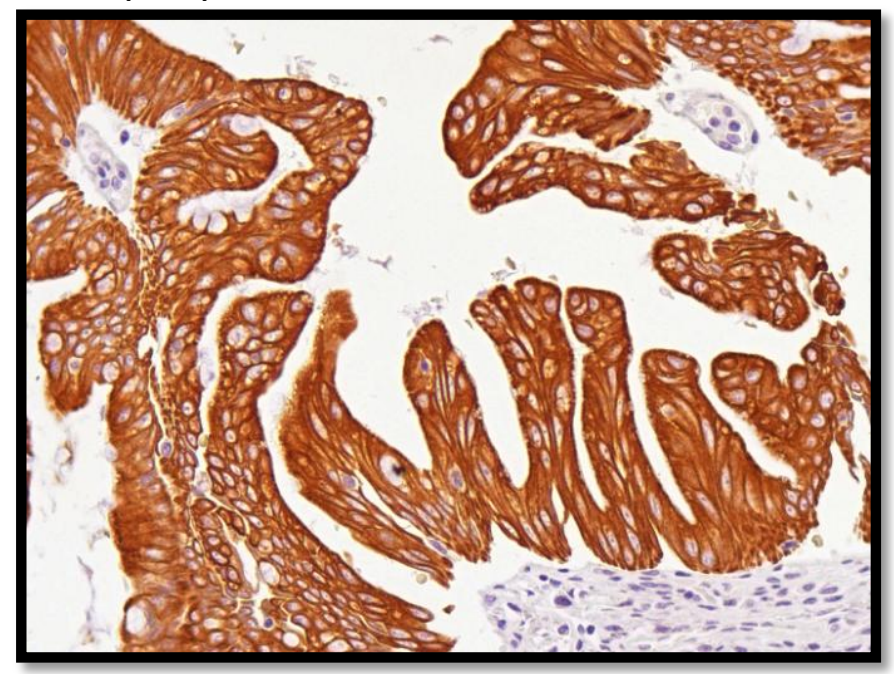

Figura 14: CK7 - marcação imunoistoquímica de padrão citoplasmático e de membrana em AAV tipo pancreatobiliar (400x) 
Através da análise de Modelo Linear Generalizado (Generalized Linear Model ou GLM) com distribuição binomial e ligação canônica (logística), equivalente a uma regressão logística, identificamos como principais marcadores para a diferenciação do tipo histológico o MUC1, MUC2 e CDX2 (Tabela 8).

Tabela 8: Modelo linear generalizado para identificar os principais marcadores imunoistoquímicos para determinação do tipo histológico.

\begin{tabular}{llllll}
\hline Coeficiente & Estimativa & Erro padrão & Efeito & IC 95\% & $\mathrm{p}$ \\
\hline Intercepto & 0,9507 & 1,2550 & 0,7213 & $(0,18 ; 0,97)$ & 0,44876 \\
MUC1 & 1,5025 & 0,7331 & 4,49295 & $(1,07 ; 18,9)$ & $\mathbf{0 , 0 4 0 4 1}$ \\
MUC2 & $-1,6284$ & 0,7471 & $5,0957 \S$ & $(1,18 ; 22,4)$ & $\mathbf{0 , 0 2 9 3 0}$ \\
MUC5AC & 0,1424 & 0,7748 & 1,1530 & $(0,25 ; 5,26)$ & 0,854178 \\
MUC6 & $-0,1200$ & 0,6995 & $1,1275 \S$ & $(0,29 ; 4,44)$ & 0,86375 \\
CK7 & 0,9899 & 0,8678 & 2,6910 & $(0,49 ; 14,74)$ & 0,25400 \\
CK17 & 0,7993 & 0,7362 & 2,3560 & $(0,53 ; 10,3)$ & 0,23900 \\
CK20 & 0,2685 & 0,8350 & 1,3080 & $(0,25 ; 6,72)$ & 0,74780 \\
CD10 & $-0,8099$ & 0,7962 & $2,248 \S$ & $(0,47 ; 10,7)$ & 0,30909 \\
CDX2 & $-2,7204$ & 0,7610 & $15,1864 \S$ & $(3,42 ; 67,49)$ & $\mathbf{0 , 0 0 0 3 5}$
\end{tabular}

$\S$ chance para tipo intestinal

Aplicamos o mesmo modelo usando apenas os marcadores que apresentaram significância estatística para diferenciação do tipo histológico. Determinamos então que um adenocarcinoma da ampola de Vater com MUC1 positivo tem 4,40 [IC 95\%: 1,06; 18,19] vezes a chance de ser pancreático se comparado com outro MUC1 negativo. Um tumor MUC2 positivo tem 5,49 [IC 95\%: 1,$59 ; 18,93$ ] vezes a chance de ser intestinal se comparado a outro MUC2 negativo. 
Por fim, um carcinoma com CDX2 positivo tem 16,15 [IC 95\%: 4,58; 56,97] vezes a chance de ser TI se comparado com outro CDX2 negativo (Tabela 9).

Tabela 9: Modelo linear generalizado para identificar os efeitos dos marcadores apontados como significantes para determinação do tipo histológico.

\begin{tabular}{llllll}
\hline Coeficiente & Estimativa & Erro padrão & Efeito & IC 95\% & $p$ \\
\hline Intercepto & 1,4388 & 0,7422 & 0,8083 & $(0,50 ; 0,95)$ & 0.05256 \\
MUC1 & 1,4810 & 0,7245 & 4,3943 & $(1,06 ; 18,19)$ & $\mathbf{0 . 0 4 0 9 4}$ \\
MUC2 & $-1,7025$ & 0,6317 & $5,4876 \S$ & $(1,59 ; 18,93)$ & $\mathbf{0 . 0 0 7 0 3}$ \\
CDX2 & $-2,7821$ & 0,6431 & $16,1529 \S$ & $(4,58 ; 56,97)$ & $<0,0001$ \\
\hline
\end{tabular}

$\S$ chance para tipo intestinal

Aplicamos o modelo para determinar o valor da associação do CDX2 e do MUC2 para a diferenciação do tipo histológico. Verificamos que a probabilidade de um adenocarcinoma da ampola de Vater CDX2 e MUC2 negativos ser TPB é 90\% [IC 95\% 0,73; 0,97]. Tumores que forem positivos para MUC2 e CDX2 tem 19,50 [IC 95\%: $5,23 ; 72,77]$ vezes a chance de ser TI se comparado com um tumor que tem MUC2 e CDX2 negativos (Tabela 10). 
Tabela 10: Modelo linear generalizado para identificar os efeitos dos marcadores MUC2 e CDX2 associados.

\begin{tabular}{llllll}
\hline Coeficiente & Estimativa & Erro & Efeito & IC 95\% & $p$ \\
& & padrão & & \\
\hline Intercepto & 2,1972 & 0.6085 & 0,9000 & $(0,50 ; 0,95)$ & 0,000305 \\
MUC2+/CDX2+ & $-2,9704$ & 0.6719 & $19,4997 \S$ & $(5,23 ; 72,77)$ & $<0,0001$ \\
\hline
\end{tabular}

$\S$ chance para o tipo intestinal

A probabilidade de um adenocarcinoma da ampola de Vater MUC1 negativo e CDX2 e MUC2 positivos ser do tipo intestinal é de $91,7 \%$. Tumores que tiveram MUC1 negativo e MUC2 e CDX2 positivos tem 19,13 [IC 95\%: 4,12; 88,85] vezes a chance de ser intestinal se comparado com um indivíduo que tem MUC1 positivo e MUC2 e CDX2 negativos (Tabela 11).

Tabela 11: Modelo linear generalizado para identificar os efeitos dos marcadores MUC1, MUC2 e CDX2 associados.

\begin{tabular}{lccccc}
\hline Coeficiente & Estimativa & Erro padrão & Efeito & IC & $\mathrm{p}$ \\
\hline Intercepto & 2,3979 & 0,7385 & 0,9167 & $(0,72 ; 0,98)$ & 0,001167 \\
MUC1- & $-2,9513$ & 0.7835 & $19,1423 \S$ & $(4,12 ; 88,85)$ & $\mathbf{0 . 0 0 0 1 6 5}$ \\
/CDX2+/MUC2+ & & & & & \\
\hline
\end{tabular}

§chance para o tipo intestinal

Adenocarcinomas da ampola de Vater que tiveram MUC1 e CK7 negativos e MUC2 e CDX2 positivos tem 16,95 [IC 95\%: 4,53; 63,41] vezes a chance de ser TI se comparado com outros que tenham MUC1 e CK7 positivos e MUC2 e CDX2 negativos (Tabela 12). 
Tabela 12: Modelo linear generalizado para identificar os efeitos dos marcadores MUC1, CK7, MUC2 e CDX2 associados.

\begin{tabular}{llllll}
\hline Coeficiente & Estimativa & Erro padrão & Efeito & IC & $\mathrm{p}$ \\
\hline Intercepto & 0,7932 & 0,2765 & 0,6885 & $(0,56 ; 0,79)$ & 0,0412 \\
MUC1-/CK7- & $-2,8301$ & 0,6732 & $16,9472 \S$ & $(4,53 ; 63,41)$ & \\
/CDX2+/MUC2+ & & & & & $<0,0001$ \\
\hline
\end{tabular}

$\S$ chance para tipo intestinal

Quando relacionamos cada marcador com critérios clínicos e anatomopatológicos, encontramos relação significativa com invasão neural ausente e CDX2 positivo ( $p=0,027)$, invasão neural ausente e $\operatorname{CD} 10$ positivo $(p=0,04)$, invasão neural presente e CK7 positivo, invasão neural e invasão linfática presente e MUC 1 positivo ( $p=0,029)$, MUC5AC positivo e tamanho da lesão maior que $2 \mathrm{~cm}(p=0,04)$ e idade maior que 60 anos $(p=0,04)$. O marcador MUC1 positivo relacionou-se significativamente com carcinomas moderadamente e pouco diferenciados $(p=0,03)$ e MUC2 positivo com carcinomas bem diferenciados $(p=0,045)$. Nenhum marcador correlacionou-se significativamente com o estadio tumoral e presença de metástase linfonodal.

Sete tumores foram classificados como tipos incomuns. Analisamos como esses tumores expressaram os marcadores imunoistoquímicos (tabela 13) e aplicamos os modelos de regressão logística expostos nas tabelas 10 e 11, indicando dessa forma, qual a probabilidade de cada caso ser do tipo pancreatobiliar (tabela 14). 
Tabela 13: Marcadores imunoistoquímicos para os tumores tipo incomuns .

$\begin{array}{llllll}\text { MUC } 1 & \text { MUC } 2 & \text { CDX } 2 & \text { CD10 } & \text { CK } 20 & \text { CK7 }\end{array}$

\begin{tabular}{|c|c|c|c|c|c|c|}
\hline Caso 1: mucinoso & + & + & - & - & - & + \\
\hline Caso 2: mucinoso & - & + & + & + & + & - \\
\hline Caso 3: mucinoso & + & + & + & + & + & + \\
\hline Caso 4: mucinoso & + & + & + & - & + & + \\
\hline Caso 5: mucinoso & - & + & + & + & + & - \\
\hline Caso 6: células claras & + & - & - & - & - & + \\
\hline Caso 7: adenoescamoso & + & - & - & - & - & + \\
\hline
\end{tabular}

Tabela 14: Análise da probabilidade de ser tipo pancreatobiliar dos tumores incomuns, segundo análise GLM.

\begin{tabular}{lll}
\hline & Probabilidade TPB & Probabilidade TPB \\
& (GLM Tabela 10) & (GLM Tabela 11) \\
\hline Caso 1: mucinoso & $77,16 \%$ & $89,99 \%$ \\
Caso 2: mucinoso & $4,54 \%$ & $31,58 \%$ \\
Caso 3: mucinoso & $17,30 \%$ & $31,58 \%$ \\
Caso 4: mucinoso & $17,3 \%$ & $31,58 \%$ \\
Caso 5: mucinoso & $4,54 \%$ & $31,58 \%$ \\
Caso 6: células claras & $94,88 \%$ & $89,99 \%$ \\
Caso 7: adenoescamoso & $94,88 \%$ & $89,99 \%$ \\
\hline
\end{tabular}

Realizamos então, utilizando apenas os resultados dos marcadores imunoistoquímicos CDX2, MUC2 e MUC1, uma nova classificação para o tipo histológico, aplicando o GLM da tabela 11. Foi atribuída a cada paciente uma 
probabilidade para o tipo pancreatobiliar, de acordo com esse modelo logístico. Para escolher um ponto de corte que permitisse classificar os pacientes entre $\mathrm{TI}$ e TPB foi usada a técnica de "bootstrap" para selecionar o ponto que maximizasse a sensibilidade e a especificidade na curva ROC (figura 7). Esse ponto de corte foi de 0,534, ou seja, quem tem probabilidade maior que $53,4 \%$ foi classificado como TPB Essa classificação imunoistoquímica apresenta 47 tumores do tipo intestinal e 40 do tipo pancreatobiliar, excluídos 3 casos onde não foi possível a realização dos 3 marcadores e os 7 casos de tumores incomuns. A sensibilidade dessa nova classificação para determinação do tipo histológico foi de $80 \%$, a especificidade foi de $90,5 \%$ e a acurácia é de $85,1 \%$. Na maioria dos tumores, a classificação imunoistoquímica e a classificação histológica foram concordantes (Kappa de 0,702, $p<0,001)$

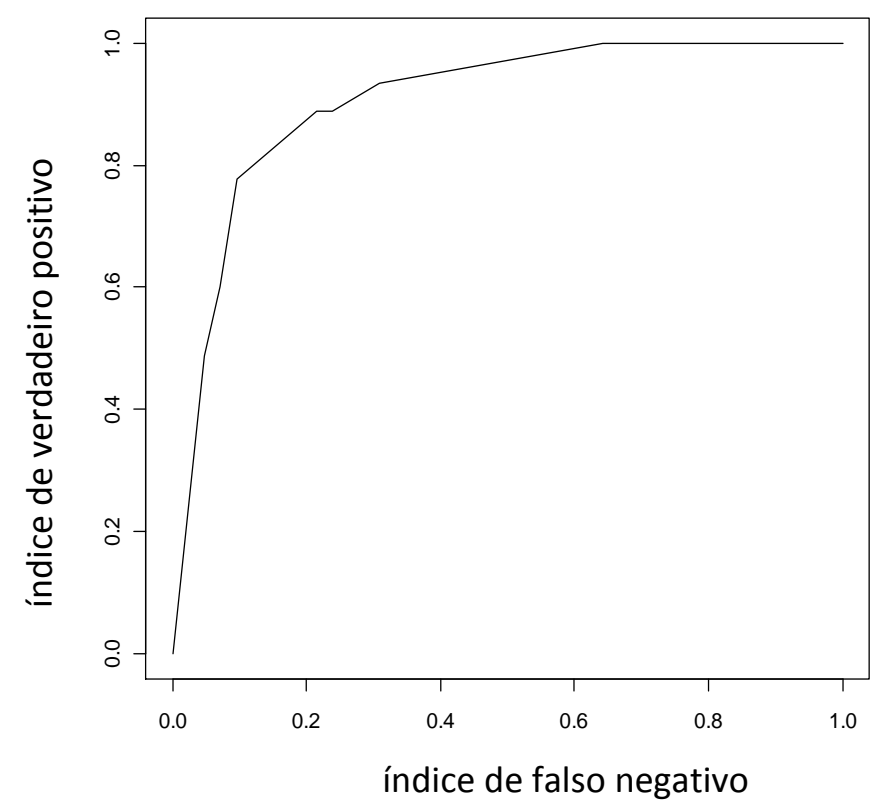

Figura 15: Curva ROC - Curva da relação de verdadeiros positivos (sensibilidade) em relação aos falsos negativos para determinação do tipo pancreatobiliar conforme variação do valor de ponto de corte 
Tabela 15: Comparação da classificação histológica com a classificação imunoistoquímica dos AAV.

Classificação Histológica

\begin{tabular}{lll}
\hline TI & TPB & Total
\end{tabular}

Classificação Imunoistoquímica

$\begin{array}{cccc}\text { Intestinal } & 38 & 9 & 47 \\ \text { Pancreatobiliar } & 4 & 36 & 40 \\ \text { Total } & 42 & 45 & 87\end{array}$


4.4. Marcadores imunoistoquímicos de alterações genéticas

Trinta e cinco pacientes $(36,1 \%)$ apresentaram expressão imunoistoquímica para proteína p53. Houve relação entre p53 positivo e tumores menos diferenciados (teste de qui-quadrado de Pearson, $p=0,05$ ) e invasão linfática presente (teste de qui-quadrado de Pearson, $p=0,006$ ). Não houve diferença significativa da expressão de p53 entre os tipos intestinal e pancreatobiliar, tanto pela classificação histológica quanto pela imunoistoquímica (tabela 16). 
Tabela 16: Relação entre imunoexpressão do p53 e características clínicas e anatomopatológicas

\begin{tabular}{|c|c|c|c|}
\hline & $\begin{array}{l}\text { P53 positivo } \\
(n=35)\end{array}$ & $\begin{array}{l}\text { P53 negativo } \\
(n=62)\end{array}$ & Valores $p$ \\
\hline Sexo & & & 0,644 \\
\hline Masculino & 13 & 26 & \\
\hline Feminino & 22 & 36 & \\
\hline \multicolumn{4}{|l|}{ Idade } \\
\hline$<60$ anos & 20 & 36 & 0,930 \\
\hline$\geq 60$ anos & 15 & 26 & \\
\hline pT & & & 0,063 \\
\hline T1 e T2 & 17 & 42 & \\
\hline T3 e T4 & 18 & 20 & \\
\hline Acometimento linfonodal & & & 0,626 \\
\hline Sim & 13 & 20 & \\
\hline Não & 22 & 42 & \\
\hline Estadiamento TNM & & & 0,216 \\
\hline IA & 5 & 20 & \\
\hline IB & 7 & 12 & \\
\hline IIA & 10 & 9 & \\
\hline IIB & 13 & 20 & \\
\hline IV & 0 & 1 & \\
\hline Diferenciação & & & 0,050 \\
\hline Bem & 8 & 14 & \\
\hline Moderado & 18 & 43 & \\
\hline Pouco & 9 & 5 & \\
\hline Invasão Vascular & & & 0,885 \\
\hline Presente & 2 & 4 & \\
\hline Ausente & 33 & 58 & \\
\hline Invasão linfática & & & 0,006 \\
\hline Presente & 16 & 12 & \\
\hline Ausente & 19 & 50 & \\
\hline Invasão perineural & & & 0,328 \\
\hline Presente & 6 & 16 & \\
\hline Ausente & 29 & 46 & \\
\hline Tipo histológico & & & 0,598 \\
\hline Intestinal & 16 & 27 & \\
\hline Pancreatobiliar & 15 & 32 & \\
\hline Classificação IH & & & 0,574 \\
\hline TI & 18 & 29 & \\
\hline TPB & 13 & 27 & \\
\hline
\end{tabular}


O p16 foi expresso em 30 AAVs (30,9\%). Não houve diferença significativa da expressão de p16 entre os tipos intestinal e pancreatobiliar, tanto pela classificação histológica quanto pela imunoistoquímica; assim como critérios clínicos e anatomopatológicos (tabela 17). 
Tabela 17: Relação entre imunoexpressão do p16 e características clínicas e anatomopatológicas

\begin{tabular}{|c|c|c|c|}
\hline & $\begin{array}{l}\text { P16 positivo } \\
(n=30)\end{array}$ & $\begin{array}{l}\text { P16 negativo } \\
(n=67)\end{array}$ & Valores $p$ \\
\hline Sexo & & & 0,634 \\
\hline Masculino & 11 & 28 & \\
\hline Feminino & 19 & 39 & \\
\hline \multicolumn{4}{|l|}{ Idade } \\
\hline$<60$ anos & 16 & 40 & 0,557 \\
\hline$\geq 60$ anos & 14 & 27 & \\
\hline pT & & & 0,735 \\
\hline T1 e T2 & 11 & 27 & \\
\hline T3 e T4 & 19 & 40 & \\
\hline Acometimento linfonodal & & & 0,626 \\
\hline Sim & 11 & 22 & \\
\hline Não & 19 & 45 & \\
\hline Estadiamento TNM & & & 0,539 \\
\hline IA & 6 & 19 & \\
\hline IB & 6 & 13 & \\
\hline IIA & 7 & 12 & \\
\hline IIB & 10 & 23 & \\
\hline IV & 1 & 0 & \\
\hline Diferenciação & & & 0,337 \\
\hline Bem & 7 & 15 & \\
\hline Moderado & 21 & 40 & \\
\hline Pouco & 2 & 12 & \\
\hline Invasão Vascular & & & 0,297 \\
\hline Presente & 3 & 3 & \\
\hline Ausente & 27 & 64 & \\
\hline Invasão linfática & & & 0,749 \\
\hline Presente & 8 & 20 & \\
\hline Ausente & 22 & 47 & \\
\hline Invasão perineural & & & 0,918 \\
\hline Presente & 7 & 15 & \\
\hline Ausente & 23 & 52 & \\
\hline Tipo histológico & & & 0,456 \\
\hline Intestinal & 14 & 33 & \\
\hline Pancreatobiliar & 16 & 27 & \\
\hline Classificação IH & & & 0,206 \\
\hline TI & 11 & 29 & \\
\hline TPB & 19 & 28 & \\
\hline
\end{tabular}

O Ki67 apresentou proliferação acentuada (acima de 10\% das células coradas) em 36 AAVs (37,1\%). Não houve diferença significativa da expressão do 
Ki67 entre os tipos intestinal e pancreatobiliar, tanto pela classificação histológica quanto pela imunoistoquímica; assim como critérios clínicos e anatomopatológicos (tabela 18). 
Tabela 18: Relação entre imunoexpressão do Ki67 e características clínicas e anatomopatológicas

\begin{tabular}{|c|c|c|c|}
\hline & $\begin{array}{l}\text { Ki67 positivo } \\
(n=36)\end{array}$ & $\begin{array}{l}\text { Ki67 negativo } \\
(n=61)\end{array}$ & Valores $p$ \\
\hline Sexo & & & 0,822 \\
\hline Masculino & 15 & 24 & \\
\hline Feminino & 21 & 37 & \\
\hline \multicolumn{4}{|l|}{ Idade } \\
\hline$<60$ anos & 22 & 34 & 0,605 \\
\hline$\geq 60$ anos & 14 & 27 & \\
\hline pT & & & 0,965 \\
\hline T1 e T2 & 14 & 24 & \\
\hline T2 e T3 & 22 & 37 & \\
\hline Acometimento linfonodal & & & 0,580 \\
\hline Sim & 11 & 22 & \\
\hline Não & 25 & 39 & \\
\hline Estadiamento TNM & & & 0,679 \\
\hline IA & 10 & 15 & \\
\hline IB & 7 & 12 & \\
\hline$\| A$ & 8 & 11 & \\
\hline IIB & 10 & 23 & \\
\hline IV & 1 & 0 & \\
\hline Diferenciação & & & 0,130 \\
\hline Bem & 11 & 11 & \\
\hline Moderado & 18 & 43 & \\
\hline Pouco & 7 & 7 & \\
\hline Invasão Vascular & & & 0,122 \\
\hline Presente & 4 & 2 & \\
\hline Ausente & 32 & 59 & \\
\hline Invasão linfática & & & 0,856 \\
\hline Presente & 10 & 18 & \\
\hline Ausente & 26 & 43 & \\
\hline Invasão perineural & & & 0,919 \\
\hline Presente & 8 & 14 & \\
\hline Ausente & 28 & 47 & \\
\hline Tipo histológico & & & 0,755 \\
\hline Intestinal & 19 & 28 & \\
\hline Pancreatobiliar & 16 & 27 & \\
\hline Classificação IH & & & 0,871 \\
\hline TI & 16 & 24 & \\
\hline TPB & 18 & 29 & \\
\hline
\end{tabular}




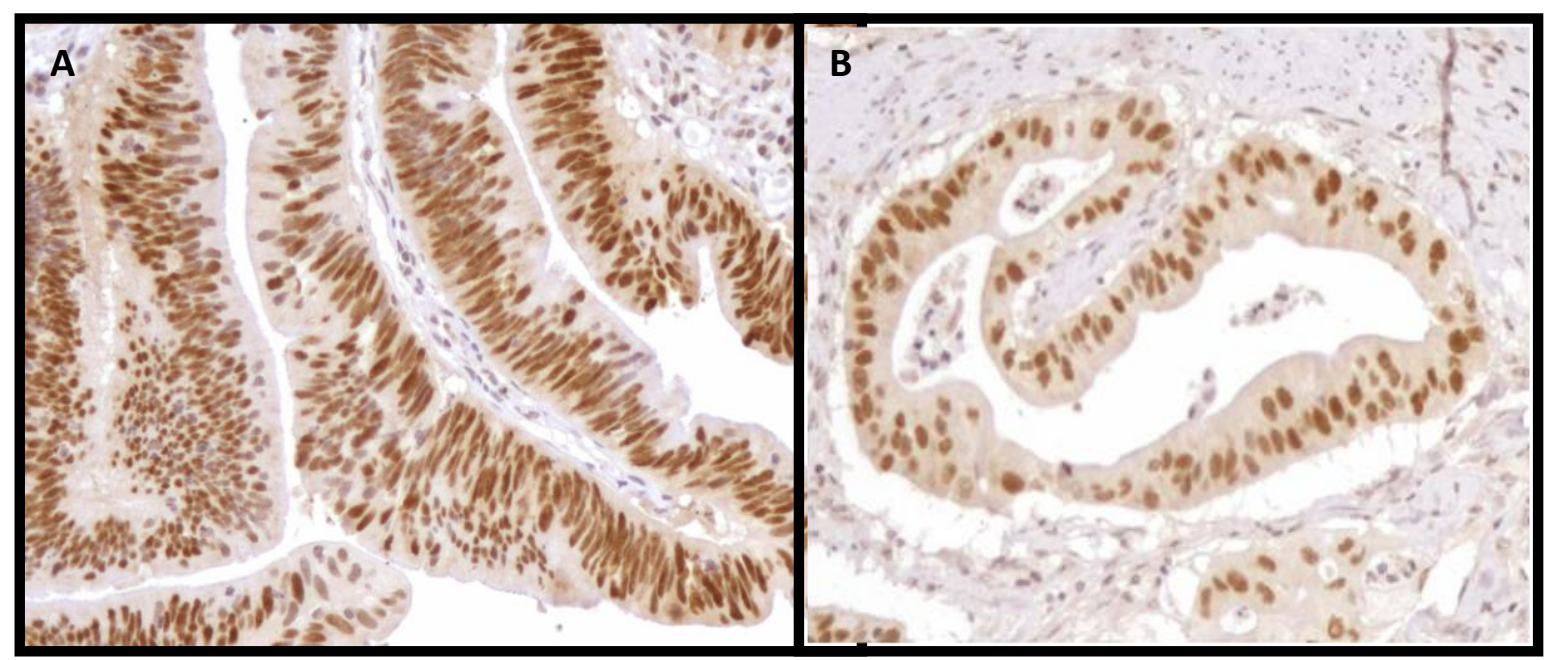

Figura 16: p53 - marcação imunoistoquímica de padrão nuclear em AAV, A tipo intestinal, B tipo pancreatobiliar (400x)

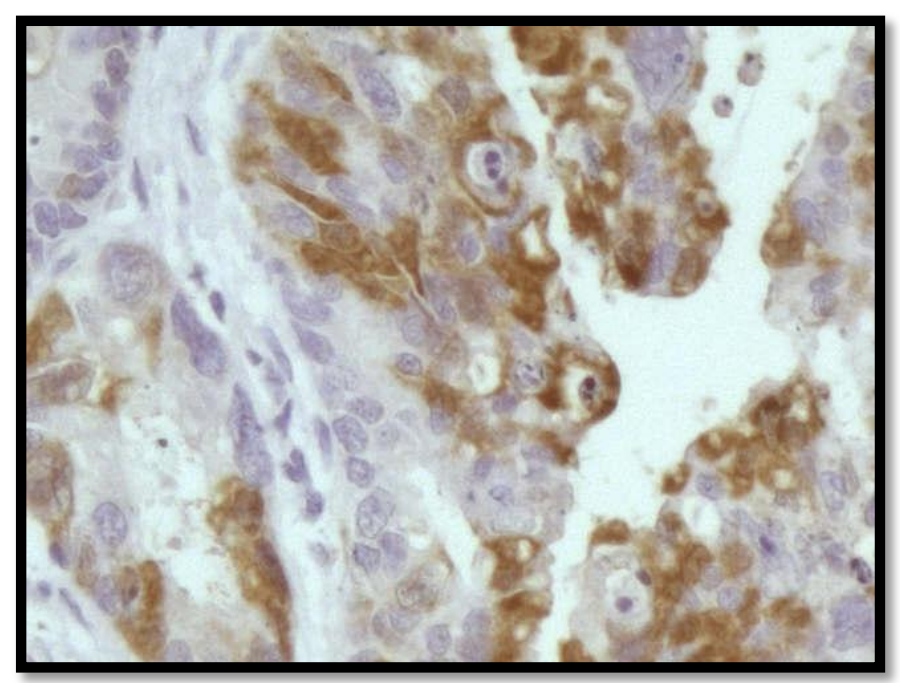

Figura 17: p16 - marcação imunoistoquímica de padrão citoplasmático em AAV tipo pancreatobiliar $(400 x)$

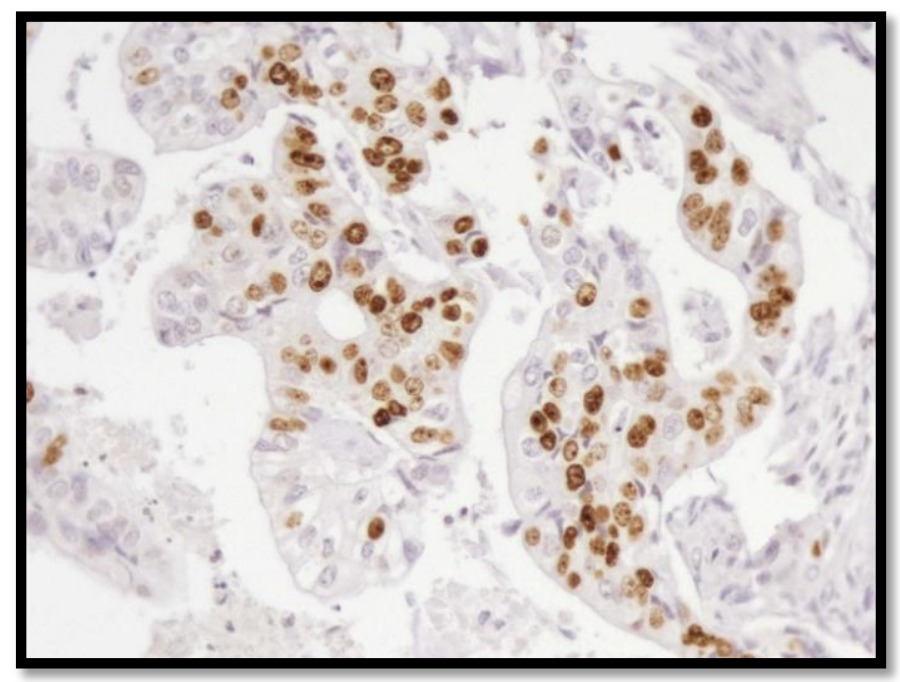

Figura 18: Ki67 - marcação imunoistoquímica de padrão nuclear em AAV tipo pancreatobiliar (400x) 


\subsection{Instabilidade de Microsatélites}

Observou-se perda de expressão para os três marcadores de instabilidade de microssatélites, hMLH1, hMSH2 e hMSH6 em apenas 1 caso de AAV. Trata-se de um tumor do tipo intestinal histológico e imunoistoquímico, com sobrevivência acima de 200 meses. Houve um caso com dupla perda de expressão, hMSH6 e hMSH2, também do tipo histológico intestinal e longa sobrevivência.Treze casos $(13,4 \%)$ apresentaram perda de expressão em pelo menos uma proteína MMR. Observou-se perda de expressão do hMLH1 em 3/96 (3,1\%), do hMSH2 em 4/95 (4,2\%) e do hMSH6 em 9/96 (9,4\%) dos casos de AAV (tabela 19).

Tabela 19: Frequência das diversas possibilidades de perfis de expressão de proteínas MMR

\begin{tabular}{llcc}
\hline & & $\mathrm{n}$ & $\begin{array}{l}\text { \% em relação à pelo menos } 1 \\
\text { negativo }(\mathrm{n}=13)\end{array}$ \\
\hline Um MMR negativo & MLH1- MSH2+ MSH6+ & 2 & $15,4 \%$ \\
& MLH1+ MSH2- MSH6+ & 2 & $15,4 \%$ \\
& MLH1+ MSH2+ MSH6- & 7 & $53,8 \%$ \\
Dois MMR negativos & MLH1+ MSH2- MSH6- & 1 & $7,7 \%$ \\
Três MMR negativos & MLH1- MSH2- MSH6- & 1 & $7,7 \%$ \\
& Total & 13 & $100 \%$ \\
\hline
\end{tabular}

Não houve correlação entre as variáveis analisadas e a alteração de hMLH1, hMSH2 e hMSH6 (tabela 20, 21 e 22). 


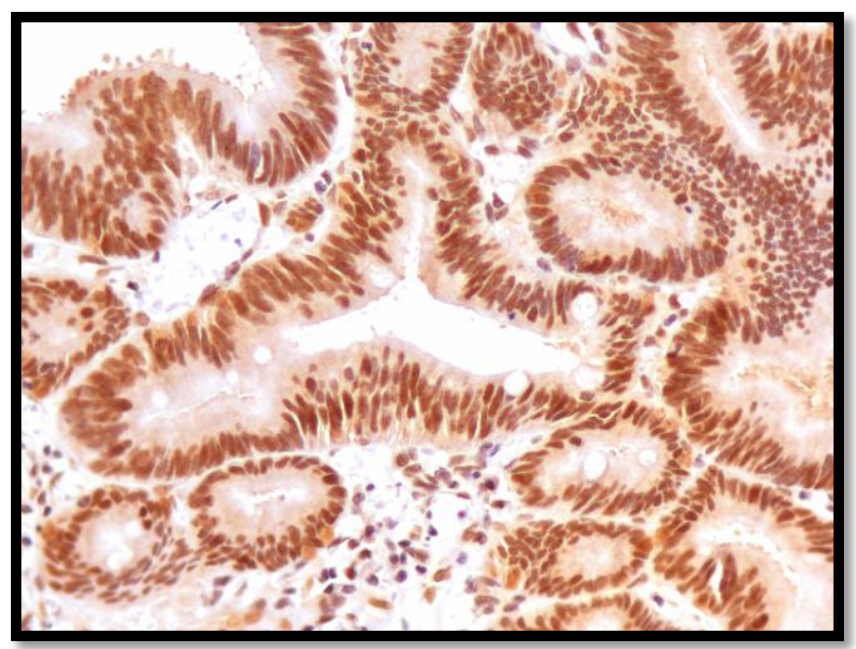

Figura 19: hMLH1 - marcação imunoistoquímica de padrão nuclear em AAV tipo intestinal (400x)

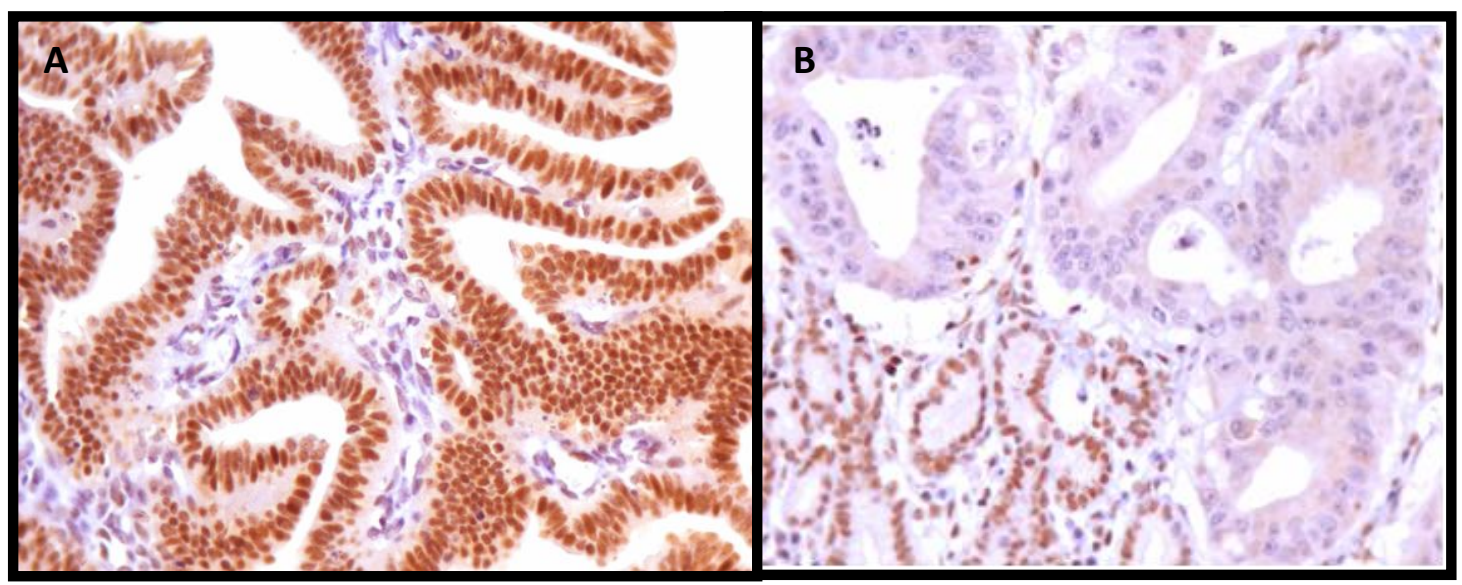

Figura 20: hMSH2 -marcação imunoístoquímica de padrão nuclear em AAV; A, positiva; B, negativa frente a controle de tecido não neoplásico positivo (400x)

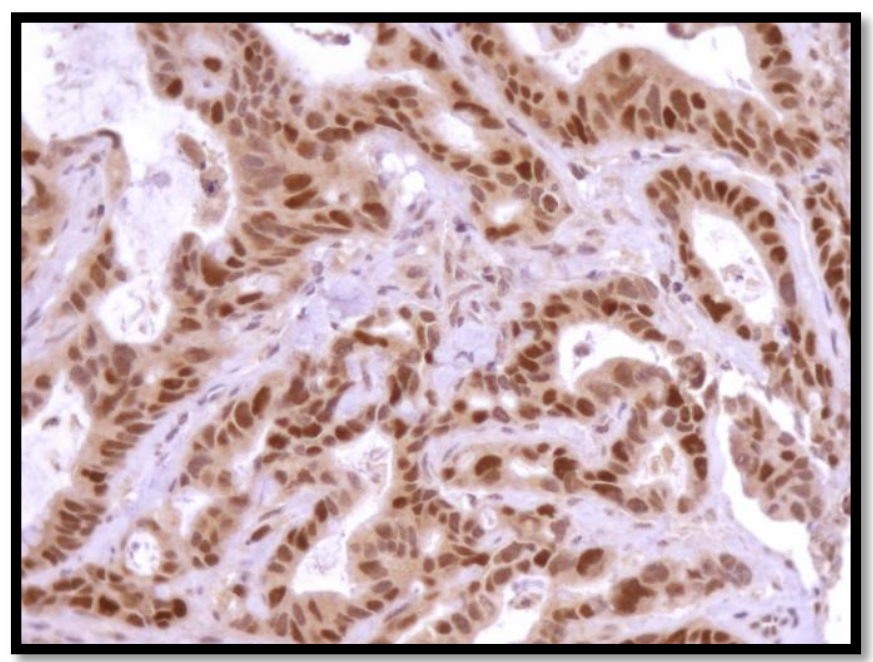

Figura 21: hMSH6 - marcação imunoistoquímica de padrão nuclear em AAV tipo pancreatobiliar (400x) 
Tabela 20: Relação entre expressão de hMLH1 e características clínicas e anatomopatológicas

\begin{tabular}{|c|c|c|c|}
\hline & $\begin{array}{l}\text { hMLH1 alterado } \\
(n=3)\end{array}$ & $\begin{array}{l}\text { hMLH1 não alterado } \\
(n=93)\end{array}$ & Valores $p$ \\
\hline Sexo & & & $0,822^{*}$ \\
\hline Masculino & 2 & 56 & \\
\hline Feminino & 1 & 37 & \\
\hline \multicolumn{4}{|l|}{ Idade } \\
\hline$<60$ anos & 3 & 3è & $0,069 *$ \\
\hline$\geq 60$ anos & 0 & 56 & \\
\hline pT & & & $0,275^{*}$ \\
\hline T1 e T2 & 3 & 55 & \\
\hline T2 e T3 & 0 & 38 & \\
\hline Acometimento linfonodal & & & $1,000 *$ \\
\hline Sim & 2 & 61 & \\
\hline Não & 1 & 32 & \\
\hline Estadiamento TNM & & & $0,902 *$ \\
\hline $\mathrm{IA}$ & 1 & 23 & \\
\hline IB & 1 & 18 & \\
\hline$\| A$ & 0 & 20 & \\
\hline IIB & 1 & 31 & \\
\hline IV & 0 & 1 & \\
\hline Diferenciação & & & $0,481^{*}$ \\
\hline Bem & 0 & 22 & \\
\hline Moderado & 2 & 58 & \\
\hline Pouco & 1 & 13 & \\
\hline Invasão Vascular & & & $1,000 *$ \\
\hline Presente & 3 & 87 & \\
\hline Ausente & 0 & 6 & \\
\hline Invasão linfática & & & $0,544^{*}$ \\
\hline Presente & 3 & 65 & \\
\hline Ausente & 0 & 28 & \\
\hline Invasão perineural & & & $1,000 *$ \\
\hline Presente & 3 & 71 & \\
\hline Ausente & 0 & 22 & \\
\hline Tipo histológico & & & $1,000 *$ \\
\hline Intestinal & 1 & 42 & \\
\hline Pancreatobiliar & 2 & 44 & \\
\hline Classificação IH & & & $0,497^{*}$ \\
\hline TI & 0 & 40 & \\
\hline TPB & 2 & 45 & \\
\hline
\end{tabular}

*teste exato de Fisher 
Tabela 21: Relação entre expressão de hMSH2 e características clínicas e anatomopatológicas

\begin{tabular}{|c|c|c|c|}
\hline & $\begin{array}{l}\text { hMSH2 alterado } \\
(n=4)\end{array}$ & $\begin{array}{l}\text { hMSH2 não alterado } \\
(\mathrm{n}=91)\end{array}$ & Valores $p$ \\
\hline Sexo & & & $1,000^{*}$ \\
\hline Masculino & 2 & 55 & \\
\hline Feminino & 2 & 36 & \\
\hline \multicolumn{4}{|l|}{ Idade } \\
\hline$<60$ anos & 2 & 37 & $0,545^{*}$ \\
\hline$\geq 60$ anos & 2 & 54 & \\
\hline pT & & & $1,000 *$ \\
\hline T1 e T2 & 3 & 55 & \\
\hline T2 e T3 & 1 & 36 & \\
\hline Acometimento linfonodal & & & $1,000 *$ \\
\hline Sim & 3 & 60 & \\
\hline Não & 1 & 31 & \\
\hline Estadiamento TNM & & & $0,474 *$ \\
\hline $\mathrm{IA}$ & 1 & 23 & \\
\hline IB & 1 & 18 & \\
\hline$\| A$ & 1 & 18 & \\
\hline IIB & 1 & 31 & \\
\hline V & 0 & 1 & \\
\hline Diferenciação & & & $0,693 *$ \\
\hline Bem & 0 & 22 & \\
\hline Moderado & 4 & 55 & \\
\hline Pouco & 0 & 14 & \\
\hline Invasão Vascular & & & $1,000 *$ \\
\hline Presente & 4 & 85 & \\
\hline Ausente & 0 & 6 & \\
\hline Invasão linfática & & & $1,000 *$ \\
\hline Presente & 3 & 65 & \\
\hline Ausente & 1 & 26 & \\
\hline Invasão perineural & & & $1,000 *$ \\
\hline Presente & 3 & 70 & \\
\hline Ausente & 1 & 21 & \\
\hline Tipo histológico & & & $1,000 *$ \\
\hline Intestinal & 2 & 41 & \\
\hline Pancreatobiliar & 2 & 43 & \\
\hline Classificação IH & & & $1,000 *$ \\
\hline TI & 2 & 45 & \\
\hline TPB & 2 & 37 & \\
\hline
\end{tabular}

*teste exato de Fisher 
Tabela 22: Relação entre expressão de hMSH6 e características clínicas e anatomopatológicas

\begin{tabular}{|c|c|c|c|}
\hline & $\begin{array}{l}\text { hMSH6 alterado } \\
(n=9)\end{array}$ & $\begin{array}{l}\text { hMSH6 não alterado } \\
(\mathrm{n}=87)\end{array}$ & Valores $p$ \\
\hline Sexo & & & $0,737^{*}$ \\
\hline Masculino & 5 & 53 & \\
\hline Feminino & 4 & 34 & \\
\hline \multicolumn{4}{|l|}{ Idade } \\
\hline$<60$ anos & 4 & 36 & $0,563 *$ \\
\hline$\geq 60$ anos & 5 & 51 & \\
\hline pT & & & $0,312 *$ \\
\hline T1 e T2 & 7 & 51 & \\
\hline T2 e T3 & 2 & 36 & \\
\hline Acometimento linfonodal & & & $0,158^{*}$ \\
\hline Sim & 8 & 55 & \\
\hline Não & 1 & 32 & \\
\hline Estadiamento TNM & & & $0,576^{*}$ \\
\hline IA & 3 & 21 & \\
\hline IB & 3 & 16 & \\
\hline$\| A$ & 2 & 17 & \\
\hline IIB & 1 & 32 & \\
\hline V & 0 & 1 & \\
\hline Diferenciação & & & $0,788^{*}$ \\
\hline Bem & 2 & 20 & \\
\hline Moderado & 5 & 55 & \\
\hline Pouco & 2 & 12 & \\
\hline Invasão Vascular & & & $1,000 *$ \\
\hline Presente & 9 & 81 & \\
\hline Ausente & 0 & 6 & \\
\hline Invasão linfática & & & $1,000^{*}$ \\
\hline Presente & 7 & 61 & \\
\hline Ausente & 2 & 26 & \\
\hline Invasão perineural & & & $0,113^{*}$ \\
\hline Presente & 9 & 65 & \\
\hline Ausente & 0 & 21 & \\
\hline Tipo histológico & & & $0,305^{*}$ \\
\hline Intestinal & 6 & 37 & \\
\hline Pancreatobiliar & 3 & 43 & \\
\hline Classificação IH & & & $0,727^{* *}$ \\
\hline TI & 4 & 43 & \\
\hline TPB & 5 & 35 & \\
\hline
\end{tabular}

*teste exato de Fisher 


\subsection{Expressão do CEA e CA 19-9}

Setenta e sete doentes apresentaram imunoexpressão positiva para CEA $(79,4 \%)$ e $86(88,6 \%)$ foram positivos para a expressão de CA19-9. O CEA correlacionou-se significativamente com o p16, CA19-9 e CDX2 (Tabela 23). Entretanto, não houve diferença na expressão do CEA entre o TI e TPB. Também não houve relação da expressão do CEA com expressão de marcadores de instabilidade de microssatélites, assim como demais características clinicas e anatomopatológicas.

Tabela 23: Relação entre a imunoexpressão do CEA e demais marcadores imunoistoquímicos

\begin{tabular}{llll}
\hline & $\begin{array}{l}\text { CEA positivo } \\
(\mathrm{n}=77)\end{array}$ & $\begin{array}{l}\text { CEA negativo } \\
(\mathrm{n}=20)\end{array}$ & Valores $\mathrm{p}$ \\
\hline P16 & & & $0,003 \S$ \\
Positivo & 29 & 1 & \\
negativo & 48 & 19 & $0,031^{*}$ \\
CA19.9 & & & \\
Positivo & 71 & 15 & $0,023^{*}$ \\
negativo & 6 & 5 & \\
CDX2 & & & \\
Positivo & 45 & 14 & \\
negativo & 32 & & \\
\hline § teste exato de Fischer & &
\end{tabular}

Quando comparamos o marcador CA19-9 com variáveis clínicas, anatomopatológicas e demais marcadores, encontramos apenas relação com o sexo masculino (teste de qui-quadrado de Pearson, $p=0,019$ ). 


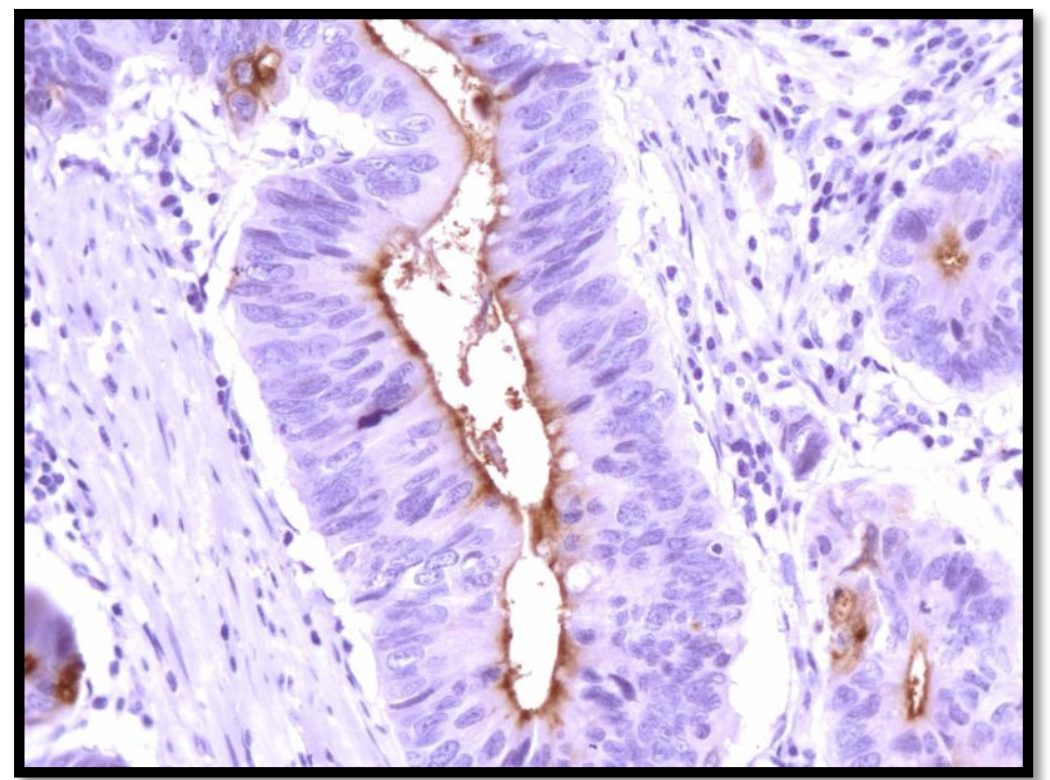

Figura 22: CEA - marcação imunoistoquímica de padrão citoplasmático em AAV tipo intestinal $(400 x)$

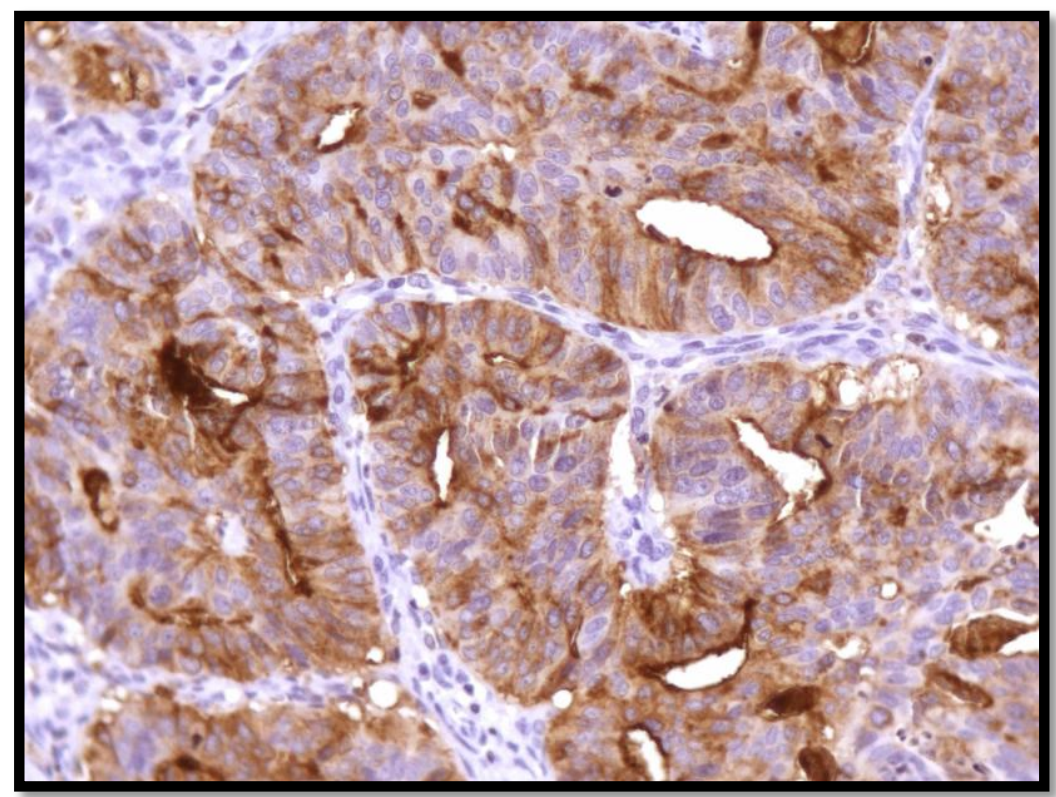

Figura 23: CA19-9 - marcação imunoistoquímica de padrão citoplasmático em AAV tipo pancreatobiliar (400x) 
4.7. Análise da expressão dos marcadores relacionados à carcinogênese com o tipo histológico

Realizamos a comparação da expressão dos diversos marcadores entre os tipos histológicos e pela classificação imunoistoquímica (Tabela 24). Não encontramos nenhuma diferença significativa para a expressão desses marcadores entre os tipos tumorais.

Tabela 24: Expressão dos marcadores relacionados à carcinogênese e o tipo histológico e classificação imunoistoquímica dos AAVs

\begin{tabular}{|c|c|c|c|c|c|c|}
\hline \multirow[t]{2}{*}{ Marcador } & \multicolumn{2}{|c|}{ Tipo histológico } & \multicolumn{4}{|c|}{ Classificação Imunoistoquímica } \\
\hline & $\mathrm{TI}$ & TPB & & $\mathrm{TI}$ & TPB & \\
\hline p53 & $16(37,2 \%)$ & $15(31,9 \%)$ & $0,598^{*}$ & $18(38,3 \%)$ & $13(32,5 \%)$ & $0,574^{*}$ \\
\hline p16 & $16(37,2 \%)$ & $14(29,8 \%)$ & $0,456^{*}$ & $19(40,4 \%)$ & $11(27,5 \%)$ & $0,206 *$ \\
\hline Ki67 & $16(37,2 \%)$ & $19(40,4 \%)$ & $0,755^{*}$ & $18(38,3 \%)$ & $16(40 \%)$ & $0,871^{*}$ \\
\hline CEA & $36(83,7 \%)$ & $36(76,6 \%)$ & $0,399 *$ & $40(85,1 \%)$ & $31(77,5 \%)$ & $0,361 *$ \\
\hline CA 19-9 & $36(83,7 \%)$ & $44(93,6 \%)$ & $0,136^{*}$ & $40(85,1 \%)$ & $38(95 \%)$ & $0,131^{*}$ \\
\hline hMLH1 & $1(2,3 \%)$ & $2(2,3 \%)$ & $0,526 \S$ & $2(4,3 \%)$ & $0(0 \%)$ & $0,289 \S$ \\
\hline hMSH2 & $2(4,7 \%)$ & $2(4,4 \%)$ & $0,674 \S$ & $2(4,3 \%)$ & $2(5,1 \%)$ & $0,618 \S$ \\
\hline hMLH6 & $6(14 \%)$ & $3(6,5 \%)$ & $0,209 \S$ & $4(8,5 \%)$ & $5(12,5 \%)$ & $0,397 \S$ \\
\hline $\begin{array}{l}\text { MMR } \\
\text { alterado }\end{array}$ & $6(14 \%)$ & $7(15,2 \%)$ & $0,866^{*}$ & $5(10,6 \%)$ & $7(17,5 \%)$ & $0,355^{*}$ \\
\hline
\end{tabular}

\footnotetext{
* teste Qui-quadrado de Pearson § teste exato de Fisher
} 
4.8. Fatores associados à recidiva precoce ou longa sobrevivência livre de doença

Comparamos os doentes que apresentaram óbito precoce, em menos de 20 meses, relacionado à doença neoplásica $(n=18)$ com aqueles com sobrevivência maior que 120 meses $(n=26)$. Verificamos a relação entre Ki67 negativo (teste exato de Fisher, $p<0,001$ ) e alteração de pelo menos uma proteína de reparo (teste exato de Fisher, $\mathrm{p=0,015}$ ) com sobrevivência maior que 120 meses (tabela 25). 
Tabela 25: Comparação entre doentes com óbito após menos de $\mathbf{2 0}$ meses do tratamento cirúrgico e aqueles com sobrevivência maior que $\mathbf{1 2 0}$ meses, em relação aos critérios clínicos, anatomopatológicos e marcadores imunoistoquímicos

\begin{tabular}{|c|c|c|c|}
\hline & $\begin{array}{l}\text { Obito }<20 \text { meses } \\
(n=18)\end{array}$ & $\begin{array}{l}\text { Obito >120meses } \\
(n=26)\end{array}$ & Valores $p$ \\
\hline Idade & & & $0,540^{*}$ \\
\hline$<60$ anos & 8 & 10 & \\
\hline$\geq 60$ anos & 14 & 12 & \\
\hline $\mathrm{Pt}$ & & & $0,118^{*}$ \\
\hline T1 e T2 & 9 & 19 & \\
\hline T2 e T3 & 9 & 7 & \\
\hline Acometimento linfonodal & & & $0,100 *$ \\
\hline Sim & 10 & 8 & \\
\hline Não & 8 & 18 & \\
\hline Estadiamento TNM & & & $0,372 *$ \\
\hline $\mathrm{IA}$ & 4 & 10 & \\
\hline $\mathrm{IB}$ & 3 & 4 & \\
\hline IIA & 1 & 4 & \\
\hline IIB & 9 & 8 & \\
\hline V & 1 & 0 & \\
\hline Tipo histológico & & & $0,604^{*}$ \\
\hline Intestinal & 8 & 8 & \\
\hline Pancreatobiliar & 10 & 14 & \\
\hline Classificação IH & & & $0,338^{*}$ \\
\hline $\mathrm{TI}$ & 10 & 8 & \\
\hline TPB & 8 & 12 & \\
\hline p53 & & & $0,119 \S$ \\
\hline positivo & 3 & 10 & \\
\hline negativo & 15 & 16 & \\
\hline p16 & & & $0,258^{*}$ \\
\hline positivo & 7 & 6 & \\
\hline negativo & 11 & 20 & \\
\hline Ki67 & & & $<0,001 \S$ \\
\hline positivo & 11 & 2 & \\
\hline negativo & 7 & 24 & \\
\hline hMLH1 & & & $0,186 \S$ \\
\hline positivo & 18 & 22 & \\
\hline negativo & 0 & 3 & \\
\hline hMSH2 & & & $0,595 \S$ \\
\hline positivo & 17 & 24 & \\
\hline negativo & 0 & 1 & \\
\hline hMSH6 & & & $0,055 \S$ \\
\hline positivo & 18 & 20 & \\
\hline negativo & 0 & 5 & \\
\hline MMR alterado & & & $0,015 \S$ \\
\hline Sim & 7 & 18 & \\
\hline Não & 0 & 18 & \\
\hline
\end{tabular}

* teste Qui-quadrado de Pearson $\S$ teste exato de Fisher 


\subsection{Análise de Sobrevivência}

O seguimento médio dos doentes foi de 80 meses, variando de 9 a 321 meses. A sobrevivência global foi de $90,3 \%$ em um ano, 71,5\% em 3 anos, $64,2 \%$ em 5 anos e 53,3\% em 10 anos. A sobrevivência média foi de 150,4 meses, com mediana de 128,2 . Quatorze pacientes perderam seguimento, porém apenas sete antes de completarem 5 anos de sobrevivência. Trinta e cinco pacientes estão vivos até o momento. Quinze pacientes permanecem vivos há mais de 10 anos da operação. Para análise de sobrevivência foram excluídos os três casos de óbito intra-hospitalar.

Fatores clínicos e anatomopatológicos foram analisados a fim de determinar os que afetaram a sobrevivência. Na análise univariável, estiveram relacionados com pior sobrevivência a presença de linfonodos acometidos pela neoplasia, estadiamento TNM, invasão linfática e a classificação histológica (Tabela 26, figuras 8-11). 
Tabela 26: Fatores relacionados à sobrevivência, em análise univariada.

\begin{tabular}{|c|c|c|c|}
\hline Variável & $\mathbf{N}$ & $\begin{array}{c}\text { Sobrevivência média } \\
\text { (meses) }\end{array}$ & $\mathbf{p}^{*}$ \\
\hline Linfonodos & & & $<0,001$ \\
\hline Positivos & 32 & $36,7 \pm 3,8$ & \\
\hline Negativos & 62 & $53,8 \pm 1,9$ & \\
\hline Estadio & & & $<0.001$ \\
\hline 1 & 43 & $53,8 \pm 2,5$ & \\
\hline ॥ & 50 & $43,8 \pm 2,8$ & \\
\hline III & 0 & & \\
\hline IV & 1 & $5,49 \pm 0$ & \\
\hline Tipo histologico & & & 0,021 \\
\hline Intestinal & 41 & $51,78 \pm 2,61$ & \\
\hline pancreatobiliar & 46 & $44,04 \pm 2,10$ & \\
\hline Classificação IH & & & 0,084 \\
\hline $\mathrm{TI}$ & 45 & $50,13 \pm 2,85$ & \\
\hline TPB & 39 & $43,68 \pm 3,31$ & \\
\hline Invasão linfática & & & 0,004 \\
\hline Presente & 26 & $38,72 \pm 3,99$ & \\
\hline Ausente & 68 & $51,27 \pm 2,14$ & \\
\hline $\mathrm{CDX} 2$ & & & 0,129 \\
\hline Positive & 49 & $50,21 \pm 2,69$ & \\
\hline Negativo & 45 & $45,22 \pm 3,01$ & \\
\hline P53 & & & 0,940 \\
\hline Positive & 34 & $47,34 \pm 3,08$ & \\
\hline Negativo & 60 & $48,08 \pm 2,64$ & \\
\hline P16 & & & 0,500 \\
\hline Postivo & 30 & $46,32 \pm 3,87$ & \\
\hline negativo & 64 & $48,35 \pm 2,37$ & \\
\hline KI67 & & & 0,404 \\
\hline Positive & 36 & $45,17 \pm 3,71$ & \\
\hline Negativo & 58 & $49,47 \pm 2,28$ & \\
\hline CEA & & & 0,320 \\
\hline Positive & 74 & $46,86 \pm 2,31$ & \\
\hline Negativo & 20 & $51,14 \pm 31$ & \\
\hline CA19-9 & & & 0,760 \\
\hline Positive & 83 & $47,71 \pm 2,12$ & \\
\hline Negativo & 11 & $47,49 \pm 6,81$ & \\
\hline hHMLH1 & & & 0,813 \\
\hline positive & 90 & $47,14 \pm 2,07$ & \\
\hline negativo & 3 & $60,00 \pm 0$ & \\
\hline hHMSH2 & & & 0,867 \\
\hline positive & 89 & $47,82 \pm 2,07$ & \\
\hline negativo & 3 & $57,07 \pm 5,60$ & \\
\hline hHMSH6 & & & 0,235 \\
\hline positive & 85 & $49,37 \pm 2,17$ & \\
\hline negativo & 8 & $59,92 \pm 0,11$ & \\
\hline MMR alterado & & & 0,631 \\
\hline $\operatorname{sim}$ & 12 & $58,50 \pm 1,53$ & \\
\hline não & 81 & $45,88 \pm 2,22$ & \\
\hline
\end{tabular}

*teste de Log-rank 


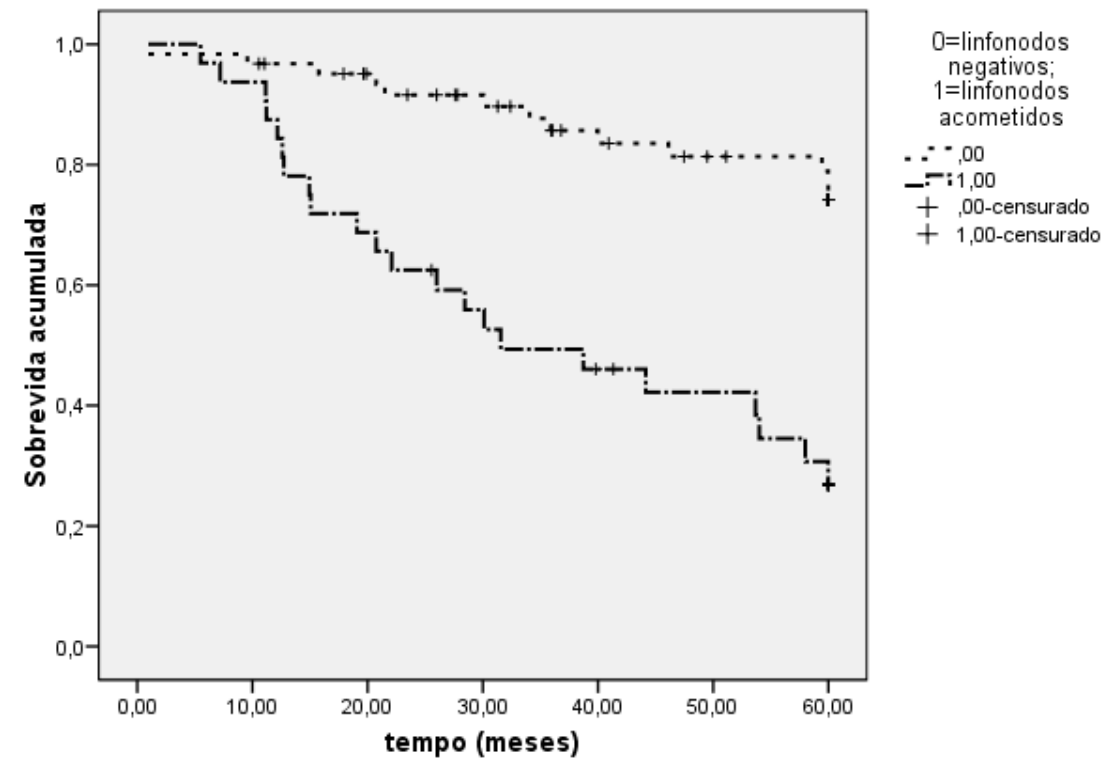

Figura 24: Curva de sobrevivência em cinco anos em relação ao acometimento linfonodal, $p<0,001$

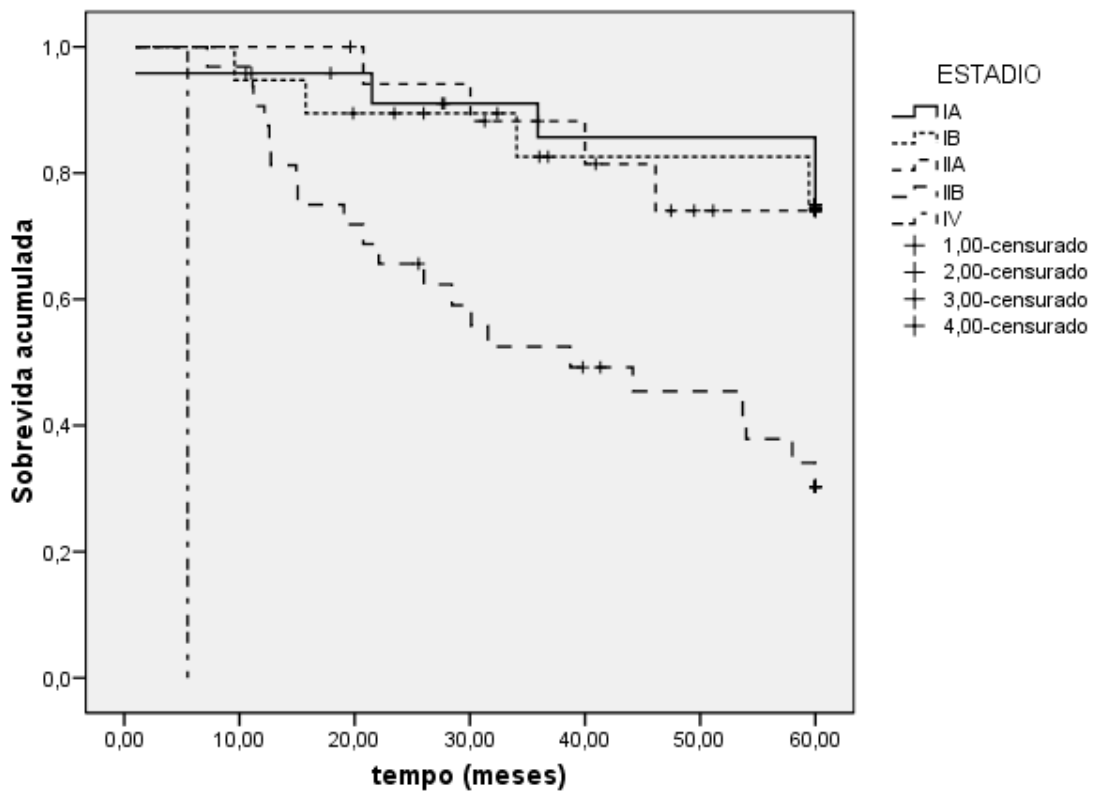

Figura 25: Curva de sobrevivência em cinco anos em relação ao estadiamento TNM, $p<0,001$ 


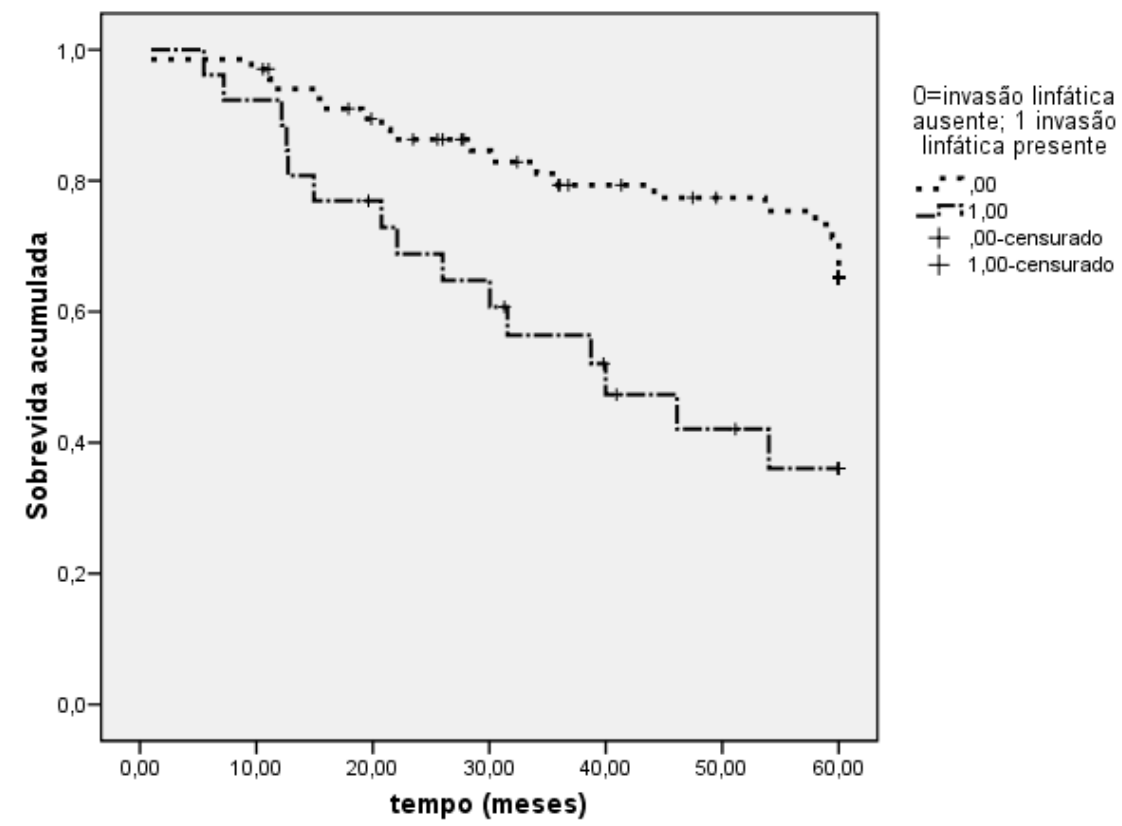

Figura 26: Curva de sobrevivência em relação à invasão linfática, $p=0,004$

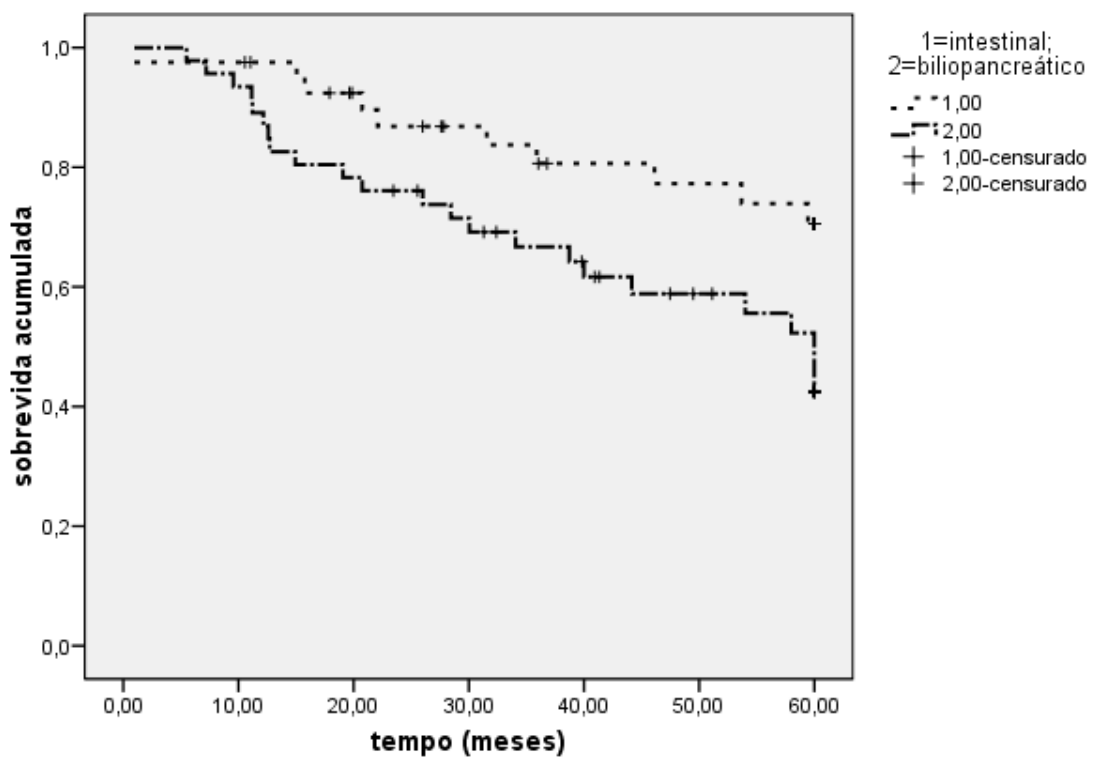

Figura 27: Curva de sobrevivência em relação ao tipo histológico, p=0,021 
Realizamos então a análise pelo modelo de risco proporcional com cura (proportional hazard with cure). Exerceram influência independente no prognóstico o acometimento linfonodal e a invasão linfática (Tabela 27).

Tabela 27: Modelo de risco proporcional com cura

\begin{tabular}{lccc}
\hline \multicolumn{1}{c}{ Fator } & Risco relativo & IC 95\% & P \\
\hline Acometimento linfonodal & 4,12 & 2,$17 ; 7,82$ & $<0,001$ \\
Invasão linfática & 2,31 & 1,$19 ; 4,49$ & 0,013 \\
Tipo histológico pancreatobiliar & 1,08 & 0,$13 ; 9,59$ & 0,801 \\
\hline
\end{tabular}

Foi observado que realmente há uma fração de cura $(p=0.070)$. Pacientes com linfonodos acometidos apresentam uma chance de óbito igual a 4,12 [IC 95\%; $2,17 ; 7,82]$ vezes a dos pacientes sem linfonodos. Já os casos com invasão linfática apresentam uma chance de óbito igual a 2,31 [IC 95\%: 1,19; 4,49] vezes a dos pacientes sem invasão linfática. O tipo histológico pancreatobiliar não se relacionou com pior sobrevivência em análise multivariada. 
5. Discussão 


\section{DISCUSSÃO}

A discussão é apresentada em duas partes; a primeira refere-se à casuística e ao método empregado e suas limitações e na segunda parte consideram-se os resultados relativos aos marcadores imunoistoquímicos para determinação da origem tecidual e marcadores de alterações genéticas e instabilidade de microssatélites

\subsection{Casuística e método empregado}

O carcinoma da ampola de Vater pode originar-se da mucosa duodenal que recobre a ampola, do epitélio do canal pancreatobiliar comum, do epitélio do ducto biliar distal, ou do epitélio do ducto pancreático distal. Assim, apresenta espectro de diferentes neoplasias, relacionadas à diferentes origens teciduais, evolução diversa, merecendo provávelmente tratamentos diferenciados.

Na prática, há uma dificuldade em se determinar o tecido histológico de origem devido a heterogeneidade histológica dos tumores, a falta de uma nomenclatura universal, e a presença de lesões pré-neoplásicas acompanhando carcinomas invasivos em mais de um sítio (20). 
O AAV, embora pouco frequente, apresenta maiores índices de ressecabilidade que os adenocarcinomas do pâncreas, o que nos permite analisar uma séria relativamente ampla de doentes com tumores ressecados com intenção curativa. Dessa forma, é possível analisar os resultados em função da sobrevivência.

Este estudo pretendeu incluir todos os AAVs operados num longo período de tempo, a fim de possibilitar a análise de sobrevivência. Uma de suas limitações é que, devido à raridade desse tumor, os casos foram estudados na grande maioria de forma retrospectiva, através da análise de prontuários. Apenas a partir de 2003 pudemos fazer um seguimento prospectivo através de banco de dados informatizado do Serviço de Vias Biliares e Pâncreas.

No entanto, um dado de grande relevância no estudo refere-se à anatomiapatológica. Este dado foi rigorosamente revisado para o estudo por dois patologistas experientes, com leitura das lâminas antigas e confecção de novas lâminas, a partir dos blocos de parafina.

O seguimento dos doentes é fator crítico já que não é realizado de forma planificada em nossa instituição. Trinta e dois doentes dos 35 vivos até o momento são acompanhadados ambulatorialmente. Alguns óbitos ocorreram na instituição, constando informações em prontuário, outros foram confirmados através do atestado de óbito arquivado do SVOC (Serviço de Verificação de Óbitos da Capital). Embora tenha se procurado máxima exatidão nos dados relativos ao óbito, é possível que ocorram falhas já que algumas informações foram prestadas por familiares. Devido a esses fatores, realizamos apenas análise de sobrevivência 
global, e não sobrevivência livre de doença. Houve perda de seguimento em 14 casos, sendo sete antes de cinco anos.

Finalmente, não foi possível controlar o tratamento recebido após a ressecção; alguns pacientes receberam quimioterapia, o que pode influenciar a sobrevivência. No entanto, atualmente não há dados na literatura que suportem o benefício do tratamento adjuvante nesta patologia.(123, 124)

\section{Técnica de imunoistoquímica e uso do tissue microarray}

A técnica de imunoistoquímica foi escolhida por ser bem estabelecida e empregada de rotina na prática clínica (125), o que torna fácil a aplicação dos resultados obtidos.

A técnica de "tissue microarray" foi baseada nos trabalhos de Kononen et al (126) e propicia a racionalização de custos e de tempo despendidos no estudo de cortes histológicos, seja corados por H\&E ou submetidos à métodos imunoistoquímicos, com comprovada acurácia e validação dos resultados das análises em diversos estudos prévios (127-132).

A aplicabilidade do TMA para antígenos relacionados à instabilidade de microssatélites pode ser considerada mais delicada, já que a anormalidade é a não expressão dos marcadores. Para evitar falsos negativos devido a falhas técnicas, todos os casos negativos no TMA (21 casos) foram revisados na lâmina completa. 
Essa revisão encontrou cinco falsos negativos no TMA, um para MLH1 e quatro para $\mathrm{MSH} 2$.

\subsection{Discussão relativa aos resultados}

5.2.1 Marcadores imunoistoquímicos para diferenciação do epitélio de origem

A primeira classificação dos AAV em tipo intestinal e pancreatobiliar foi feita por Kimura et al em 1994 (19). Examinando 53 casos, eles descreveram características anatomopatológicas que podiam dividi-los em TI e TPB. Observou-se que os tumores classificados como TI apresentavam melhor prognóstico e menos metástases linfonodais.

Somente em 2000 Albores-Saavedra definiu as características anatomopatológicas que classificariam esses dois tipos de AAV, além de outros tipos de adenocarcinomas, menos comuns (20). Essa classificação ainda é empregada atualmente e foi utilizada como base para a definição de TI e TPB em nosso estudo.

A classificação histológica dos AAV em TI e TPB tornou-se necessária para comparação de terapêuticas clínicas e estudos prognósticos para esses tumores. $\mathrm{Na}$ 
casuística do Memorial Sloan-Kettering Cancer Center com 140 casos de AAVs, o TI correspondeu a $49 \%$ e o TPB a $22 \%$ dos casos (20). De 55 casos estudados por Zhou et al, $44 \%$ foram classificados como TPB, $27 \%$ como $\mathrm{Tl}$ e $29 \%$ como tipos incomuns ou mistos. Já Roh et al publicaram em 200734 casos, 64,7\% TPB e 35,35\% TI (34).

Em tese de livre docência defendida por Jukemura J, foram analisados histologicamente 97 casos desta casuística (35). Os tumores foram classificados por patologista experiente, sendo $44,3 \%$ do TI, $48,5 \%$ do TPB e $7,2 \%$ de tipos incomuns. Verificou-se maiores índices de acometimento linfonodal, estádios mais avançados, invasão linfática e perineural no TPB. Além disso, os pacientes com TI apresentaram maior sobrevivência (35).

Usando os critérios anatomopatológicos descritos por Albores-Saavedra (20), patologistas especializados são capazes de classificar os subtipos tumorais (intestinal e pancreatobiliar) em cerca de $90 \%$ dos casos (133). Em muitos casos o fenótipo não é uniforme. Além disso, muitas vezes é difícil diferenciar os AAV de outros tumores periampulares, principalmente nos materiais de biópsia. A fim de melhor caracterizar os tipos tumorais, iniciaram então os estudos utilizando imunoexpressão. Entretanto, os painéis de marcadores utilizados não são uniformes. Alguns utilizaram apenas citoqueratinas (32), outros apenas apomucinas (4), outros painéis mistos com marcadores diversos $(34,74)$.

Em nosso estudo foi realizado um painel amplo incluindo todos os marcadores já testados previamente para AAVs (CK7, CK17, CK20, MUC1, MUC2, MUC5AC, MUC6, CDX2) e CD10. 
Os marcadores que apresentaram frequência de positividade significativa maior para o TI foram o MUC2, o CK20, o CD10 e o CDX2 e para o TPB, MUC1 e CK7. O CDX2 foi aquele que apresentou melhor acurácia $(82,2 \%)$. Os marcadores do TPB apresentaram boa sensibilidade, porém uma especificidade baixa por terem sido positivos em vários casos do TI. Aplicando-se um modelo de regressão logística, concluímos que a associação de marcadores com maior capacidade de predizer o tipo histológico é composta pelo CDX2, MUC2 e MUC1. Além disso, este estudo mostrou que o $\mathrm{CDX} 2+$, mesmo quando utilizado isoladamente, determina uma possibilidade 16 vezes maior de o tumor ser TI que TPB. A associação MUC2+/ MUC1- aumenta essa possibilidade em mais de 19 vezes.

Aplicando-se essa associação de marcadores foi possível classificar os 7 carcinomas incomus, com possibilidade de acerto superior à $80 \%$. Pudemos também reclassificar todos os AAVs utilizando apenas esses três marcadores imunoistoquímicos. Essa nova classificação apresentou uma ótima concordância com a classificação histológica (coeficiente $k=0,702$ ). Para os TIs a concordância foi de $90 \%$ e para os TPBs de $80 \%$.

Zhou et al utilizaram apenas a combinação CK7/CK20 para classificar os AAVs. Houve uma boa concordância entre o TPB e expressão CK7+/CK20-, de 87,5\%. Entretanto, a expressão CK7-/CK20+ concordou em apenas $60 \%$ para os Tls e apenas 4 dos 16 tumores ditos mistos puderam ser classificados (32).

As mucinas foram utilizadas inicialmente por Matsubayashi et al numa série de 52 casos, incluindo 23 AAV, 24 adenomas com carcinoma e 5 adenomas (4). Os 
tumores TI apresentaram maior frequência de componente tumoral intraductal, presença de componente adenomatoso e expressão de MUC2, em relação do TPB (4). Outro estudo associou o MUC2 e CK7/CK20, com diferença significativa entre TI e TPB para os três marcadores. Porém, as citoqueratinas apresentaram especificidade mais baixa(5). Chu et al também demonstraram que a expressão de MUC2 e CDX2 associam-se ao fenótipo intestinal enquanto que MUC1 e CK17 associaram-se ao pancreatobiliar (3).

A expressão de CK17 em nosso estudo foi um pouco mais frequente nos AAVs TPB, porém sem diferença significativa em relação ao TI. Entretanto, expressão de CK17 em adenocarcinomas não mucinosos extra-pancreáticos é rara, e nunca de forma difusa (3).

Em nossa série, o MUC5AC esteve expresso em cerca de $70 \%$ dos casos de AAV, pouco mais frequente no TPB. Já a expressão de MUC6 ocorreu de forma similar nos dois grupos, em cerca de $44 \%$ dos casos. Esses dois marcadores são expressos normalmente na mucosa gástrica (134) e quando expressos em tumores duodenais ou AAV caracterizam uma diferenciação gástrica, com origem molecular diferente daqueles com diferenciação intestinal (134). Essa distinção ainda não foi bem estudada, merecendo melhores estudos no futuro.

Algumas séries associaram a expressão de MUC5AC com origem pancreatobiliar $(32,120,135)$. A expressão MUC1+/MUC5AC+ é característica de adenocarcinomas pancreáticos e colangiocarcinomas, ocorrendo apenas em alguns casos de adenocarcinomas esofágicos, gástricos e de colo uterino (136). Já a 
coexpressão de MUC1+, MUC5AC+ e CK17+ é um perfil único de adenocarcinomas pancreatobiliares e não ocorre em nenhum outro adenocarcinoma (3).

Parece haver uma relação entre o MUC5AC e fatores protetores da ampola de Vater. Curiosamente, os AAVs que expressam MUC5AC são encontrados muito mais frequentemente no segmento ductal pancreático da ampola que no biliar. Assim, especula-se que o suco pancreático tenha influência no desenvolvimento desses carcinomas $(4,10)$.

O CDX2 já havia sido demonstrado como um bom marcador para adenocarcinomas de origem intestinal $(74,120)$. Hansel et al $(74)$ examinaram uma série com 53 AAV e demonstraram que a expressão de CDX2 isoladamente poderia identificar os TIs, além de estar associado a um melhor prognóstico, sugerindo que esse marcador poderia ser usado como fator independente de evolução. Recentemente, Sessa et al (120) verificaram 100\% de expressão desses marcadores nos seus AAV classificados como $\mathrm{Tl}$, porém, assim como em nossa série, não comprovou a associação direta entre expressão de CDX2 e melhor sobrevivência.

Sabe-se que o CDX2 está relacionado com a manutenção da diferenciação do epitélio intestinal colônico $(67,69)$ e a perda de sua expressão está associada com a carcinogênese do câncer colônico (67). Já no câncer gástrico, a expressão de CDX2 está associada a melhor prognóstico e relaciona-se com a presença de metaplasia intestinal no epitélio do estômago (137). Sua expressão nos AAV sugere origem do epitelio duodenal, entretanto, foi verificada ocorrência desse marcador em alguns tumores pancreáticos e de vias biliares (74). Em nosso estudo, a expressão nos AAV 
TPB ocorreu em $21,3 \%$ dos casos. Assim, a analogia CDX2 e tipo intestinal não é absoluta. Também é verdade que nem todo adenocarcinoma de origem intestinal expressa CDX2, e assim como para o câncer colorretal, a perda da expressão de CDX2 pode fazer parte do processo de carcinogênese dos AAV (138)

Analisando a relação dos marcadores para determinação do tipo histológico e critérios anatomopatológicos, é interessante notar a relação entre positividade para MUC1 e tumores bem diferenciados e, inversamente, MUC2 e tumores pouco diferenciados. Sessa et al (120) buscaram essa associação entre diferenciação tumoral e marcadores, verificando uma frequência maior de tumores bem diferenciados e expressão de CDX2, porém sem significância estatística.

A análise da expressão do CD10 nos AAV é inédita neste estudo. Este marcador teve expressão significativamente maior nos Tls $(81,4 \%$ versus $51,1 \%)$. 0 CD10 está relacionado a células secretoras de muco e no pâncreas é útil no diagnóstico diferencial entre cistoadenomas mucinosos e neoplasia sólida pseudopapilar, onde a expressão ocorre na maioria dos casos, dos adenomas mucinosos papilíferos intraductais, nos quais não ocorre expressão (41).

A indefectível diferença na expressão de marcadores imunoistoquímicos parece comprovar a origem tecidual diferente para os dois tipos histológicos de AAV. Sustentando essa teoria, Ho et al (139) relataram que os genes de mucinas são regulados independentemente e que suas expressões são órgão e tipo celular específicas. Além disso, é possível que a maioria dos AAVs TI originem-se de 
adenomas enquanto que os TPB originam-se das regiões ductais pancreatobiliares, incluindo o canal comum, podendo haver exceções (4).

Na tumorigênese intestinal, não apenas no cólon e reto (140), como no delgado (141) e na ampola de Vater (10 à $91 \%$ dos casos) $(12,142,143)$, a sequência adenoma-carcinoma foi proposta. Mais de $95 \%$ dos tumores benignos da papila são adenomas do tipo intestinal (5) e nos adenocarcinomas $\mathrm{TI}$, a presença de componente adenomatoso ocorre em $90 \%$ dos casos (4), sugerindo essa origem tumoral. Na verdade, lesões precursoras podem originar-se tanto da mucosa tipo intestinal quanto da mucosa do segmento pancreático e biliar, conservando características de expressões de citoqueratinas e mucinas desses tecidos (5). Entretanto, nos AAV TPB a evidência de lesões precursoras é mais rara, podendo ser evidenciado por lesão intraductal pancreática associada $(4,144)$.

O prognóstico dos AAVs depende do estadio, acometimento linfonodal e diferenciação histológica $(14,27,30,35,145-147)$. Em nosso estudo, apenas o acometimento linfonodal e a invasão linfática foram fatores independentes relacionados ao prognóstico.

A influência do tipo histológico é de difícil determinação devido à grande variância de terminologias e métodos classificatórios (20). O tipo histológico intestinal esteve relacionado com melhor sobrevivência em nosso estudo em análise univariada, porém não conseguimos provar diferença utilizando a classificação imunoistoquímica ou mesmo a expressão de qualquer marcador. 0 tipo intestinal apresentou melhor sobrevivência em algumas séries publicadas (19, 
$20,33,34,117)$, não verificada em outros estudos $(3,32)$. Na maioria das casuísticas nas quais o TPB associou-se à pior sobrevivência, esses tumores estavam relacionados à maior acometimento linfonodal e estadios mais avançados $(19,20$, 35).

A expressão de alguns marcadores relacionados ao tipo intestinal já estiveram relacionados a um melhor prognóstico nos AAVs, como CDX2 (74) e MUC2 (148). Porém, outros estudos não conseguiram comprovar essa relação (3, 32).

Finalmente, a diferença de expressão das mucinas MUC2 e MUC1 e do CDX2 parece consistente entre adenocarcinomas ampulares TI e TPB. Esses marcadores devem ser usados de forma auxiliar aos achados anatomopatológico no diagnóstico diferencial dos AAVs. Embora pareça haver um melhor prognóstico associado ao tipo intestinal, não conseguimos comprovar uma relação entre sobrevivência e perfil imunoistoquímico.

5.2.2 Marcadores imunoistoquímicos relacionados à carcinogênese

\section{p53, p16 e Ki67}

Neste estudo, 35 pacientes (36,1\%) com AAV apresentaram expressão de p53 nos AAVs. Houve relação de p53 com neoplasias pouco diferenciadas e 
presença de invasão linfática. Não verificamos diferença na expressão do p53 entre os TI e TPB.

Em outras séries, a frequência de mutação do p53 variou entre 13\% e 46\% (93-97). A mutação do p53 esteve associada à transformação de adenomas e carcinomas de baixo grau em carcinomas de alto grau $(94,97,117)$. Outros estudos relacionaram essa mutação com metástase linfonodal e estadios mais avançados (94, 95). Já a relação dessa expressão com tipos histológicos intestinal e pancreatobiliar não foi demonstrada (97).

O papel da mutação do p53 na carcinogênese já foi estudado nos mais diversos carcinomas. No carcinoma ductal do pâncreas, por exemplo, a mutação do p53 foi relacionada à evolução neoplásica, uma vez que sua ocorrência é mais frequente em estadios avançados e aumenta progressivamente da displasia para o carcinoma (92).

No AAV também já foi demonstrado o caráter evolutivo da mutação do p53 durante a transformação maligna do adenoma para carcinoma, mas a maioria dos estudos falharam ao tentar correlacionar a expressão do p53 com menor sobrevivência $(94,95,149,150)$, assim como em nosso estudo. Apenas dois estudos relataram uma pior evolução nos tumores com expressão do p53 $(94,151)$, ainda que apenas em análise univariada.

A expressão do p16 ocorreu em 30,6\% dos AAVs desse estudo. Este marcador não apresentou relação com sobrevivência nem com os diferentes tipos histológicos. Moore et al (152) encontraram boa correlação entre análise genética com 
imunoistoquímica, com 25\% de mutação do p16 em AAVs. Já Ueki et al (101) verificaram 70,6\% de alteração do p16 em AVVs em analise genética, porém sem confirmação de imunoexpressão, e sem ralação com pior sobrevivência.

Em estudo recente foi demonstrado que tanto no câncer pancreático quanto no AAV, a perda de heterozigozidade para o p16 está relacionado à maior agressividade tumoral e pior sobrevivência (153). Porém, essa alteração pode não determinar a expressão da proteína p16 no tecido tumoral. Novos estudos comparando alterações genéticas e imunoperoxidase poderão responder qual o real papel do p16 como marcador tecidual.

O Ki67 foi expresso em $37 \%$ dos AAVs desse estudo, considerando positivos casos com expressão em mais de $10 \%$ das células. Embora não encontrassemos pior sobrevivência para doentes que o expressaram pela análise de sobrevivência pelo método de log-rank, houve relação entre pacientes com sobrevivência curta e expressão desse marcador em relação àqueles com sobrevivência prolongada.

O Ki67 já havia sido demonstrado como um indicador prognóstico para o câncer de mama (154) e pulmão (155). Vaidya et al também compararam pacientes operados por AAV com curta e longa sobrevivência em relação aos índices de Ki67, encontrando significativamente maiores expressões no primeiro grupo (156). Por ser um bom marcador de proliferação celular, o Ki67 parece ser um marcador prognóstico não órgão específico. 


\section{Instabilidade de microssatélites}

A instabilidade de microssatélites (IMS) geralmente é estudada através da extração de DNA e análise de sequências de genes (hMSH2, hMSH6, hMLH1, hPMS1, hPMS2). Outro gene analisado é o BAT-26, cuja mutação é o marcador mais sensível para deteç̧ão de tumores com fenótipo de IMS (157). Para confirmar a instabilidade, é possível analisar a expressão de enzimas codificadas por esses genes nos tecidos, através do uso de anticorpos para hMLH1, hMSH2 e hMSH6.

Neste estudo foi realizado apenas a imunoistoquímica para avaliar a perda de expressão das proteínas de reparo do DNA (MMR), já que vários estudos demonstraram alta sensibilidade e especificidade da não expressão desses marcadores e a presença de IMS (158-165).

Não há até o momento um estudo amplo utilizando imunoistoquímica para determinar a presença de IMS nas neoplasias ampulares e sua relação com fatores clínicos, anatomopatológicos e sobrevivência. Neste contexto, a nossa série é a primeira a realizar um painel imunoistoquímico para caracterizar a expressão das proteínas de reparo do DNA nos AAV.

A falta de expressão de pelo menos uma proteína de reparo ocorreu em 13,6\% (13/97) dos casos estudados. Apenas um caso apresentou associação de perda de expressão para as três proteínas testadas, e um para duas. Embora não tenha sido comprovada melhor sobrevivência nos pacientes com IMS, na análise comparativa entre doentes com sobrevivência breve e longa, esse foi um fator significante. 
Os resultados relativos à IMS são pouco concordantes na literatura. Utilizando sequenciamento gênico, Park et al encontraram uma frequência de 34,6\% de IMS em 1 a 3 dinucleotídeos dos nove testados nos adenomas de ampola de Vater, 28,1\% nos carcinomas e $10 \%$ nas lesões metastáticas de AAVs (118). Nenhum caso apresentava mutação do BAT-26 e também não houve perda de imunoexpressão tecidual para anticorpos anti-hMLH1 e hMLH2 nos tecidos tumorais de nenhum dos casos.

Em um estudo de Imai et al, 77,8\% do AAVs apresentaram mutações na sequência do gene TGFBRII (166). Já Suto et al encontraram 12,5\% de IMS em 16 casos estudados, não verificando relação dessa alteração com critérios anatomopatológicos ou prognóstico (167). Achille el al estudaram 25 AAV e encontraram 20\% de IMS (117). Esses tumores estiveram associados a um melhor prognóstico e embora sem significância estatística, eram mais frequentemente pouco diferenciados e com menos metástases linfonodais. Em nosso estudo a IMS foi também mais frequente nos tumores pouco diferenciados $(21,4 \%$ versus $13,3 \%$ nos moderadamente diferenciados e $9,1 \%$ nos bem diferenciados) e com ausência de metástase linfonodal $(15,9 \%$ versus $9,1 \%$ dos pacientes com metástases linfonodais). Esses achados são semelhantes aos verificados para o carcinoma colorretal (168).

Nos adenocarcinomas pancreáticos, a IMS é muito menos frequente que no AAV. Em uma série com 82 carcinomas ductais descritos por Goggins et al, apenas 3 apresentaram erros de replicação do DNA (169), sendo todos pouco diferenciados e 
do tipo medular. A fim de melhor caracterizar esses tumores, Wilentz et al estudaram geneticamente 21 casos de carcinomas medulares; encontrando $23 \%$ de IMS (170). Num estudo incluíndo apenas carcinomas ductais mucinosos, selecionados pela expressão de MUC1 e MUC2, nenhum dos 11 casos apresentaram IMS (171). No cólon, carcinomas mucinosos com expressão de MUC2 apresentam frequentemente IMS (172). Nas neoplasias intraductais papilíferos mucinosos, a IMS foi verificada em apenas $10 \%$ dos casos(173).

Em estudo também utilizando apenas imunoistoquímica, Sessa et al encontraram uma freqüência de 9,5\% de IMS em 53 AAVs, confirmados pela ausência de expressão de pelo menos 2 das proteínas hMLH1, hMSH2, hMSH6 e hPMS2 (120). Os 5 casos com IMS apresentavam histologia compatível com TI, expressavam CDX2 e apresentaram melhor sobrevivência que os demais.

Já foi demonstrada a relação de IMS com melhor prognóstico para o câncer gástrico (174), colorretal (113) e mama (175). No AAV, apenas Scarpa et al conseguiram verificar essa relação (117). Isso se deve provavelmente devido à baixa frequência de IMS no AAV e ao pequeno número de casos na maioria das séries.

Um estudo de perfis genéticos do AAVs revelou duas possíveis vias de alterações (117). O primeiro grupo de tumores foi caracterizado por alterações de K-ras, p53, p16, assim como perdas de alelos nos cromossomos 3p, 5q, 17p e 18q, alterações geralmente verificadas na sequência adenoma-carcinoma e semelhantes àquelas dos carcinomas colorretais. O segundo grupo caracterizou-se por altos níveis de instabilidade de microssatélites e mutações do gene TGF-BRII, alterações 
características do chamado caminho do fenótipo-mutado (117). Esse grupo estaria associado a um melhor prognóstico. Embora ainda não haja comprovação indubitável desta hipótese, poderiamos supor que os AAVs TI estariam relacionados com a segunda via e os TPB, com a primeira.

Até o momento, os estudos de IMS são controversos e incluem em sua maioria um número limitado de casos. Nossa frequência está de acordo com o estudo publicado mais recentemente (120), assim como melhor prognóstico desses casos. Porém, não conseguimos provar a associação dessa alteração com o tipo histológico intestinal.

\section{CEA e CA19-9}

O carcinoma antígeno embrionário (CEA) é expresso nos tecidos endodermais durante os dois primeiros trimestres da vida fetal e também nos carcinomas gastrointestinais e alguns tumores de origem epitelial, como pâncreas, mama, pulmão, ovário e tireóide. Como sua expressão no tecido normal é negligenciável, sua expressão é utilizada como marcador tumoral na prática clínica.

Neste estudo, o CEA foi expresso em $79 \%$ dos AAV, e esteve relacionado significativamente com a expressão de p16, CA19-9 e CDX2. Kimura et al analisaram a expressão de CEA na ampola de Vater e verificaram que no tecido normal ou com atipia leve esse marcador nunca é expresso. Na atipia moderada ou grave essa expressão ocorreu em 4,3\% dos casos, e nos carcinomas em 78,6\% (176). Hasleton 
et al sugeriram que a expressão de CEA no citoplasma das células de adenomas poderia ser um índice de malignização na papila de Vater (177).

Em estudo comparativo entre carcinomas duodenais e ampulares, essa expressão foi de $73 \%$ e $63 \%$, respectivamente (95). Assim como em nossa série, não houve correlação com estadiamento e grau histológico. Zhou et al verificaram que o CEA esteve significativamente mais expresso nos AAVs TI (32). Em nosso estudo, a positividade do CEA foi maior no TI (83,7\% versus $76,6 \%)$, porém sem significância estatística.

O CA19-9 foi expresso em $88 \%$ dos tecidos de AAV neste estudo. $O$ antígeno CA19-9 normalmente é encontrado em concentrações aumentadas em dosagens séricas de pacientes com carcinoma pancreático (178). Kimura et al estudaram a expressão de CA19-9 nos adenomas com atipia e nos carcinomas da ampola de Vater, verificando $87 \%$ e $64,3 \%$ de expressão, respectivamente (176). Entretanto, estudos imunoistoquímicos demonstraram que este marcador está expresso também nos ductos e células acinares do pâncreas normal $(176,179)$. Assim, poderíamos supor que este marcador estaria mais expresso no AAV TPB. Embora o TPB tenha expressado com mais frequência o CA19-9 (93,6\% versus $83,7 \%$ TI), essa diferença não foi significativa.

Kamisawa et al estudaram $24 \mathrm{AAV}$, e verificaram um pior prognóstico para pacientes com CEA e CA19-9 positivos. Entretando, em sua série, a positividade desses marcadores foi menor que 50\%, diferentemente dos resultados de séries 
mais recente (180). Neste trabalho, a expressão de CEA e CA19-9 não foi distinta entre TI e TPB, tão pouco esteve relacionada com prognóstico dos AAVs. 
6. Conclusões 


\section{6- CONCLUSÕES}

Com base na casuística e metodologia empregada, podemos concluir:

1. A utilização dos marcadores CDX2, MUC2 e MUC1 associados permite classificar com maior acurácia os AAVs em tipo intestinal e pancreatobiliar.

2. O CDX2 é o marcador de tumores de origem intestinal com maior sensibilidade e especificidade quando utilizado de forma isolada.

3. A expressão do p53 está relacionada a carcinomas menos diferenciados e com invasão linfática e a expressão do Ki67 está relacionada com óbito precoce nos doentes operados por AAV.

4. p16, CEA e CA19-9 não relacionaram-se com critérios clínicos e anatomopatológicos.

5. A perda de expressão de proteínas relacionadas à instabilidade de microssatélites ocorreu em 13,5\% dos casos e está relacionada com sobrevivência superior a 5 anos nos doentes operados por AAV.

6. Nenhum dos marcadores relacionados à carcinogênese permite diferenciar os AAV TI e TPB.

7. Das variáveis anátomo-patológicas estudadas, apenas o acometimento linfonodal e a invasão linfática apresentaram relação com menor sobrevivência em 5 anos. 
8. Nenhum marcador estudado apresentou relação com a sobrevivência. 
7-Anexos 


\section{ANEXOS}

Anexo A: Classificação TNM de acordo com a Union International Contra Le Cancer (UICC), de 2002

Tabela A1: Classificação TNM de acordo com a Union International Contra Le Cancer (UICC), de 2002.

\begin{tabular}{ll}
\hline T & Tumor primário \\
\hline TX & O tumor primário não pode ser avaliado \\
T0 & Não há evidência de tumor primário \\
Tis & Carcinoma in situ \\
T1 & Tumor limitado à ampola de Vater ou ao esfíncter de Oddi \\
T2 & Tumor que invade a parede duodenal \\
T3 & Tumor que invade pâncreas \\
T4 & Tumor que invade partes moles peri-pancreáticas, ou outros \\
& orgãos ou estruturas adjacentes \\
\hline $\mathbf{N}$ & Linfonodos regionais \\
\hline Nx & Os linfonodos regionais não podem ser avaliados \\
N0 & Ausência de metástase em linfonodos regionais \\
N1 & Metástase em linfonodos regionais \\
\hline M & Metástase à distância \\
\hline Mx & A presença de metástase à distância não pode ser avaliada \\
M0 & Ausência de metástase à distância \\
M1 & Metástase à distância \\
\hline
\end{tabular}

pTNM - Classificação Patológica

As categorias $\mathrm{pT}, \mathrm{pN}$ e $\mathrm{pM}$ correspondem às categorias $\mathrm{T}, \mathrm{N}$ e $\mathrm{M}$.

pNO O exame histológico do espécime de uma linfadenectomia regional incluirá, geralmente, 10 ou mais linfonodos. Se os linfonodos são negativos, mesmo que o número usualmente examinado seja não encontrado, classifica-se como pNO. 


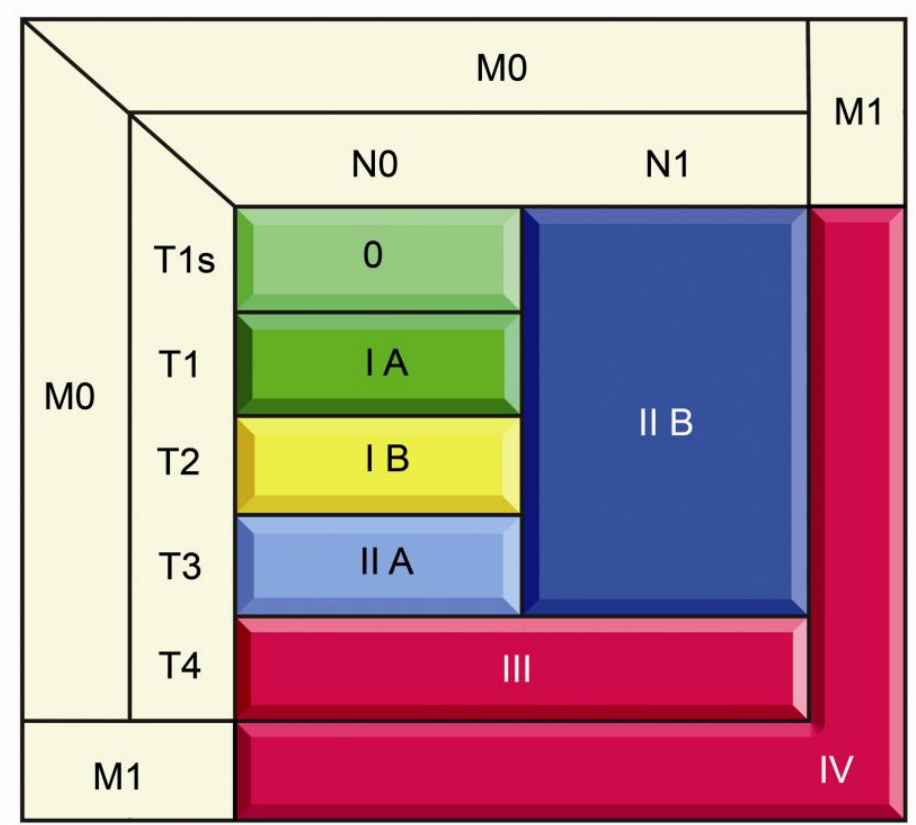

Figura A1: Grupamento por estadios nas neoplasias de ampola de Vater 
8- Referências 


\section{REFERÊNCIAS}

1. Ishibashi Y, Murakami G, Honma T, Sato TJ, Takahashi M. Morphometric study of the sphincter of oddi (hepatopancreatic) and configuration of the submucosal portion of the sphincteric muscle mass. Clin Anat. 2000;13(3):159-67.

2. Kunath $U$, Hommerding $H$. [Is the duodenal papilla an autonomic sphincter? $A$ contribution to the functional morphology (author's transl)]. Res Exp Med (Berl). 1981;178(2):103-16.

3. Chu PG, Schwarz RE, Lau SK, Yen Y, Weiss LM. Immunohistochemical staining in the diagnosis of pancreatobiliary and ampulla of Vater adenocarcinoma: application of CDX2, CK17, MUC1, and MUC2. Am J Surg Pathol. 2005 Mar;29(3):359-67.

4. Matsubayashi $H$, Watanabe H, Yamaguchi T, Ajioka $Y$, Nishikura K, Kijima H, et al. Differences in mucus and K-ras mutation in relation to phenotypes of tumors of the papilla of vater. Cancer. 1999 Aug 15;86(4):596-607.

5. Fischer HP, Zhou H. Pathogenesis of carcinoma of the papilla of Vater. J Hepatobiliary Pancreat Surg. 2004;11(5):301-9.

6. Kim RD, Kundhal PS, McGilvray ID, Cattral MS, Taylor B, Langer B, et al. Predictors of failure after pancreaticoduodenectomy for ampullary carcinoma. J Am Coll Surg. 2006 Jan;202(1):112-9.

7. Yamaguchi K, Enjoji M. Carcinoma of the ampulla of vater. A clinicopathologic study and pathologic staging of 109 cases of carcinoma and 5 cases of adenoma. Cancer. 1987 Feb 1;59(3):506-15.

8. Nakase A, Matsumoto $Y$, Uchida K, Honjo I. Surgical treatment of cancer of the pancreas and the periampullary region: cumulative results in 57 institutions in Japan. Ann Surg. 1977 Jan;185(1):52-7.

9. Yeo CJ, Cameron JL, Sohn TA, Lillemoe KD, Pitt HA, Talamini MA, et al. Six hundred fifty consecutive pancreaticoduodenectomies in the 1990s: pathology, complications, and outcomes. Ann Surg. 1997 Sep;226(3):248-57; discussion 57-60.

10. Fischer HP, Zhou H. [Pathogenesis and histomorphology of ampullary carcinomas and their precursor lesions. Review and individual findings]. Pathologe. 2003 May;24(3):196-203.

11. Paulsen FP, Bobka T, Tsokos M, Folsch UR, Tillmann BN. Functional anatomy of the papilla Vateri: biomechanical aspects and impact of difficult endoscopic intubation. Surg Endosc. 2002 Feb;16(2):296-301.

12. Howe JR, Klimstra DS, Moccia RD, Conlon KC, Brennan MF. Factors predictive of survival in ampullary carcinoma. Ann Surg. 1998 Jul;228(1):87-94.

13. Bettschart V, Rahman MQ, Engelken FJ, Madhavan KK, Parks RW, Garden OJ. Presentation, treatment and outcome in patients with ampullary tumours. Br J Surg. 2004 Dec;91(12):1600-7.

14. Yeo CJ, Sohn TA, Cameron JL, Hruban RH, Lillemoe KD, Pitt HA. Periampullary adenocarcinoma: analysis of 5-year survivors. Ann Surg. 1998 Jun;227(6):821-31.

15. Warren KW, Choe DS, Plaza J, Relihan M. Results of radical resection for periampullary cancer. Ann Surg. 1975 May;181(5):534-40.

16. Cohen JR, Kuchta N, Geller N, Shires GT, Dineen P. Pancreaticoduodenectomy. A 40year experience. Ann Surg. 1982 May;195(5):608-17. 
17. Tarazi RY, Hermann RE, Vogt DP, Hoerr SO, Esselstyn CB, Jr., Cooperman AM, et al. Results of surgical treatment of periampullary tumors: a thirty-five-year experience. Surgery. 1986 Oct;100(4):716-23.

18. Michelassi F, Erroi F, Dawson PJ, Pietrabissa A, Noda S, Handcock M, et al. Experience with 647 consecutive tumors of the duodenum, ampulla, head of the pancreas, and distal common bile duct. Ann Surg. 1989 Oct;210(4):544-54; discussion 54-6.

19. Kimura W, Futakawa N, Yamagata S, Wada Y, Kuroda A, Muto T, et al. Different clinicopathologic findings in two histologic types of carcinoma of papilla of Vater. Jpn J Cancer Res. 1994 Feb;85(2):161-6.

20. Albores-Saavedra J. Tumors of the gallbladder, extrahepatic bile ducts, and ampulla of Vater. In: Albores-Saavedra J, editor. Atlas of Tumor Pathology. Washington, D.C.: Armed Forces Institute of Pathology; 2000. p. 259:316.

21. Diener MK, Knaebel HP, Heukaufer C, Antes G, Buchler MW, Seiler CM. A systematic review and meta-analysis of pylorus-preserving versus classical pancreaticoduodenectomy for surgical treatment of periampullary and pancreatic carcinoma. Ann Surg. 2007 Feb;245(2):187-200.

22. Park YC, Kim SW, Jang JY, Ahn YJ, Park YH. Factors influencing delayed gastric emptying after pylorus-preserving pancreatoduodenectomy. J Am Coll Surg. 2003 Jun;196(6):859-65.

23. Roder JD, Stein HJ, Huttl W, Siewert JR. Pylorus-preserving versus standard pancreatico-duodenectomy: an analysis of 110 pancreatic and periampullary carcinomas. $\mathrm{Br}$ J Surg. 1992 Feb;79(2):152-5.

24. Pratt WB, Maithel SK, Vanounou T, Huang ZS, Callery MP, Vollmer CM, Jr. Clinical and economic validation of the International Study Group of Pancreatic Fistula (ISGPF) classification scheme. Ann Surg. 2007 Mar;245(3):443-51.

25. Brown KM, Tompkins AJ, Yong S, Aranha GV, Shoup M. Pancreaticoduodenectomy is curative in the majority of patients with node-negative ampullary cancer. Arch Surg. 2005 Jun;140(6):529-32; discussion 32-3.

26. Qiao QL, Zhao YG, Ye ML, Yang YM, Zhao JX, Huang YT, et al. Carcinoma of the ampulla of Vater: factors influencing long-term survival of 127 patients with resection. World J Surg. 2007 Jan;31(1):137-43; discussion 44-6.

27. Beger HG, Treitschke F, Gansauge F, Harada N, Hiki N, Mattfeldt T. Tumor of the ampulla of Vater: experience with local or radical resection in 171 consecutively treated patients. Arch Surg. 1999 May;134(5):526-32.

28. Woo SM, Ryu JK, Lee SH, Yoo JW, Park JK, Kim YT, et al. Recurrence and prognostic factors of ampullary carcinoma after radical resection: comparison with distal extrahepatic cholangiocarcinoma. Ann Surg Oncol. 2007 Nov;14(11):3195-201.

29. Allema JH, Reinders ME, van Gulik TM, van Leeuwen DJ, Verbeek PC, de Wit LT, et al. Results of pancreaticoduodenectomy for ampullary carcinoma and analysis of prognostic factors for survival. Surgery. 1995 Mar;117(3):247-53.

30. Monson JR, Donohue JH, McEntee GP, Mcllrath DC, van Heerden JA, Shorter RG, et al. Radical resection for carcinoma of the ampulla of Vater. Arch Surg. 1991 Mar;126(3):353-7.

31. Balachandran P, Sikora SS, Kapoor S, Krishnani N, Kumar A, Saxena R, et al. Long-term survival and recurrence patterns in ampullary cancer. Pancreas. 2006 May;32(4):390-5.

32. Zhou H, Schaefer N, Wolff M, Fischer HP. Carcinoma of the ampulla of Vater: comparative histologic/immunohistochemical classification and follow-up. Am J Surg Pathol. 2004 Jul;28(7):875-82. 
33. Westgaard A, Tafjord S, Farstad IN, Cvancarova M, Eide TJ, Mathisen O, et al. Pancreatobiliary versus intestinal histologic type of differentiation is an independent prognostic factor in resected periampullary adenocarcinoma. BMC Cancer. 2008;8:170.

34. Roh YH, Kim YH, Lee HW, Kim SJ, Roh MS, Jeong JS, et al. The clinicopathologic and immunohistochemical characteristics of ampulla of Vater carcinoma: the intestinal type is associated with a better prognosis. Hepatogastroenterology. 2007 Sep;54(78):1641-4.

35. Jukemura J. Influência do tipo histológico na sobrevivência tardia dos doentes com adenocarcinoma de ampola de Vater tratados cirurgicamente. São Paulo: Universidade de São Paulo; 2008.

36. Chu P, Wu E, Weiss LM. Cytokeratin 7 and cytokeratin 20 expression in epithelial neoplasms: a survey of 435 cases. Mod Pathol. 2000 Sep;13(9):962-72.

37. Moll R, Franke WW, Schiller DL, Geiger B, Krepler R. The catalog of human cytokeratins: patterns of expression in normal epithelia, tumors and cultured cells. Cell. 1982 Nov;31(1):11-24.

38. Wauters CC, Smedts F, Gerrits LG, Bosman FT, Ramaekers FC. Keratins 7 and 20 as diagnostic markers of carcinomas metastatic to the ovary. Hum Pathol. 1995 Aug;26(8):8525.

39. Lagendijk JH, Mullink H, Van Diest PJ, Meijer GA, Meijer CJ. Tracing the origin of adenocarcinomas with unknown primary using immunohistochemistry: differential diagnosis between colonic and ovarian carcinomas as primary sites. Hum Pathol. 1998 May;29(5):4917.

40. Chu PG, Weiss LM. Keratin expression in human tissues and neoplasms. Histopathology. 2002 May;40(5):403-39.

41. Handra-Luca A, Flejou JF, Rufat $\mathrm{P}$, Corcos $\mathrm{O}$, Belghiti J, Ruszniewski $\mathrm{P}$, et al. Human pancreatic mucinous cystadenoma is characterized by distinct mucin, cytokeratin and CD10 expression compared with intraductal papillary-mucinous adenoma. Histopathology. 2006 Jun;48(7):813-21.

42. McCluggage WG, Wilkinson N. Metastatic neoplasms involving the ovary: a review with an emphasis on morphological and immunohistochemical features. Histopathology. 2005 Sep;47(3):231-47.

43. Vang R, Gown AM, Barry TS, Wheeler DT, Yemelyanova A, Seidman JD, et al. Cytokeratins 7 and 20 in primary and secondary mucinous tumors of the ovary: analysis of coordinate immunohistochemical expression profiles and staining distribution in 179 cases. Am J Surg Pathol. 2006 Sep;30(9):1130-9.

44. Miettinen M. Keratin immunohistochemistry: update of applications and pitfalls. Pathol Annu. 1993;28 Pt 2:113-43.

45. Lee MJ, Lee HS, Kim WH, Choi Y, Yang M. Expression of mucins and cytokeratins in primary carcinomas of the digestive system. Mod Pathol. 2003 May;16(5):403-10.

46. Dekker J, Rossen JW, Buller HA, Einerhand AW. The MUC family: an obituary. Trends Biochem Sci. 2002 Mar;27(3):126-31.

47. Moniaux N, Escande F, Porchet N, Aubert JP, Batra SK. Structural organization and classification of the human mucin genes. Front Biosci. 2001 Oct 1;6:D1192-206.

48. Human Genome Organization Gene Nomenclature Committee. HUGO/GNC.: Available from: http://www.hugo-internqtionql.org/hugo/.

49. Kim GE, Bae HI, Park HU, Kuan SF, Crawley SC, Ho JJ, et al. Aberrant expression of MUC5AC and MUC6 gastric mucins and sialyl Tn antigen in intraepithelial neoplasms of the pancreas. Gastroenterology. 2002 Oct;123(4):1052-60. 
50. Corfield AP, Myerscough N, Longman R, Sylvester P, Arul S, Pignatelli M. Mucins and mucosal protection in the gastrointestinal tract: new prospects for mucins in the pathology of gastrointestinal disease. Gut. 2000 Oct;47(4):589-94.

51. Terada T, Ohta T, Sasaki M, Nakanuma Y, Kim YS. Expression of MUC apomucins in normal pancreas and pancreatic tumours. J Pathol. 1996 Oct;180(2):160-5.

52. Giorgadze TA, Peterman H, Baloch ZW, Furth EE, Pasha T, Shiina N, et al. Diagnostic utility of mucin profile in fine-needle aspiration specimens of the pancreas: an immunohistochemical study with surgical pathology correlation. Cancer. 2006 Jun 25;108(3):186-97.

53. Kim YS, Gum JR, Jr., Crawley SC, Deng G, Ho JJ. Mucin gene and antigen expression in biliopancreatic carcinogenesis. Ann Oncol. 1999;10 Suppl 4:51-5.

54. Yonezawa S, Horinouchi M, Osako M, Kubo M, Takao S, Arimura Y, et al. Gene expression of gastric type mucin (MUC5AC) in pancreatic tumors: its relationship with the biological behavior of the tumor. Pathol Int. 1999 Jan;49(1):45-54.

55. Swartz MJ, Batra SK, Varshney GC, Hollingsworth MA, Yeo CJ, Cameron JL, et al. MUC4 expression increases progressively in pancreatic intraepithelial neoplasia. Am J Clin Pathol. 2002 May;117(5):791-6.

56. Ho JJ, Han SW, Pan PL, Deng G, Kuan SF, Kim YS. Methylation status of promoters and expression of MUC2 and MUC5AC mucins in pancreatic cancer cells. Int J Oncol. 2003 Feb;22(2):273-9.

57. Paulsen FP, Varoga D, Paulsen AR, Corfield A, Tsokos M. Prognostic value of mucins in the classification of ampullary carcinomas. Hum Pathol. 2006 Feb;37(2):160-7.

58. Bonner CA, Loftus SK, Wasmuth JJ. Isolation, characterization, and precise physical localization of human CDX1, a caudal-type homeobox gene. Genomics. 1995 Jul 20;28(2):206-11.

59. Drummond F, Putt W, Fox M, Edwards $\mathrm{YH}$. Cloning and chromosome assignment of the human CDX2 gene. Ann Hum Genet. 1997 Sep;61(Pt 5):393-400.

60. Hong SM, Cho H, Moskaluk CA, Frierson HF, Jr., Yu E, Ro JY. CDX2 and MUC2 protein expression in extrahepatic bile duct carcinoma. Am J Clin Pathol. 2005 Sep;124(3):361-70.

61. Beck F, Chawengsaksophak K, Waring P, Playford RJ, Furness JB. Reprogramming of intestinal differentiation and intercalary regeneration in $\mathrm{Cd} \times 2$ mutant mice. Proc Natl Acad Sci U S A. 1999 Jun 22;96(13):7318-23.

62. Chawengsaksophak K, James R, Hammond VE, Kontgen F, Beck F. Homeosis and intestinal tumours in Cdx2 mutant mice. Nature. 1997 Mar 6;386(6620):84-7.

63. Tamai Y, Nakajima R, Ishikawa T, Takaku K, Seldin MF, Taketo MM. Colonic hamartoma development by anomalous duplication in $\mathrm{Cdx} 2$ knockout mice. Cancer Res. 1999 Jun 15;59(12):2965-70.

64. Wicking C, Simms LA, Evans T, Walsh M, Chawengsaksophak K, Beck F, et al. CDX2, a human homologue of Drosophila caudal, is mutated in both alleles in a replication error positive colorectal cancer. Oncogene. 1998 Aug 6;17(5):657-9.

65. Sivagnanasundaram S, Islam I, Talbot I, Drummond F, Walters JR, Edwards YH. The homeobox gene CDX2 in colorectal carcinoma: a genetic analysis. $\mathrm{Br} J$ Cancer. 2001 Jan;84(2):218-25.

66. Yagi OK, Akiyama Y, Yuasa Y. Genomic structure and alterations of homeobox gene CDX2 in colorectal carcinomas. Br J Cancer. 1999 Feb;79(3-4):440-4. 
67. Mallo GV, Soubeyran P, Lissitzky JC, Andre F, Farnarier C, Marvaldi J, et al. Expression of the $\mathrm{Cdx} 1$ and $\mathrm{Cdx} 2$ homeotic genes leads to reduced malignancy in colon cancer-derived cells. J Biol Chem. 1998 May 29;273(22):14030-6.

68. Hinoi T, Tani M, Lucas PC, Caca K, Dunn RL, Macri E, et al. Loss of CDX2 expression and microsatellite instability are prominent features of large cell minimally differentiated carcinomas of the colon. Am J Pathol. 2001 Dec;159(6):2239-48.

69. Almeida R, Silva E, Santos-Silva F, Silberg DG, Wang J, De Bolos C, et al. Expression of intestine-specific transcription factors, $C D X 1$ and $C D X 2$, in intestinal metaplasia and gastric carcinomas. J Pathol. 2003 Jan;199(1):36-40.

70. Bai YQ, Yamamoto H, Akiyama Y, Tanaka H, Takizawa T, Koike M, et al. Ectopic expression of homeodomain protein CDX2 in intestinal metaplasia and carcinomas of the stomach. Cancer Lett. 2002 Feb 8;176(1):47-55.

71. Shi $X Y$, Bhagwandeen $B$, Leong $A S . C D X 2$ and villin are useful markers of intestinal metaplasia in the diagnosis of Barrett esophagus. Am J Clin Pathol. 2008 Apr;129(4):571-7.

72. Jin T, Drucker DJ. Activation of proglucagon gene transcription through a novel promoter element by the caudal-related homeodomain protein cdx-2/3. Mol Cell Biol. 1996 Jan;16(1):19-28.

73. Werling RW, Yaziji H, Bacchi CE, Gown AM. CDX2, a highly sensitive and specific marker of adenocarcinomas of intestinal origin: an immunohistochemical survey of 476 primary and metastatic carcinomas. Am J Surg Pathol. 2003 Mar;27(3):303-10.

74. Hansel DE, Maitra A, Lin JW, Goggins M, Argani P, Yeo CJ, et al. Expression of the caudal-type homeodomain transcription factors CDX 1/2 and outcome in carcinomas of the ampulla of Vater. J Clin Oncol. 2005 Mar 20;23(9):1811-8.

75. Barbareschi M, Murer B, Colby TV, Chilosi M, Macri E, Loda M, et al. CDX-2 homeobox gene expression is a reliable marker of colorectal adenocarcinoma metastases to the lungs. Am J Surg Pathol. 2003 Feb;27(2):141-9.

76. Chang YT, Hsu C, Jeng YM, Chang MC, Wei SC, Wong JM. Expression of the caudaltype homeodomain transcription factor CDX2 is related to clinical outcome in biliary tract carcinoma. J Gastroenterol Hepatol. 2007 Mar;22(3):389-94.

77. Mclntosh GG, Lodge AJ, Watson P, Hall AG, Wood K, Anderson JJ, et al. NCL-CD10270: a new monoclonal antibody recognizing CD10 in paraffin-embedded tissue. Am J Pathol. 1999 Jan;154(1):77-82.

78. Chu PG, Chang KL, Weiss LM, Arber DA. Immunohistochemical detection of CD10 in paraffin sections of hematopoietic neoplasms: a comparison with flow cytometry detection in 56 cases. Appl Immunohistochem Mol Morphol. 2000 Dec;8(4):257-62.

79. LeBien TW, McCormack RT. The common acute lymphoblastic leukemia antigen (CD10)--emancipation from a functional enigma. Blood. 1989 Feb 15;73(3):625-35.

80. Erhuma $\mathrm{M}$, Kobel M, Mustafa T, Wulfanger J, Dralle H, Hoang-Vu C, et al. Expression of neutral endopeptidase (NEP/CD10) on pancreatic tumor cell lines, pancreatitis and pancreatic tumor tissues. Int J Cancer. 2007 Jun 1;120(11):2393-400.

81. Notohara K, Hamazaki S, Tsukayama C, Nakamoto S, Kawabata K, Mizobuchi K, et al. Solid-pseudopapillary tumor of the pancreas: immunohistochemical localization of neuroendocrine markers and CD10. Am J Surg Pathol. 2000 Oct;24(10):1361-71.

82. Hollstein $M$, Sidransky D, Vogelstein B, Harris CC. p53 mutations in human cancers. Science. 1991 Jul 5;253(5015):49-53.

83. Hsi ED. The search for meaningful prognostic markers in diffuse large B-cell lymphoma. Am J Clin Pathol. 2001 Apr;115(4):481-3. 
84. Kastan MB, Onyekwere O, Sidransky D, Vogelstein B, Craig RW. Participation of p53 protein in the cellular response to DNA damage. Cancer Res. 1991 Dec 1;51(23 Pt 1):630411.

85. Nigro JM, Baker SJ, Preisinger AC, Jessup JM, Hostetter R, Cleary K, et al. Mutations in the p53 gene occur in diverse human tumour types. Nature. 1989 Dec 7;342(6250):705-8.

86. Hussain SP, Harris CC. Molecular epidemiology of human cancer. Recent Results Cancer Res. 1998;154:22-36.

87. Fricke E, Keller G, Becker I, Rosivatz E, Schott C, Plaschke S, et al. Relationship between E-cadherin gene mutation and p53 gene mutation, p53 accumulation, Bcl-2 expression and Ki-67 staining in diffuse-type gastric carcinoma. Int J Cancer. 2003 Mar 10;104(1):60-5.

88. Sander CA, Yano T, Clark HM, Harris C, Longo DL, Jaffe ES, et al. p53 mutation is associated with progression in follicular lymphomas. Blood. 1993 Oct 1;82(7):1994-2004.

89. Wilson WH, Teruya-Feldstein J, Fest T, Harris C, Steinberg SM, Jaffe ES, et al. Relationship of $\mathrm{p53}, \mathrm{bcl}-2$, and tumor proliferation to clinical drug resistance in nonHodgkin's lymphomas. Blood. 1997 Jan 15;89(2):601-9.

90. Pellegata NS, Sessa F, Renault B, Bonato M, Leone BE, Solcia E, et al. K-ras and p53 gene mutations in pancreatic cancer: ductal and nonductal tumors progress through different genetic lesions. Cancer Res. 1994 Mar 15;54(6):1556-60.

91. DiGiuseppe JA, Hruban RH, Goodman SN, Polak M, van den Berg FM, Allison DC, et al. Overexpression of p53 protein in adenocarcinoma of the pancreas. Am J Clin Pathol. 1994 Jun;101(6):684-8.

92. Jeong S, Lee DH, Lee JI, Lee JW, Kwon KS, Kim PS, et al. Expression of Ki-67, p53, and K-ras in chronic pancreatitis and pancreatic ductal adenocarcinoma. World J Gastroenterol. 2005 Nov 21;11(43):6765-9.

93. Rashid A, Ueki T, Gao YT, Houlihan PS, Wallace C, Wang BS, et al. K-ras mutation, p53 overexpression, and microsatellite instability in biliary tract cancers: a population-based study in China. Clin Cancer Res. 2002 Oct;8(10):3156-63.

94. Park SH, Kim YI, Park YH, Kim SW, Kim KW, Kim YT, et al. Clinicopathologic correlation of p53 protein overexpression in adenoma and carcinoma of the ampulla of Vater. World J Surg. 2000 Jan;24(1):54-9.

95. Zhu L, Kim K, Domenico DR, Appert HE, Howard JM. Adenocarcinoma of duodenum and ampulla of Vater: clinicopathology study and expression of p53, c-neu, TGF-alpha, CEA, and EMA. J Surg Oncol. 1996 Feb;61(2):100-5.

96. Lee CS, Pirdas A. p53 protein immunoreactivity in cancers of the gallbladder, extrahepatic bile ducts and ampulla of Vater. Pathology. 1995 Apr;27(2):117-20.

97. Zhao B, Kimura W, Futakawa N, Muto T, Kubota K, Harihara Y, et al. p53 and p21/Waf1 protein expression and K-ras codon 12 mutation in carcinoma of the papilla of Vater. Am J Gastroenterol. 1999 Aug;94(8):2128-34.

98. Rocco JW, Sidransky D. p16(MTS-1/CDKN2/INK4a) in cancer progression. Exp Cell Res. 2001 Mar 10;264(1):42-55.

99. Chen Q, Luo G, Li B, Samaranayake LP. Expression of p16 and CDK4 in oral premalignant lesions and oral squamous cell carcinomas: a semi-quantitative immunohistochemical study. J Oral Pathol Med. 1999 Apr;28(4):158-64.

100. Hahn SA, Schmiegel WH. Recent discoveries in cancer genetics of exocrine pancreatic neoplasia. Digestion. 1998 Aug;59(5):493-501. 
101. Ueki T, Hsing AW, Gao YT, Wang BS, Shen MC, Cheng J, et al. Alterations of p16 and prognosis in biliary tract cancers from a population-based study in China. Clin Cancer Res. 2004 Mar 1;10(5):1717-25.

102. Martin AR, Chan WC, Perry DA, Greiner TC, Weisenburger DD. Aggressive natural killer cell lymphoma of the small intestine. Mod Pathol. 1995 Jun;8(5):467-72.

103. Lelle RJ. [In situ determination of the Ki-67 growth fraction (Ki-67 GF) in human tumors (studies in breast cancer)]. Acta Histochem Suppl. 1990;39:109-24.

104. Shibata N, Watari J, Fujiya M, Tanno S, Saitoh Y, Kohgo Y. Cell kinetics and genetic instabilities in differentiated type early gastric cancers with different mucin phenotype. Hum Pathol. 2003 Jan;34(1):32-40.

105. Hammarstrom S. The carcinoembryonic antigen (CEA) family: structures, suggested functions and expression in normal and malignant tissues. Semin Cancer Biol. 1999 Apr;9(2):67-81.

106. Maxwell P. Carcinoembryonic antigen: cell adhesion molecule and useful diagnostic marker. Br J Biomed Sci. 1999;56(3):209-14.

107. Ugorski M, Laskowska A. Sialyl Lewis(a): a tumor-associated carbohydrate antigen involved in adhesion and metastatic potential of cancer cells. Acta Biochim Pol. 2002;49(2):303-11.

108. Nishida K, Tasaki N, Miyagawa H, Yoshikawa T, Kondo M. Estimation of carbohydrate antigen (CA) 19-9 levels in pure pancreatic juice of patients with pancreatic cancer. Am J Gastroenterol. 1988 Feb;83(2):126-9.

109. Hamanaka Y, Hamanaka S, Suzuki M. Sialyl Lewis(a) ganglioside in pancreatic cancer tissue correlates with the serum CA 19-9 level. Pancreas. 1996 Aug;13(2):160-5.

110. Boeck S, Stieber P, Holdenrieder S, Wilkowski R, Heinemann V. Prognostic and therapeutic significance of carbohydrate antigen 19-9 as tumor marker in patients with pancreatic cancer. Oncology. 2006;70(4):255-64.

111. Malesci A, Montorsi M, Mariani A, Santambrogio R, Bonato C, Bissi O, et al. Clinical utility of the serum CA 19-9 test for diagnosing pancreatic carcinoma in symptomatic patients: a prospective study. Pancreas. 1992;7(4):497-502.

112. Miyoshi E, Haruma K, Hiyama T, Tanaka S, Yoshihara M, Shimamoto F, et al. Microsatellite instability is a genetic marker for the development of multiple gastric cancers. Int J Cancer. 2001 Nov 20;95(6):350-3.

113. Thibodeau SN, Bren G, Schaid D. Microsatellite instability in cancer of the proximal colon. Science. 1993 May 7;260(5109):816-9.

114. Lynch HT, Fusaro RM, Sandberg AA, Bixenman HA, Johnsen LR, Lynch JF, et al. Chromosome instability and the FAMMM syndrome. Cancer Genet Cytogenet. 1993 Nov;71(1):27-39.

115. Kinzler KW, Vogelstein B. Lessons from hereditary colorectal cancer. Cell. 1996 Oct 18;87(2):159-70.

116. Fearon ER, Vogelstein B. A genetic model for colorectal tumorigenesis. Cell. 1990 Jun 1;61(5):759-67.

117. Achille A, Biasi MO, Zamboni G, Bogina G, lacono C, Talamini G, et al. Cancers of the papilla of vater: mutator phenotype is associated with good prognosis. Clin Cancer Res. 1997 Oct;3(10):1841-7.

118. Park S, Kim SW, Kim SH, Darwish NS, Kim WH. Lack of microsatellite instability in neoplasms of ampulla of Vater. Pathol Int. 2003 Oct;53(10):667-70. 
119. Scarpa A, Di Pace C, Talamini G, Falconi M, Lemoine NR, lacono C, et al. Cancer of the ampulla of Vater: chromosome $17 p$ allelic loss is associated with poor prognosis. Gut. 2000 Jun;46(6):842-8.

120. Sessa F, Furlan D, Zampatti C, Carnevali I, Franzi F, Capella C. Prognostic factors for ampullary adenocarcinomas: tumor stage, tumor histology, tumor location, immunohistochemistry and microsatellite instability. Virchows Arch. 2007 Sep;451(3):64957.

121. Machado MC, da Cunha JE, Bacchella T, Bove P. A modified technique for the reconstruction of the alimentary tract after pancreatoduodenectomy. Surg Gynecol Obstet. 1976 Aug;143(2):271-2.

122. Chareton B, Coiffic J, Landen S, Bardaxoglou E, Campion JP, Launois B. Diagnosis and therapy for ampullary tumors: 63 cases. World J Surg. 1996 Jul-Aug;20(6):707-12.

123. Klinkenbijl JH, Jeekel J, Sahmoud T, van Pel R, Couvreur ML, Veenhof $\mathrm{CH}$, et al. Adjuvant radiotherapy and 5-fluorouracil after curative resection of cancer of the pancreas and periampullary region: phase III trial of the EORTC gastrointestinal tract cancer cooperative group. Ann Surg. 1999 Dec;230(6):776-82; discussion 82-4.

124. Bhatia S, Miller RC, Haddock MG, Donohue JH, Krishnan S. Adjuvant therapy for ampullary carcinomas: the Mayo Clinic experience. Int J Radiat Oncol Biol Phys. 2006 Oct 1;66(2):514-9.

125. Alves VAF BC, Vassallo J. . Manual de imunoistoquímica. São Paulo: Sociedade Brasileira de Patologia; 1999.

126. Kononen J, Bubendorf L, Kallioniemi A, Barlund M, Schraml P, Leighton S, et al. Tissue microarrays for high-throughput molecular profiling of tumor specimens. Nat Med. 1998 Jul;4(7):844-7.

127. Boone J, van Hillegersberg R, van Diest PJ, Offerhaus GJ, Rinkes IH, Kate FJ. Validation of tissue microarray technology in squamous cell carcinoma of the esophagus. Virchows Arch. 2008 May;452(5):507-14.

128. Moch $\mathrm{H}$, Kononen $\mathrm{T}$, Kallioniemi OP, Sauter G. Tissue microarrays: what will they bring to molecular and anatomic pathology? Adv Anat Pathol. 2001 Jan;8(1):14-20.

129. Gulmann C, Butler D, Kay E, Grace A, Leader M. Biopsy of a biopsy: validation of immunoprofiling in gastric cancer biopsy tissue microarrays. Histopathology. 2003 Jan;42(1):70-6.

130. Simon R, Mirlacher M, Sauter G. Tissue microarrays. Biotechniques. 2004 Jan;36(1):98-105.

131. Lee HW, Park YR, Sim J, Park RW, Kim WH, Kim JH. The tissue microarray object model: a data model for storage, analysis, and exchange of tissue microarray experimental data. Arch Pathol Lab Med. 2006 Jul;130(7):1004-13.

132. Hassan S, Ferrario C, Mamo A, Basik M. Tissue microarrays: emerging standard for biomarker validation. Curr Opin Biotechnol. 2008 Feb;19(1):19-25.

133. Carter JT, Grenert JP, Rubenstein L, Stewart L, Way LW. Tumors of the ampulla of vater: histopathologic classification and predictors of survival. J Am Coll Surg. 2008 Aug;207(2):210-8.

134. Gurbuz Y, Kloppel G. Differentiation pathways in duodenal and ampullary carcinomas: a comparative study on mucin and trefoil peptide expression, including gastric and colon carcinomas. Virchows Arch. 2004 Jun;444(6):536-41.

135. Sanada Y, Yoshida K, Konishi K, Oeda M, Ohara M, Tsutani Y. Expression of gastric mucin MUC5AC and gastric transcription factor SOX2 in ampulla of vater adenocarcinoma: 
comparison between expression patterns and histologic subtypes. Oncol Rep. 2006 May;15(5):1157-61.

136. Lau SK, Weiss LM, Chu PG. Differential expression of MUC1, MUC2, and MUC5AC in carcinomas of various sites: an immunohistochemical study. Am J Clin Pathol. 2004 Jul;122(1):61-9.

137. Mizoshita T, Tsukamoto T, Nakanishi H, Inada K, Ogasawara N, Joh T, et al. Expression of $\mathrm{Cdx} 2$ and the phenotype of advanced gastric cancers: relationship with prognosis. J Cancer Res Clin Oncol. 2003 Dec;129(12):727-34.

138. Ee HC, Erler T, Bhathal PS, Young GP, James RJ. Cdx-2 homeodomain protein expression in human and rat colorectal adenoma and carcinoma. Am J Pathol. 1995 Sep;147(3):586-92.

139. Ho SB, Niehans GA, Lyftogt C, Yan PS, Cherwitz DL, Gum ET, et al. Heterogeneity of mucin gene expression in normal and neoplastic tissues. Cancer Res. 1993 Feb 1;53(3):64151.

140. Vogelstein B, Fearon ER, Hamilton SR, Kern SE, Preisinger AC, Leppert M, et al. Genetic alterations during colorectal-tumor development. N Engl J Med. 1988 Sep 1;319(9):525-32.

141. Perzin KH, Bridge MF. Adenomas of the small intestine: a clinicopathologic review of 51 cases and a study of their relationship to carcinoma. Cancer. 1981 Aug 1;48(3):799-819.

142. Tasaka K. Carcinoma in the region of the duodenal papilla. A histopathologic study (author's transI)]. Fukuoka Igaku Zasshi. 1977 Jan;68(1):20-44.

143. Baczako K, Buchler M, Beger HG, Kirkpatrick CJ, Haferkamp O. Morphogenesis and possible precursor lesions of invasive carcinoma of the papilla of Vater: epithelial dysplasia and adenoma. Hum Pathol. 1985 Mar;16(3):305-10.

144. Agoff SN, Crispin DA, Bronner MP, Dail DH, Hawes SE, Haggitt RC. Neoplasms of the ampulla of vater with concurrent pancreatic intraductal neoplasia: a histological and molecular study. Mod Pathol. 2001 Mar;14(3):139-46.

145. Klempnauer J, Ridder GJ, Pichlmayr R. Prognostic factors after resection of ampullary carcinoma: multivariate survival analysis in comparison with ductal cancer of the pancreatic head. Br J Surg. 1995 Dec;82(12):1686-91.

146. Talbot IC, Neoptolemos JP, Shaw DE, Carr-Locke D. The histopathology and staging of carcinoma of the ampulla of Vater. Histopathology. 1988 Feb;12(2):155-65.

147. Talamini MA, Moesinger RC, Pitt HA, Sohn TA, Hruban RH, Lillemoe KD, et al. Adenocarcinoma of the ampulla of Vater. A 28-year experience. Ann Surg. 1997 May;225(5):590-9; discussion 9-600.

148. Kitamura H, Yonezawa S, Tanaka S, Kim YS, Sato E. Expression of mucin carbohydrates and core proteins in carcinomas of the ampulla of Vater: their relationship to prognosis. Jpn J Cancer Res. 1996 Jun;87(6):631-40.

149. Ajiki T, Kamigaki T, Hasegawa Y, Fujino Y, Suzuki Y, Takeyama Y, et al. Proliferating cell nuclear antigen, p53, and c-erbB-2 expression in relation to clinicopathological variables and prognosis in cancer of the ampulla of Vater. Hepatogastroenterology. 2001 SepOct;48(41):1266-70.

150. Takashima M, Ueki T, Nagai E, Yao T, Yamaguchi K, Tanaka M, et al. Carcinoma of the ampulla of Vater associated with or without adenoma: a clinicopathologic analysis of 198 cases with reference to p53 and Ki-67 immunohistochemical expressions. Mod Pathol. 2000 Dec;13(12):1300-7. 
151. Santini D, Tonini G, Vecchio FM, Borzomati D, Vincenzi B, Valeri S, et al. Prognostic value of $\mathrm{Bax}, \mathrm{Bcl}-2, \mathrm{p} 53$, and TUNEL staining in patients with radically resected ampullary carcinoma. J Clin Pathol. 2005 Feb;58(2):159-65.

152. Moore PS, Orlandini S, Zamboni G, Capelli P, Rigaud G, Falconi M, et al. Pancreatic tumours: molecular pathways implicated in ductal cancer are involved in ampullary but not in exocrine nonductal or endocrine tumorigenesis. Br J Cancer. 2001 Jan;84(2):253-62.

153. Franko J, Krasinskas AM, Nikiforova MN, Zarnescu NO, Lee KK, Hughes SJ, et al. Loss of heterozygosity predicts poor survival after resection of pancreatic adenocarcinoma. J Gastrointest Surg. 2008 Oct;12(10):1664-72; discussion 72-3.

154. Wintzer HO, Zipfel I, Schulte-Monting J, Hellerich U, von Kleist S. Ki-67 immunostaining in human breast tumors and its relationship to prognosis. Cancer. 1991 Jan $15 ; 67(2): 421-8$.

155. Tungekar MF, Gatter KC, Dunnill MS, Mason DY. Ki-67 immunostaining and survival in operable lung cancer. Histopathology. 1991 Dec;19(6):545-50.

156. Vaidya P, Yosida T, Sakakura T, Yatani R, Noguchi T, Kawarada Y. Combined analysis of expression of c-erbB-2, Ki-67 antigen, and tenascin provides a better prognostic indicator of carcinoma of the papilla of Vater. Pancreas. 1996 Mar;12(2):196-201.

157. Zhou XP, Hoang JM, Li YJ, Seruca R, Carneiro F, Sobrinho-Simoes M, et al. Determination of the replication error phenotype in human tumors without the requirement for matching normal DNA by analysis of mononucleotide repeat microsatellites. Genes Chromosomes Cancer. 1998 Feb;21(2):101-7.

158. Lucci-Cordisco E, Boccuto L, Neri G, Genuardi M. The use of microsatellite instability, immunohistochemistry and other variables in determining the clinical significance of MLH1 and MSH2 unclassified variants in Lynch syndrome. Cancer Biomark. 2006;2(1-2):11-27.

159. Marcus VA, Madlensky L, Gryfe R, Kim H, So K, Millar A, et al. Immunohistochemistry for hMLH1 and hMSH2: a practical test for DNA mismatch repair-deficient tumors. Am J Surg Pathol. 1999 Oct;23(10):1248-55.

160. Staebler A, Lax SF, Ellenson LH. Altered expression of hMLH1 and hMSH2 protein in endometrial carcinomas with microsatellite instability. Hum Pathol. 2000 Mar;31(3):354-8.

161. Fogt F, Zimmerman RL, Poremba C, Noffsinger AE, Alsaigh N, Rueschoff J. Immunohistochemical screening of mismatch repair genes hMLH1, hMSH2, and hMSH6 in dysplastic lesions of the colon. Appl Immunohistochem Mol Morphol. 2002 Mar;10(1):57-61. 162. Skarda J, Fridman E, Plevova P, Hajduch M, Radova L, Ofek E, et al. Prognostic value of hMLH1 and hMSH2 immunohistochemical expression in non-small cell lung cancer. $A$ tissue microarray study. Biomed Pap Med Fac Univ Palacky Olomouc Czech Repub. 2006 Nov;150(2):255-9.

163. Kassem HS, Varley JM, Hamam SM, Margison GP. Immunohistochemical analysis of expression and allelotype of mismatch repair genes (hMLH1 and hMSH2) in bladder cancer. Br J Cancer. 2001 Feb 2;84(3):321-8.

164. Geisler JP, Geisler HE, Miller GA, Wiemann MC, Zhou Z, Crabtree W. Immunohistochemical staining of the mismatch repair gene, $\mathrm{hMSH} 2$, and survival in patients with ovarian carcinoma. Eur J Gynaecol Oncol. 2000;21(3):237-40.

165. Manavis J, Gilham P, Davies R, Ruszkiewicz A. The immunohistochemical detection of mismatch repair gene proteins ( $\mathrm{MLH} 1, \mathrm{MSH} 2, \mathrm{MSH}$, and PMS2): practical aspects in antigen retrieval and biotin blocking protocols. Appl Immunohistochem Mol Morphol. 2003 Mar;11(1):73-7. 
166. Imai Y, Tsurutani N, Oda H, Inoue T, Ishikawa T. Genetic instability and mutation of the TGF-beta-receptor-II gene in ampullary carcinomas. Int J Cancer. 1998 May 4;76(3):40711.

167. Suto T, Habano W, Sugai T, Uesugi N, Kanno S, Saito K, et al. Infrequent microsatellite instability in biliary tract cancer. J Surg Oncol. 2001 Feb;76(2):121-6.

168. Kim H, Jen J, Vogelstein B, Hamilton SR. Clinical and pathological characteristics of sporadic colorectal carcinomas with DNA replication errors in microsatellite sequences. Am J Pathol. 1994 Jul;145(1):148-56.

169. Goggins M, Offerhaus GJ, Hilgers W, Griffin CA, Shekher M, Tang D, et al. Pancreatic adenocarcinomas with DNA replication errors (RER+) are associated with wild-type K-ras and characteristic histopathology. Poor differentiation, a syncytial growth pattern, and pushing borders suggest RER+. Am J Pathol. 1998 Jun;152(6):1501-7.

170. Wilentz RE, Goggins M, Redston M, Marcus VA, Adsay NV, Sohn TA, et al. Genetic, immunohistochemical, and clinical features of medullary carcinoma of the pancreas: A newly described and characterized entity. Am J Pathol. 2000 May;156(5):1641-51.

171. Luttges J, Beyser K, Pust S, Paulus A, Ruschoff J, Kloppel G. Pancreatic mucinous noncystic (colloid) carcinomas and intraductal papillary mucinous carcinomas are usually microsatellite stable. Mod Pathol. 2003 Jun;16(6):537-42.

172. Biemer-Huttmann AE, Walsh MD, McGuckin MA, Simms LA, Young J, Leggett BA, et al. Mucin core protein expression in colorectal cancers with high levels of microsatellite instability indicates a novel pathway of morphogenesis. Clin Cancer Res. 2000 May;6(5):1909-16.

173. Nakata B, Yashiro M, Nishioka N, Aya M, Yamada S, Takenaka C, et al. Very low incidence of microsatellite instability in intraductal papillary-mucinous neoplasm of the pancreas. Int J Cancer. 2002 Dec 20;102(6):655-9.

174. dos Santos NR, Seruca R, Constancia M, Seixas M, Sobrinho-Simoes M. Microsatellite instability at multiple loci in gastric carcinoma: clinicopathologic implications and prognosis. Gastroenterology. 1996 Jan;110(1):38-44.

175. Paulson TG, Wright FA, Parker BA, Russack V, Wahl GM. Microsatellite instability correlates with reduced survival and poor disease prognosis in breast cancer. Cancer Res. 1996 Sep 1;56(17):4021-6.

176. Kimura W, Ohtsubo K. Incidence, sites of origin, and immunohistochemical and histochemical characteristics of atypical epithelium and minute carcinoma of the papilla of Vater. Cancer. 1988 Apr 1;61(7):1394-402.

177. Hasleton PS, Shah S, Buckley CH, Tweedle DE. Ampullary carcinoma associated with multiple duodenal villous adenomas. Am J Gastroenterol. 1980 May;73(5):418-22.

178. Del Villano BC, Brennan S, Brock P, Bucher C, Liu V, McClure M, et al. Radioimmunometric assay for a monoclonal antibody-defined tumor marker, CA 19-9. Clin Chem. 1983 Mar;29(3):549-52.

179. Atkinson BF, Ernst CS, Herlyn M, Steplewski Z, Sears HF, Koprowski H. Gastrointestinal cancer-associated antigen in immunoperoxidase assay. Cancer Res. 1982 Nov;42(11):4820-3. 180. Kamisawa T, Fukayama M, Koike M, Tabata I, Egawa N, Isawa T, et al. Carcinoma of the ampulla of Vater: expression of cancer-associated antigens inversely correlated with prognosis. Am J Gastroenterol. 1988 Oct;83(10):1118-23. 
Apêndice 


\section{APÊNDICE 1: DADOS CLÍNICOS E LABORATORIAIS}

\begin{tabular}{|c|c|c|c|c|c|c|c|c|c|c|c|c|}
\hline $\mathrm{N}$ & RGHC & Sexo & Idade & $\begin{array}{c}\text { perda } \\
\text { peso }>10 \%\end{array}$ & $\begin{array}{l}\begin{array}{l}\text { Náuseas } \\
\text { vômitos }\end{array} \\
\end{array}$ & Icterícia & \begin{tabular}{|c|}
$\begin{array}{c}\text { Dor } \\
\text { abdominal }\end{array}$ \\
\end{tabular} & procedimento & \begin{tabular}{|c|} 
Data \\
Procedimento \\
\end{tabular} & \begin{tabular}{|l|}
$\mathrm{Hb}$ \\
$(\mathrm{g} / \mathrm{dl})$ \\
\end{tabular} & \begin{tabular}{|l|} 
bil \\
(g/dl) \\
\end{tabular} & $\begin{array}{l}\begin{array}{l}\text { Albumina } \\
\text { (g/dl) }\end{array} \\
\end{array}$ \\
\hline 1 & $13501588 \mathrm{E}$ & $\mathrm{F}$ & 70 & não & $\operatorname{sim}$ & não & não & $D P+V B$ & 12/6/1999 & 12,9 & 12,9 & 3,90 \\
\hline 2 & $2979292 \mathrm{~F}$ & $\mathrm{M}$ & 69 & não & não & não & $\operatorname{sim}$ & $\mathrm{DP}+\mathrm{VB}$ & $4 / 6 / 2001$ & 13,6 & 1 & 5,00 \\
\hline 3 & 2198956B & $\mathrm{M}$ & 50 & sim & não & sim & não & $G D P+V B$ & 29/07/1997 & 13,6 & 5,9 & 3,50 \\
\hline 4 & 2645364B & $\mathrm{M}$ & 67 & não & não & $\operatorname{sim}$ & não & $\mathrm{DP}+\mathrm{VB}$ & 23/02/1999 & 11,8 & 4,4 & 3,30 \\
\hline 5 & 2992320D & M & 69 & $\operatorname{sim}$ & $\operatorname{sim}$ & $\operatorname{sim}$ & $\operatorname{sim}$ & $G D P+V B$ & 21/06/1994 & 11 & 2,5 & 3,60 \\
\hline 6 & $2328936 \mathrm{C}$ & $\mathrm{M}$ & 53 & $\operatorname{sim}$ & $\operatorname{sim}$ & $\operatorname{sim}$ & $\operatorname{sim}$ & GDP+VB & $7 / 10 / 1995$ & 11 & 31,7 & 2,70 \\
\hline 7 & $3312961 \mathrm{E}$ & $\mathrm{F}$ & 67 & sim & não & não & $\operatorname{sim}$ & $G D P+V B$ & $22 / 3 / 2004$ & 12,6 & 1,1 & 3,90 \\
\hline 8 & $3297326 C$ & $\mathrm{M}$ & 69 & $\operatorname{sim}$ & não & $\operatorname{sim}$ & não & $D P+V B$ & 7/5/1999 & 13,2 & 12,2 & 3,40 \\
\hline 9 & $3252307 \mathrm{~B}$ & $\mathrm{~F}$ & 67 & $\operatorname{sim}$ & não & $\operatorname{sim}$ & $\operatorname{sim}$ & $\mathrm{DP}+\mathrm{VB}$ & $8 / 10 / 1998$ & 11,1 & 5,2 & \\
\hline 10 & 3185797J & $\mathrm{F}$ & 65 & $\operatorname{sim}$ & não & sim & sim & DP & $15 / 06 / 1999$ & 11,8 & 19,7 & 3,40 \\
\hline 11 & $3143460 \mathrm{~F}$ & $\mathrm{M}$ & 72 & $\operatorname{sim}$ & $\operatorname{sim}$ & $\operatorname{sim}$ & não & GDP+VB & $21 / 5 / 1996$ & 13,1 & 33 & 3,00 \\
\hline 12 & 32700951 & $\mathrm{~F}$ & 59 & não & não & $\operatorname{sim}$ & não & GDP & 4/1/1999 & 10,8 & 6,1 & 3,10 \\
\hline 13 & $3290850 \mathrm{D}$ & $\mathrm{M}$ & 54 & $\operatorname{sim}$ & não & $\operatorname{sim}$ & sim & DP & $31 / 08 / 1999$ & 11,6 & 1,5 & 3,10 \\
\hline 14 & $13613551 \mid$ & $\mathrm{M}$ & 73 & $\operatorname{sim}$ & não & sim & não & $D P+V B$ & $1 / 5 / 2004$ & 11,3 & 15,1 & 2,50 \\
\hline 15 & $3264506 \mathrm{~A}$ & $\mathrm{M}$ & 54 & $\operatorname{sim}$ & não & $\operatorname{sim}$ & não & $D P+V B$ & $17 / 11 / 1998$ & 12,2 & 20,8 & 2,50 \\
\hline 16 & $2872363 \mathrm{H}$ & $\mathrm{F}$ & 64 & sim & não & $\operatorname{sim}$ & não & $G D P+V B$ & $16 / 02 / 1995$ & 14,2 & 2,3 & 3,20 \\
\hline 17 & 13648633J & $\mathrm{M}$ & 65 & não & não & $\operatorname{sim}$ & não & $D P+V B$ & $14 / 9 / 2004$ & 9,9 & 16,6 & 3,10 \\
\hline 18 & $13529536 \mathrm{C}$ & $\mathrm{M}$ & 61 & não & não & não & $\operatorname{sim}$ & $D P+V B$ & $2 / 5 / 2001$ & 15 & 0,9 & 3,90 \\
\hline 19 & 3274648J & $\mathrm{M}$ & 68 & $\operatorname{sim}$ & $\operatorname{sim}$ & não & sim & DP & 18/01/1999 & 10,5 & 0,4 & \\
\hline 20 & $3164132 \mathrm{H}$ & $\mathrm{M}$ & 63 & $\operatorname{sim}$ & não & $\operatorname{sim}$ & não & GDP & $10 / 10 / 1996$ & 13,3 & 2,7 & 3,10 \\
\hline 21 & $3117316 \mathrm{~F}$ & $\mathrm{M}$ & 61 & $\operatorname{sim}$ & $\operatorname{sim}$ & sim & sim & $D P+V B$ & $26 / 12 / 1995$ & 11,2 & 2,4 & \\
\hline 22 & $3196258 \mathrm{H}$ & $\mathrm{M}$ & 47 & $\operatorname{sim}$ & não & $\operatorname{sim}$ & $\operatorname{sim}$ & GDP & $10 / 6 / 1997$ & 10,9 & 10 & 3,40 \\
\hline 23 & $5196320 \mathrm{E}$ & $\mathrm{M}$ & 64 & $\operatorname{sim}$ & não & sim & $\operatorname{sim}$ & $D P+V B$ & $8 / 6 / 2001$ & 10,1 & 1,2 & 3,20 \\
\hline 24 & 2968517B & $M$ & 70 & $\operatorname{sim}$ & não & não & não & $G D P+V B$ & $10 / 11 / 1994$ & 13,7 & 0,4 & 4,20 \\
\hline 25 & $2247189 \mathrm{~F}$ & $\mathrm{~F}$ & 74 & $\operatorname{sim}$ & $\operatorname{sim}$ & não & $\operatorname{sim}$ & $D P+V B$ & $10 / 6 / 2002$ & 11 & 0,7 & 3,90 \\
\hline 26 & $3246570 \mathrm{~J}$ & $\mathrm{~F}$ & 39 & $\operatorname{sim}$ & não & $\operatorname{sim}$ & $\operatorname{sim}$ & DP & $16 / 11 / 1998$ & 13,3 & 3,2 & 4,30 \\
\hline 27 & $3189828 \mathrm{~F}$ & $\mathrm{M}$ & 52 & não & não & não & não & $\mathrm{DP}+\mathrm{VB}$ & $8 / 4 / 1997$ & 15,2 & 0,5 & 4,60 \\
\hline 28 & $3186488 \mathrm{H}$ & $\mathrm{M}$ & 53 & $\operatorname{sim}$ & não & $\operatorname{sim}$ & $\operatorname{sim}$ & $G D P+V B$ & 4/3/1997 & 12,8 & 1,2 & \\
\hline 29 & 3177983E & $M$ & 47 & $\operatorname{sim}$ & $\operatorname{sim}$ & não & $\operatorname{sim}$ & DP & $2 / 2 / 1998$ & 15,4 & 0,6 & 4,27 \\
\hline 30 & 5055967I & $\mathrm{F}$ & 70 & $\operatorname{sim}$ & $\mathrm{sim}$ & $\operatorname{sim}$ & $\operatorname{sim}$ & $\mathrm{DP}+\mathrm{VB}$ & $26 / 11 / 2002$ & 11,3 & 1,4 & 3,10 \\
\hline 31 & $3268609 \mathrm{G}$ & $\mathrm{M}$ & 23 & não & não & sim & $\operatorname{sim}$ & $D P+V B$ & $14 / 12 / 1998$ & 11,7 & 21,6 & 2,90 \\
\hline 32 & $3284256 \mathrm{H}$ & $\mathrm{M}$ & 31 & $\operatorname{sim}$ & $\operatorname{sim}$ & não & $\operatorname{sim}$ & $D P+V B$ & 26/07/1999 & 9,5 & 0,8 & 3,80 \\
\hline 33 & 29835511 & $\mathrm{M}$ & 57 & $\operatorname{sim}$ & não & sim & $\operatorname{sim}$ & $G D P+V B$ & 27/06/1994 & 12,8 & 14,4 & 4,10 \\
\hline 34 & $13687478 \mathrm{D}$ & $\mathrm{F}$ & 61 & $\operatorname{sim}$ & $\operatorname{sim}$ & não & não & $\mathrm{DP}+\mathrm{VB}$ & $16 / 6 / 1985$ & 10,2 & 0,9 & 3,60 \\
\hline 35 & 31604921 & $\mathrm{~F}$ & 68 & não & não & $\operatorname{sim}$ & não & GDP+VB & $12 / 8 / 1996$ & 11,3 & 12,4 & 3,80 \\
\hline 36 & 134809621 & $\mathrm{M}$ & 64 & $\operatorname{sim}$ & $\operatorname{sim}$ & $\operatorname{sim}$ & $\operatorname{sim}$ & $\mathrm{DP}+\mathrm{VB}$ & $17 / 03 / 2003$ & 12,5 & 6,6 & 2,10 \\
\hline 37 & $13605625 \mathrm{~F}$ & $\mathrm{~F}$ & 68 & não & NT & $\operatorname{sim}$ & $\operatorname{sim}$ & DP & $11 / 4 / 2003$ & 9,2 & 25,1 & \\
\hline 38 & $13577745 \mathrm{~F}$ & $\mathrm{~F}$ & 64 & $\operatorname{sim}$ & não & $\operatorname{sim}$ & $\operatorname{sim}$ & $D P+V B$ & $11 / 6 / 2002$ & 13,2 & 2,9 & 3,60 \\
\hline 39 & $13520173 \mathrm{~K}$ & $\mathrm{M}$ & 59 & $\operatorname{sim}$ & não & sim & não & $D P+V B$ & $13 / 11 / 2000$ & 13,3 & 3 & 3,90 \\
\hline 40 & $13520610 \mathrm{~A}$ & $\mathrm{~F}$ & 65 & não & $\operatorname{sim}$ & $\operatorname{sim}$ & $\operatorname{sim}$ & DP & $12 / 12 / 2000$ & 12 & 27,5 & 2,80 \\
\hline 41 & 5067191K & $\mathrm{F}$ & 65 & $\operatorname{sim}$ & não & não & $\operatorname{sim}$ & $D P+V B$ & $22 / 10 / 2002$ & 10,4 & 0,4 & 4,10 \\
\hline 42 & 134874831 & $\mathrm{~F}$ & 51 & $\operatorname{sim}$ & $\operatorname{sim}$ & não & $\operatorname{sim}$ & $D P+V B$ & $25 / 08 / 2003$ & 15,4 & 0,4 & 4,30 \\
\hline 43 & $13495146 \mathrm{~A}$ & $\mathrm{M}$ & 83 & $\operatorname{sim}$ & não & não & não & $D P+V B$ & $15 / 7 / 2003$ & 13,1 & 1,2 & 2,80 \\
\hline 44 & $13627162 \mathrm{~F}$ & $\mathrm{~F}$ & 62 & não & $\operatorname{sim}$ & $\operatorname{sim}$ & não & $D P+V B$ & $13 / 4 / 2004$ & 8,9 & 7,9 & 3,00 \\
\hline
\end{tabular}




\begin{tabular}{|c|c|c|c|c|c|c|c|c|c|c|c|c|}
\hline 45 & $13659939 \mathrm{C}$ & $\mathrm{F}$ & 38 & $\operatorname{sim}$ & não & $\operatorname{sim}$ & $\operatorname{sim}$ & $D P+V B$ & $7 / 12 / 2004$ & 12,6 & 1,3 & 4,10 \\
\hline 46 & 2351629J & $M$ & 53 & não & não & não & $\operatorname{sim}$ & DP & $26 / 09 / 2000$ & 15,2 & 0,6 & 4,60 \\
\hline 47 & $2987402 G$ & $\mathrm{M}$ & 70 & $\operatorname{sim}$ & não & não & $\operatorname{sim}$ & $\mathrm{DP}+\mathrm{VB}$ & $31 / 03 / 1997$ & 11,6 & 0,7 & 4,00 \\
\hline 48 & 31731621 & $\mathrm{~F}$ & 34 & $\operatorname{sim}$ & $\operatorname{sim}$ & $\operatorname{sim}$ & $\operatorname{sim}$ & $G D P+V B$ & $12 / 11 / 1996$ & 10,5 & 7 & \\
\hline 49 & 3173317K & $\mathrm{F}$ & 64 & não & não & $\operatorname{sim}$ & não & $\mathrm{GDP}+\mathrm{VB}$ & $14 / 11 / 1996$ & 12 & 1,8 & \\
\hline 50 & $3012329 \mathrm{~J}$ & $\mathrm{M}$ & 68 & $\operatorname{sim}$ & não & $\operatorname{sim}$ & não & $\mathrm{GDP}+\mathrm{VB}$ & $24 / 10 / 1995$ & 13,2 & 8,7 & 4,10 \\
\hline 51 & 2960488B & $\mathrm{M}$ & 77 & $\operatorname{sim}$ & não & $\operatorname{sim}$ & não & $D P+V B$ & $21 / 05 / 2002$ & 10,2 & 1,5 & 3,60 \\
\hline 52 & $3279736 \mathrm{H}$ & $\mathrm{M}$ & 78 & $\operatorname{sim}$ & não & $\operatorname{sim}$ & não & DP & $15 / 03 / 1999$ & 10,3 & 2,3 & 2,90 \\
\hline 53 & $2956951 \mathrm{G}$ & $\mathrm{F}$ & 49 & não & $\operatorname{sim}$ & $\operatorname{sim}$ & $\operatorname{sim}$ & $G D P+V B$ & $5 / 2 / 1995$ & 12,4 & 2,6 & \\
\hline 54 & 29101011 & $\mathrm{M}$ & 64 & não & não & $\operatorname{sim}$ & não & $\mathrm{GDP}+\mathrm{VB}$ & $19 / 7 / 1993$ & 11,4 & 15,8 & 3,30 \\
\hline 55 & 136879041 & $M$ & 65 & $\operatorname{sim}$ & não & $\operatorname{sim}$ & não & $G D P+V B$ & $31 / 5 / 2005$ & 13,1 & 13,9 & 3,80 \\
\hline 56 & $3369458 \mathrm{~K}$ & $\mathrm{~F}$ & 68 & sim & não & sim & $\operatorname{sim}$ & $D P+V B$ & $21 / 9 / 2001$ & 10,5 & 3,3 & 3,40 \\
\hline 57 & $13567544 \mathrm{~J}$ & $\mathrm{M}$ & 68 & $\operatorname{sim}$ & não & $\operatorname{sim}$ & não & $D P+V B$ & $3 / 1 / 2002$ & 11,6 & 48,5 & 2,80 \\
\hline 58 & $13681185 B$ & $\mathrm{~F}$ & 68 & não & não & $\operatorname{sim}$ & $\operatorname{sim}$ & $D P+V B$ & $26 / 9 / 2006$ & & & \\
\hline 59 & $3313905 \mathrm{C}$ & $\mathrm{M}$ & 72 & $\operatorname{sim}$ & não & $\operatorname{sim}$ & $\operatorname{sim}$ & $D P+V B$ & 20/12/1999 & 12,5 & 1,9 & 2,90 \\
\hline 60 & 136021561 & $\mathrm{M}$ & 61 & não & & & & $\mathrm{DP}$ & $5 / 5 / 2005$ & 11,1 & 3,3 & 3,70 \\
\hline 61 & 2910303J & $\mathrm{M}$ & 39 & não & & $\operatorname{sim}$ & & $G D P+V B$ & 6/6/1993 & 11 & 5,7 & 3,90 \\
\hline 62 & $13676766 \mathrm{H}$ & $\mathrm{M}$ & 32 & $\operatorname{sim}$ & não & $\operatorname{sim}$ & $\operatorname{sim}$ & $\mathrm{DP}+\mathrm{VB}$ & $12 / 4 / 2005$ & 11,9 & 0,8 & 3,70 \\
\hline 63 & $13692377 \mathrm{~F}$ & $\mathrm{M}$ & 42 & $\operatorname{sim}$ & não & $\operatorname{sim}$ & não & $D P+V B$ & $28 / 6 / 2005$ & 7,3 & 17 & 2,90 \\
\hline 64 & $13658975 \mathrm{~K}$ & $M$ & 45 & $\operatorname{sim}$ & não & $\operatorname{sim}$ & $\operatorname{sim}$ & $D P+V B$ & $25 / 11 / 2004$ & 14,4 & 1,2 & 4,40 \\
\hline 65 & $2548538 B$ & $\mathrm{~F}$ & 53 & não & $\operatorname{sim}$ & $\operatorname{sim}$ & $\operatorname{sim}$ & GDP & $27 / 8 / 1992$ & 10,3 & 2,3 & 2,90 \\
\hline 66 & $13662384 B$ & $\mathrm{~F}$ & 69 & não & & & & $D P+V B$ & $28 / 12 / 2004$ & 11,3 & 1,6 & 3,90 \\
\hline 67 & 2901806J & $M$ & 63 & $\operatorname{sim}$ & $\operatorname{sim}$ & $\operatorname{sim}$ & $\operatorname{sim}$ & $G D P+V B$ & $8 / 3 / 1993$ & 13,9 & 7,2 & 1,80 \\
\hline 68 & $13450895 \mathrm{H}$ & $\mathrm{F}$ & 79 & $\operatorname{sim}$ & não & $\operatorname{sim}$ & não & $D P+V B$ & $18 / 7 / 2002$ & 12,8 & 2,5 & 4,00 \\
\hline 69 & $2860694 \mathrm{~B}$ & $\mathrm{M}$ & 60 & $\operatorname{sim}$ & $\operatorname{sim}$ & $\operatorname{sim}$ & $\operatorname{sim}$ & $D P+V B$ & $30 / 7 / 1992$ & 12,4 & 10,1 & 3,90 \\
\hline 70 & $2818636 \mathrm{H}$ & $\mathrm{F}$ & 59 & $\operatorname{sim}$ & não & $\operatorname{sim}$ & $\operatorname{sim}$ & $G D P+V B$ & $7 / 4 / 1992$ & 11 & 2,5 & 3,90 \\
\hline 71 & $13732448 \mathrm{~F}$ & $\mathrm{M}$ & 58 & & & $\operatorname{sim}$ & & $D P+V B$ & $23 / 5 / 2006$ & 12.6 & 8,2 & 2,40 \\
\hline 72 & 2012970J & $\mathrm{F}$ & 58 & $\operatorname{sim}$ & não & $\operatorname{sim}$ & não & GDP & $17 / 12 / 1982$ & 12,4 & 7,2 & \\
\hline 73 & $2750911 \mathrm{H}$ & $M$ & 34 & & & & & $\mathrm{GDP}+\mathrm{VB}$ & 1/1/1990 & & & \\
\hline 74 & 2535416B & $\mathrm{F}$ & 41 & não & $\operatorname{sim}$ & $\operatorname{sim}$ & $\operatorname{sim}$ & GDP & $29 / 6 / 1988$ & 10,5 & 28 & 4,40 \\
\hline 75 & $2510431 \mathrm{E}$ & $\mathrm{M}$ & 33 & $\operatorname{sim}$ & não & $\operatorname{sim}$ & $\operatorname{sim}$ & GDP & $4 / 12 / 1987$ & 12 & 15,6 & 4,20 \\
\hline 76 & 13663461B & $M$ & 69 & & & & & DP & $9 / 9 / 2005$ & 13,6 & 0,9 & 3,10 \\
\hline 77 & $13757874 C$ & $\mathrm{M}$ & 46 & & & & & $D P+V B$ & $7 / 11 / 2006$ & 14,6 & 0,4 & 4,30 \\
\hline 78 & $2815893 \mathrm{~K}$ & $\mathrm{~F}$ & 77 & & & & & $\mathrm{GDP}+\mathrm{VB}$ & 4/11/1991 & & & \\
\hline 79 & 2792144E & $\mathrm{M}$ & 60 & & & & & GDP & 1/7/1991 & & & \\
\hline 80 & $13746393 \mathrm{G}$ & $\mathrm{F}$ & 74 & não & não & não & não & DP & $8 / 8 / 2006$ & 10.7 & 0,8 & 4,10 \\
\hline 81 & $13719096 \mathrm{H}$ & $\mathrm{M}$ & 54 & $\operatorname{sim}$ & não & $\operatorname{sim}$ & não & $D P+V B$ & $17 / 1 / 2006$ & 10,3 & 28,1 & 2,80 \\
\hline 82 & $2298291 \mathrm{E}$ & $\mathrm{M}$ & 30 & sim & não & $\operatorname{sim}$ & $\operatorname{sim}$ & GDP & 26/9/1983 & 10 & 5 & 3,80 \\
\hline 83 & 25318451 & $\mathrm{M}$ & 55 & não & não & $\operatorname{sim}$ & $\operatorname{sim}$ & $D P+V B$ & $20 / 3 / 2006$ & 9,6 & 1,5 & 3,50 \\
\hline 84 & 27672331 & $\mathrm{~F}$ & 59 & & & & & GDP & $1 / 6 / 1992$ & 11 & & 4,20 \\
\hline 85 & $2945535 C$ & $\mathrm{M}$ & 55 & $\operatorname{sim}$ & não & $\operatorname{sim}$ & não & $\mathrm{GDP}+\mathrm{VB}$ & $13 / 7 / 1981$ & 9,7 & 27,9 & 2,40 \\
\hline 86 & 20910361 & $\mathrm{~F}$ & 47 & $\operatorname{sim}$ & $\operatorname{sim}$ & não & $\operatorname{sim}$ & $\mathrm{GDP}+\mathrm{VB}$ & $15 / 7 / 1985$ & 9,9 & 0,6 & 3,80 \\
\hline 87 & $13739854 \mathrm{~K}$ & $\mathrm{~F}$ & 71 & & & & & $D P+V B$ & $11 / 7 / 2006$ & 14,4 & 2,7 & 2,60 \\
\hline 88 & $2683556 C$ & $\mathrm{~F}$ & 44 & $\operatorname{sim}$ & $\operatorname{sim}$ & $\operatorname{sim}$ & $\operatorname{sim}$ & GDP & $21 / 2 / 1990$ & & & \\
\hline 89 & 33382261 & 2 & 78 & & $\operatorname{sim}$ & $\operatorname{sim}$ & $\operatorname{sim}$ & $D P+V B$ & $16 / 6 / 2000$ & 8,9 & 7,1 & 2,50 \\
\hline 90 & 25065001 & $M$ & 62 & não & não & não & 2 & $D P+V B$ & $10 / 1 / 2006$ & 13,3 & 2,3 & 4,10 \\
\hline 91 & $2804319 \mathrm{E}$ & 2 & 58 & $\operatorname{sim}$ & $\operatorname{sim}$ & $\operatorname{sim}$ & $\operatorname{sim}$ & $\mathrm{GDP}+\mathrm{VB}$ & $12 / 12 / 1991$ & 10,3 & & 3,20 \\
\hline 92 & $13725124 \mathrm{H}$ & 2 & 57 & & & $\operatorname{sim}$ & & $D P+V B$ & $9 / 5 / 2006$ & 12,6 & 0,3 & 4,20 \\
\hline
\end{tabular}




\begin{tabular}{|l|l|l|l|l|l|l|l|l|l|l|c|c|}
93 & $13784253 \mathrm{I}$ & $\mathrm{M}$ & 64 & não & não & $\operatorname{sim}$ & $\operatorname{sim}$ & $\mathrm{DP}+\mathrm{VB}$ & $19 / 6 / 2007$ & 8,9 & 1,9 & 4,40 \\
\hline 94 & $13784346 \mathrm{E}$ & $\mathrm{M}$ & 67 & não & não & não & $\operatorname{sim}$ & DP+VB & $4 / 6 / 2007$ & 13,9 & 0,6 & 3,50 \\
\hline 95 & $2414399 \mathrm{C}$ & 2 & 69 & & & $\operatorname{sim}$ & não & GDP & $30 / 12 / 1985$ & 12,1 & 9,2 & \\
\hline 96 & $2071719 \mathrm{G}$ & $\mathrm{M}$ & 39 & & & $\operatorname{sim}$ & não & GDP+VB & $12 / 1 / 1979$ & 12.4 & 19 & 3,4 \\
\hline 97 & $2485469 \mathrm{E}$ & $\mathrm{M}$ & 76 & & & $\operatorname{sim}$ & não & DP & $27 / 5 / 1987$ & 13,6 & 13,7 & \\
\hline
\end{tabular}

\section{LEGENDA:}

RGHC; registro geral do Hospital das Clínicas

Sexo: $M$, masculino; $F$, feminino

Procedimento: DP, duodenopancreatectomia; VB, colecistectomia; GDP, gastroduodenopancreatectomia

$\%$, por cento

$\mathrm{Hb}$, hemoglobina

Bil, bilirrubina

$\mathrm{g} / \mathrm{dl}$, gramas por decilitro 


\section{APÊNDICE 2: DADOS ANATOMOPATOLÓGICOS}

\begin{tabular}{|c|c|c|c|c|c|c|c|c|c|c|c|}
\hline $\mathrm{N}$ & Diag. patológico & tipo histológico & Tam & \begin{tabular}{|l|} 
Gânglios \\
positivos
\end{tabular} & \begin{tabular}{|l|} 
Gânglios \\
Dissecados
\end{tabular} & Grau dif & \begin{tabular}{|l|} 
Inv \\
Vasc \\
\end{tabular} & \begin{tabular}{|l|} 
Inv \\
Linf \\
\end{tabular} & \begin{tabular}{|l|} 
Inv \\
Neur \\
\end{tabular} & estadio & TNM \\
\hline 1 & adenocarcinoma & padrão intestinal & 3,0 & 1 & 14 & $\bmod$ & 0 & 0 & 0 & T2N1 & IIB \\
\hline 2 & adenocarcinoma & padrão intestinal & 1,5 & 0 & 10 & $\bmod$ & 0 & 0 & 1 & T3N1 & IIB \\
\hline 3 & adenocarcinoma & padrão intestinal & 1,3 & 0 & 22 & $\bmod$ & 0 & 1 & 0 & T3NO & IIA \\
\hline 4 & adenocarcinoma & padrão bilio - pancreático & 1,0 & 0 & 6 & $\bmod$ & 0 & 0 & 0 & T1NO & IA \\
\hline 5 & adenocarcinoma & padrão intestinal & 2,0 & 0 & 22 & $\bmod$ & 1 & 1 & 0 & T3NO & IIA \\
\hline 6 & adenocarcinoma & padrão bilio - pancreático & 3,0 & 6 & 28 & $\bmod$ & 0 & 1 & 1 & T3N1 & IIB \\
\hline 7 & adenocarcinoma & padrão bilio - pancreático & 2,0 & 0 & 17 & $\bmod$ & 0 & 0 & 1 & T3NO & IIA \\
\hline 8 & adenocarcinoma & padrão intestinal & 3,0 & 0 & 20 & $\bmod$ & 0 & 0 & 0 & T1NO & IA \\
\hline 9 & adenocarcinoma & padrão intestinal & 1,5 & 1 & 11 & $\bmod$ & 0 & 1 & 1 & T3N1 & IIB \\
\hline 10 & adenocarcinoma & padrão bilio - pancreático & 3,0 & 0 & 13 & $\bmod$ & 0 & 1 & 0 & T3NO & IIA \\
\hline 11 & adenocarcinoma & padrão intestinal & 1,0 & 0 & 10 & $\bmod$ & 0 & 0 & 0 & T1NO & IA \\
\hline 12 & adenocarcinoma & padrão bilio - pancreático & 1,7 & 0 & 15 & $\bmod$ & 0 & 1 & 0 & T3NO & IIA \\
\hline 13 & adenocarcinoma & padrão intestinal & 8,0 & 1 & 20 & $\bmod$ & 0 & 0 & 0 & T2N1 & IIB \\
\hline 14 & adenocarcinoma & padrão intestinal & 0,7 & 0 & 5 & $\bmod$ & 0 & 1 & 0 & T3NO & IIA \\
\hline 15 & adenocarcinoma & padrão bilio - pancreático & 3,5 & 4 & 6 & pouco & 0 & 1 & 1 & T3N1 & IIB \\
\hline 16 & adenocarcinoma & mucinoso & 3,0 & 0 & 13 & $\bmod$ & 0 & 1 & 1 & T3NO & IIA \\
\hline 17 & adenocarcinoma & padrão bilio - pancreático & 2,5 & 1 & 12 & pouco & 0 & 1 & 0 & T3N1 & IIB \\
\hline 18 & adenocarcinoma & padrão intestinal & 1,5 & 0 & 11 & $\bmod$ & 0 & 0 & 1 & T3NO & IIA \\
\hline 19 & adenocarcinoma & padrão bilio - pancreático & 4,0 & 6 & 9 & $\bmod$ & 0 & 0 & 1 & T3N1 & IIB \\
\hline 20 & adenocarcinoma & padrão bilio - pancreático & 1,8 & 10 & 15 & $\bmod$ & 1 & 1 & 1 & T3N1 & IIB \\
\hline 21 & adenocarcinoma & padrão intestinal & 1,3 & 0 & 19 & $\bmod$ & 0 & 0 & 0 & T1NO & IA \\
\hline 22 & adenocarcinoma & padrão bilio - pancreático & 1,0 & 0 & 26 & pouco & 0 & 1 & 1 & T3NO & IIA \\
\hline 23 & adenocarcinoma & padrão intestinal & 3,5 & 0 & 13 & bem & 0 & 0 & 0 & T2NO & IB \\
\hline 24 & adenocarcinoma & mucinoso & 3,0 & 0 & 47 & bem & 0 & 0 & 0 & T2NO & IB \\
\hline 25 & adenocarcinoma & mucinoso & 3,0 & 5 & 16 & $\bmod$ & 0 & 0 & 0 & T2N1 & IIB \\
\hline 26 & adenocarcinoma & padrão intestinal & 3,5 & 1 & 1 & $\bmod$ & 0 & 0 & 0 & T2N1 & IIB \\
\hline 27 & adenocarcinoma & padrão intestinal & 1,9 & 0 & 23 & pouco & 0 & 0 & 0 & T1NO & IA \\
\hline 28 & adenocarcinoma & padrão intestinal & 5,0 & 0 & 16 & pouco & 0 & 1 & 0 & T3NO & IIA \\
\hline 29 & adenocarcinoma & padrão bilio - pancreático & 1,0 & 0 & 0 & bem & 0 & 0 & 0 & T1NO & IA \\
\hline 30 & adenocarcinoma & padrão bilio - pancreático & 1,5 & 0 & 18 & $\bmod$ & 0 & 0 & 0 & T1NO & IA \\
\hline 31 & adenocarcinoma & padrão bilio - pancreático & 1,5 & 3 & 22 & $\bmod$ & 0 & 1 & 0 & T3N1 & IIB \\
\hline 32 & adenocarcinoma & padrão intestinal & 6,0 & 0 & 23 & $\bmod$ & 0 & 0 & 0 & T2NO & IB \\
\hline 33 & adenocarcinoma & padrão bilio - pancreático & 2,4 & 9 & 16 & bem & 0 & 1 & 1 & T3N1 & IIB \\
\hline 34 & adenocarcinoma & padrão bilio - pancreático & 1,2 & 3 & 4 & mod & 0 & 0 & 0 & T1N1 & IIB \\
\hline 35 & adenocarcinoma & padrão intestinal & 2,5 & 0 & 15 & bem & 0 & 0 & 0 & T2NO & IB \\
\hline 36 & adenocarcinoma & padrão intestinal & 1,5 & 1 & 1 & pouco & 0 & 1 & 0 & T3N1 & IIB \\
\hline 37 & adenocarcinoma & padrão bilio - pancreático & 2,0 & 0 & 4 & $\bmod$ & 0 & 1 & 0 & T3NO & IIA \\
\hline 38 & adenocarcinoma & padrão bilio - pancreático & 1,4 & 0 & 17 & bem & 0 & 0 & 0 & T1NO & IA \\
\hline 39 & adenocarcinoma & padrão bilio - pancreático & 2,0 & 0 & 8 & $\bmod$ & 0 & 0 & 0 & T1NO & IA \\
\hline 40 & adenocarcinoma & padrão intestinal & 3,0 & 0 & 11 & $\bmod$ & 0 & 0 & 0 & T2NO & IB \\
\hline 41 & adenocarcinoma & padrão intestinal & 1,2 & 0 & 6 & bem & 0 & 0 & 0 & T1NO & IA \\
\hline 42 & adenocarcinoma & padrão bilio - pancreático & 1,5 & 0 & 10 & bem & 0 & 0 & 1 & T3NO & IIA \\
\hline 43 & adenocarcinoma & padrão bilio - pancreático & 1,5 & 4 & 26 & pouco & 0 & 1 & 0 & T3N1 & IIB \\
\hline 44 & adenocarcinoma & mucinoso & 3,5 & 0 & 16 & bem & 0 & 0 & 1 & T3NO & IIA \\
\hline
\end{tabular}




\begin{tabular}{|c|c|c|c|c|c|c|c|c|c|c|c|}
\hline 45 & adenocarcinoma & padrão bilio - pancreático & 1,5 & 0 & 1 & $\bmod$ & 0 & $\mid 1$ & 1 & T3NO & IIA \\
\hline 46 & adenocarcinoma & padrão intestinal & 2,2 & 0 & 38 & $\bmod$ & 0 & 0 & 0 & T2NO & IB \\
\hline 47 & adenocarcinoma & padrão intestinal & 4,0 & 6 & 6 & mod & 0 & 1 & 0 & T3N1 & IIB \\
\hline 48 & adenocarcinoma & padrão intestinal & 5,0 & 0 & 8 & $\bmod$ & 0 & 0 & 0 & T2NO & IB \\
\hline 49 & adenocarcinoma & padrão intestinal & 1,5 & 0 & 36 & $\bmod$ & 0 & 0 & 0 & T1NO & IA \\
\hline 50 & adenocarcinoma & padrão bilio - pancreático & 3,0 & 1 & 20 & $\bmod$ & 0 & 0 & 1 & T3N1 & IIB \\
\hline 51 & adenocarcinoma & padrão intestinal & 2,0 & 0 & 6 & $\bmod$ & 1 & 0 & 1 & T3NO & IIA \\
\hline 52 & adenocarcinoma & padrão intestinal & 3,0 & 0 & 24 & $\bmod$ & 0 & 1 & 0 & T3NO & IIA \\
\hline 53 & adenocarcinoma & padrão intestinal & 0,3 & 0 & 10 & bem & 0 & 0 & 0 & T1NO & IA \\
\hline 54 & adenocarcinoma & padrão intestinal & 2,5 & 0 & 24 & $\bmod$ & 0 & 0 & 0 & T2NO & IB \\
\hline 55 & adenocarcinoma & padrão bilio - pancreático & 2,5 & 0 & 12 & $\bmod$ & 0 & 1 & 1 & T3NO & IIA \\
\hline 56 & adenocarcinoma & padrão intestinal & 3,5 & 0 & 15 & bem & 0 & 0 & 0 & T2NO & IB \\
\hline 57 & adenocarcinoma & padrão bilio - pancreático & 1,5 & 2 & 7 & $\bmod$ & 1 & 0 & 1 & T3N1 & IIB \\
\hline 58 & adenocarcinoma & padrão bilio - pancreático & 2,5 & 1 & 4 & $\bmod$ & 0 & 1 & 1 & T3N1 & IIB \\
\hline 59 & adenocarcinoma & padrão intestinal & 2,1 & 0 & 19 & $\bmod$ & 0 & 0 & 0 & T2NO & IB \\
\hline 60 & adenocarcinoma & padrão intestinal & 3,5 & 0 & 3 & bem & 0 & 0 & 0 & T2NO & IB \\
\hline 61 & adenoescamoso & adenoecamoso & 2,6 & 2 & 29 & pouco & 0 & 1 & 0 & T3N1 & IIB \\
\hline 62 & adenocarcinoma & padrão intestinal & 3,5 & 0 & 18 & $\bmod$ & 0 & 0 & 0 & T2NO & IB \\
\hline 63 & adenocarcinoma & padrão bilio - pancreático & 4,5 & 4 & 16 & $\bmod$ & 1 & 1 & 0 & T3N1M1 & IV \\
\hline 64 & adenocarcinoma & padrão bilio - pancreático & 2,3 & 1 & 7 & $\bmod$ & 0 & 0 & 0 & T2N1 & IIB \\
\hline 65 & adenocarcinoma & padrão intestinal & 6,0 & 4 & 37 & bem & 0 & 0 & 0 & T2N1 & IIB \\
\hline 66 & adenocarcinoma & padrão bilio - pancreático & 4,3 & 0 & 2 & bem & 0 & 0 & 0 & T2NO & IB \\
\hline 67 & adenocarcinoma & mucinoso & 6,0 & 2 & 9 & bem & 0 & 0 & 0 & T2N1 & IIB \\
\hline 68 & adenocarcinoma & padrão intestinal & 3,0 & 0 & 13 & bem & 0 & 0 & 0 & T2NO & IB \\
\hline 69 & acenocarcinoma & células claras & 1,5 & 0 & 31 & $\bmod$ & 0 & 0 & 0 & T1NO & IA \\
\hline 70 & adenocarcinoma & padrão bilio - pancreático & 1,5 & 2 & 21 & $\bmod$ & 0 & 1 & 1 & T3N1 & IIB \\
\hline 71 & adenocarcinoma & padrão bilio - pancreático & 2,3 & 0 & 0 & $\bmod$ & 0 & 0 & 0 & T2NO & IB \\
\hline 72 & adenocarcinoma & padrão bilio - pancreático & 3,0 & 1 & 11 & $\bmod$ & 0 & 0 & 0 & T2N1 & IIB \\
\hline 73 & adenocarcinoma & padrão bilio - pancreático & 1,5 & 0 & 39 & bem & 0 & 0 & 0 & T1NO & IA \\
\hline 74 & adenocarcinoma & padrão bilio - pancreático & 2,5 & 0 & 9 & $\bmod$ & 0 & 0 & 0 & T2NO & IB \\
\hline 75 & adenocarcinoma & padrão bilio - pancreático & 1,5 & 0 & 13 & $\bmod$ & 0 & 0 & 0 & T1NO & IA \\
\hline 76 & adenocarcinoma & padrão bilio - pancreático & 2,9 & 3 & 6 & pouco & 0 & 0 & 0 & T2N1 & IIB \\
\hline 77 & adenocarcinoma & padrão intestinal & 2 & 0 & 7 & $\bmod$ & 0 & 0 & 0 & T1NO & IA \\
\hline 78 & adenocarcinoma & padrão bilio - pancreático & 2,0 & 0 & 8 & $\bmod$ & 0 & 0 & 0 & T1NO & IA \\
\hline 79 & adenocarcinoma & padrão intestinal & 3,0 & 1 & 11 & pouco & 0 & 0 & 0 & T2N1 & IIB \\
\hline 80 & adenocarcinoma & padrão intestinal & 2,0 & 0 & 5 & $\bmod$ & 0 & 0 & 0 & T1NO & IA \\
\hline 81 & adenocarcinoma & padrão intestinal & 2,0 & 0 & 8 & $\bmod$ & 0 & 0 & 0 & T1NO & IA \\
\hline 82 & adenocarcinoma & padrão bilio - pancreático & 1,0 & 1 & 5 & $\bmod$ & 0 & 0 & 0 & T1N1 & IIB \\
\hline 83 & adenocarcinoma & padrão bilio - pancreático & 7,0 & 3 & 10 & pouco & 0 & 0 & 0 & T2N1 & IIB \\
\hline 84 & adenocarcinoma & padrão bilio - pancreático & 2,0 & 0 & 38 & $\bmod$ & 0 & 0 & 0 & T1NO & IA \\
\hline 85 & adenocarcinoma & padrão bilio - pancreático & 3,0 & 0 & 7 & $\bmod$ & 0 & 0 & 1 & T3NO & IIA \\
\hline 86 & adenocarcinoma & padrão intestinal & 2,5 & 0 & 4 & $\bmod$ & 0 & 0 & 0 & T2NO & IB \\
\hline 87 & adenocarcinoma & padrão bilio - pancreático & 1,0 & 1 & 11 & $\bmod$ & 1 & 1 & 0 & T3N1 & IIB \\
\hline 88 & adenocarcinoma & padrão bilio - pancreático & 3,0 & 0 & 4 & $\bmod$ & 0 & 1 & 1 & T3NO & IIA \\
\hline 89 & adenocarcinoma & $\begin{array}{l}\text { padrão bilio - } \\
\text { pancreáticos }\end{array}$ & 4,5 & 0 & 3 & $\bmod$ & 0 & 0 & 0 & T2NO & IB \\
\hline 90 & adenocarcinoma & padrão intestinal & 2,0 & 0 & 5 & bem & 0 & 0 & 0 & T1NO & IA \\
\hline 91 & adenocarcinoma & padrão bilio - pancreático & 2,5 & 1 & 7 & bem & 0 & 0 & 0 & T2N1 & IIB \\
\hline 92 & adenocarcinoma & padrão intestinal & 2,4 & 0 & 12 & bem & 0 & 0 & 0 & T2NO & IB \\
\hline
\end{tabular}




\begin{tabular}{|l|l|l|l|l|l|l|l|l|l|l|l|}
93 & adenocarcinoma & padrão intestinal & 2,0 & 0 & 14 & bem & 0 & 0 & 0 & T1N0 & IA \\
\hline 94 & adenocarcinoma & padrão intestinal & 1,5 & 0 & 4 & bem & 0 & 0 & 0 & T1N0 & IA \\
\hline 95 & adenocarcinoma & padrão bilio - pancreático & 3,0 & 2 & 5 & mod & 0 & 0 & 0 & T2N1 & IIB \\
\hline 96 & adenocarcinoma & padrão bilio - pancreático & 2,0 & 0 & 2 & pouco & 0 & 0 & 0 & T1N0 & IA \\
\hline 97 & adenocarcinoma & padrão bilio - pancreático & 1,5 & 0 & 4 & mod & 0 & 0 & 0 & T1N0 & IA \\
\hline
\end{tabular}

\section{LEGENDA}

Diag., diagnóstico

Tam, tamanho, diâmetro tumoral no maior eixo

Grau dif, grau de diferenciação tumoral

Inv. Vasc., invasão vascular

Inv. Linf., invasão linfática

Inv. Neur., invasão neural

TNM, vide anexo 1 


\section{APÊNDICE 3: RESULTADOS DAS ANÁLISES IMUNOISTOQUÍMICAS}

\begin{tabular}{|c|c|c|c|c|c|c|c|c|c|c|c|c|c|c|c|c|c|}
\hline $\mathrm{N}$ & MUC1 & MUC2 & MUC6 & CK7 & CK20 & P53 & P16 & KI67 & CK17 & CD10 & CEA & CA19-9 & CDX2 & MUC5AC & MLH2 & MSH1 & MSH6 \\
\hline 1 & 0 & 1 & 1 & 0 & 1 & 1 & 1 & 0 & 0 & 1 & 1 & 0 & 1 & 1 & 1.0 & 1.0 & 1.0 \\
\hline 2 & 1 & 1 & 1 & 1 & 1 & 1 & 1 & 1 & 1 & 1 & 1 & 1 & 1 & 1 & 1.0 & 1.0 & 1.0 \\
\hline 3 & 1 & 0 & 0 & 1 & 1 & 1 & 0 & 0 & 1 & 1 & 1 & 0 & 1 & 1 & 1.0 & 1.0 & 1.0 \\
\hline 4 & 1 & 0 & 1 & 0 & 1 & 0 & 0 & 1 & 1 & 1 & 0 & 1 & 1 & 1 & 1.0 & 1.0 & 1.0 \\
\hline 5 & 1 & 1 & 0 & 0 & 1 & 1 & 1 & 0 & 0 & 1 & 1 & 1 & 1 & 0 & 1.0 & 1.0 & 1.0 \\
\hline 6 & 1 & 0 & 0 & 1 & 0 & 0 & 0 & 0 & 1 & 0 & 0 & 1 & 0 & 1 & 1.0 & 1.0 & 1.0 \\
\hline 7 & 1 & 0 & 1 & 1 & 0 & 0 & 0 & 0 & 1 & 1 & 0 & 1 & 0 & 1 & 1.0 & 1.0 & 1.0 \\
\hline 8 & 1 & 1 & 1 & 1 & 0 & 0 & 1 & 1 & 0 & 0 & 0 & 1 & 0 & 1 & 1.0 & 1.0 & 1.0 \\
\hline 9 & 1 & 0 & 1 & 0 & 1 & 0 & 1 & 0 & 1 & 1 & 1 & 1 & 1 & 1 & 1.0 & 1.0 & 1.0 \\
\hline 10 & 1 & 1 & 1 & 1 & 0 & 1 & 1 & 1 & 0 & 1 & 1 & 1 & 0 & 1 & 1.0 & 1.0 & 0.0 \\
\hline 11 & 1 & 0 & 1 & 1 & 0 & 1 & 0 & 0 & 1 & 1 & 1 & 1 & 1 & 1 & 0.0 & 1.0 & 0.0 \\
\hline 12 & 1 & 0 & 0 & 1 & 1 & 1 & 0 & 0 & 1 & 0 & 1 & 1 & 0 & 1 & 1.0 & 1.0 & 1.0 \\
\hline 13 & 0 & 1 & 0 & 1 & 1 & 1 & 1 & 0 & 0 & 1 & 1 & 1 & 1 & 0 & 1.0 & 1.0 & 1.0 \\
\hline 14 & 0 & 1 & 0 & 1 & 1 & 0 & 0 & 1 & 0 & 1 & 1 & 1 & 1 & 1 & 1.0 & 1.0 & 1.0 \\
\hline 15 & 1 & 0 & 0 & 1 & 0 & 1 & 0 & 0 & 1 & 0 & 1 & 1 & 0 & 0 & 1.0 & 1.0 & 1.0 \\
\hline 16 & 0 & 1 & 0 & 0 & 1 & 0 & 0 & 0 & 0 & 1 & 1 & 0 & 1 & 0 & 1.0 & 1.0 & 1.0 \\
\hline 17 & 1 & 0 & 0 & 1 & 0 & 1 & 0 & 0 & 1 & 0 & 1 & 1 & 0 & 0 & 1.0 & 1.0 & 1.0 \\
\hline 18 & 0 & 0 & 1 & 1 & 0 & 0 & 1 & 0 & 1 & 0 & 1 & 1 & 1 & 1 & 1.0 & 1.0 & 1.0 \\
\hline 19 & 1 & 1 & 1 & 1 & 1 & 0 & 1 & 1 & 1 & 1 & 1 & 1 & 0 & 1 & 1.0 & 1.0 & 1.0 \\
\hline 20 & 1 & 1 & 1 & 1 & 1 & 0 & 0 & 0 & 1 & 1 & 1 & 1 & 0 & 1 & 1.0 & 1.0 & 1.0 \\
\hline 21 & 0 & 1 & 1 & 1 & 1 & 0 & 0 & 0 & 1 & 0 & 1 & 1 & 1 & 1 & 1.0 & 1.0 & 1.0 \\
\hline 22 & 1 & 0 & 0 & 1 & 0 & 1 & 1 & 1 & 1 & 1 & 1 & 1 & 0 & 1 & 1.0 & 1.0 & 1.0 \\
\hline 23 & 1 & 1 & 1 & 1 & 1 & 1 & 0 & 0 & 0 & 1 & 0 & 1 & 1 & 1 & 1.0 & 1.0 & 1.0 \\
\hline 24 & 1 & 1 & 0 & 1 & 1 & 1 & 1 & 0 & 1 & 1 & 1 & 1 & 1 & 1 & 1.0 & 1.0 & 1.0 \\
\hline 25 & 1 & 1 & 1 & 1 & 1 & 1 & 1 & 0 & 1 & 0 & 1 & 1 & 1 & 1 & 1.0 & 1.0 & 1.0 \\
\hline 26 & 0 & 1 & 0 & 1 & 1 & 1 & 1 & 0 & 0 & 1 & 1 & 0 & 1 & 0 & 1.0 & 1.0 & 1.0 \\
\hline 27 & 1 & 0 & 1 & 1 & 0 & 1 & 0 & 1 & 0 & 1 & 1 & 1 & 0 & 0 & 1.0 & 1.0 & 0.0 \\
\hline 28 & 1 & 1 & 1 & 1 & 1 & 1 & 0 & 0 & 1 & 1 & 1 & 1 & 1 & 1 & 1.0 & 1.0 & 0.0 \\
\hline 29 & 0 & 0 & 0 & 1 & 0 & 1 & 1 & 0 & 0 & 1 & 1 & 1 & 0 & 1 & 1.0 & 1.0 & 1.0 \\
\hline 30 & 1 & 0 & 0 & 1 & 1 & 0 & 0 & 0 & 1 & 1 & 1 & 1 & 1 & 1 & 1.0 & 1.0 & 1.0 \\
\hline 31 & 0 & 0 & 1 & 1 & 0 & 1 & 0 & 0 & 0 & 1 & 0 & 1 & 0 & 1 & & 1.0 & 1.0 \\
\hline 32 & 1 & 1 & 0 & 0 & 1 & 0 & 0 & 1 & 1 & 1 & 1 & 1 & 1 & 0 & 1.0 & 1.0 & 1.0 \\
\hline 33 & 1 & 1 & 1 & 1 & 1 & 1 & 0 & 0 & 1 & 1 & 1 & 1 & 0 & 0 & 1.0 & 1.0 & 1.0 \\
\hline 34 & 1 & 0 & 1 & 1 & 0 & 1 & 1 & 1 & 1 & 1 & 1 & 1 & 0 & 1 & 1.0 & 1.0 & 1.0 \\
\hline 35 & 0 & 0 & 0 & 1 & 0 & 1 & 0 & 0 & 1 & 1 & 1 & 1 & 0 & 1 & 1.0 & 1.0 & 0.0 \\
\hline 36 & 1 & 1 & 1 & 1 & 1 & 1 & 1 & 1 & 1 & 1 & 1 & 1 & 1 & 1 & 1.0 & 1.0 & 1.0 \\
\hline 37 & 1 & 1 & 1 & 1 & 1 & 1 & 1 & 1 & 1 & 1 & 1 & 1 & 1 & 1 & 1.0 & 1.0 & 1.0 \\
\hline 38 & 0 & 0 & 0 & 1 & 0 & 1 & 0 & 0 & 1 & 1 & 1 & 1 & 0 & 1 & 1.0 & 1.0 & 1.0 \\
\hline 39 & 0 & 0 & 0 & 1 & 0 & 0 & 1 & 1 & 0 & 1 & 1 & 1 & 0 & 0 & 1.0 & 1.0 & 1.0 \\
\hline 40 & 0 & 1 & 0 & 1 & 1 & 1 & 0 & 1 & 1 & 0 & 1 & 1 & 1 & 1 & 1.0 & 1.0 & 1.0 \\
\hline 41 & 0 & 1 & 1 & 1 & 1 & 1 & 0 & 1 & 1 & 1 & 1 & 1 & 1 & 1 & 1.0 & 1.0 & 1.0 \\
\hline 42 & 1 & 1 & 0 & 1 & 1 & 0 & 0 & 1 & 0 & 0 & 1 & 1 & 1 & 1 & 1.0 & 1.0 & 1.0 \\
\hline 43 & 1 & 0 & 1 & 1 & 0 & 1 & 0 & 1 & 1 & 1 & 0 & 1 & 0 & 1 & 1.0 & 1.0 & 1.0 \\
\hline 44 & 1 & 1 & 1 & 1 & 0 & 0 & 1 & 1 & 1 & 0 & 0 & 1 & 0 & 1 & 1.0 & 1.0 & 1.0 \\
\hline
\end{tabular}




\begin{tabular}{|c|c|c|c|c|c|c|c|c|c|c|c|c|c|c|c|c|c|}
\hline 45 & 1 & 1 & 1 & 1 & 0 & 0 & 0 & 1 & 1 & 0 & 0 & 0 & 0 & 3 & 1.0 & 1.0 & 1.0 \\
\hline 46 & 0 & 1 & 1 & 1 & 1 & 1 & 1 & 0 & 1 & 1 & 1 & 1 & 1 & 1 & 1.0 & 1.0 & 1.0 \\
\hline 47 & 1 & 1 & 0 & 0 & 1 & 1 & 0 & 0 & 1 & 1 & 1 & 1 & 1 & 0 & 1.0 & 1.0 & 1.0 \\
\hline 48 & 1 & 1 & 0 & 0 & 1 & 1 & 0 & 0 & 1 & 0 & 1 & 1 & 1 & 0 & 1.0 & 1.0 & 1.0 \\
\hline 49 & 1 & 1 & 0 & 1 & 1 & 1 & 0 & 0 & 1 & 1 & 1 & 1 & 1 & 1 & 1.0 & 1.0 & 1.0 \\
\hline 50 & 1 & 0 & 0 & 1 & 0 & 0 & 1 & 0 & 1 & 0 & 1 & 1 & 0 & 1 & 1.0 & 1.0 & 1.0 \\
\hline 51 & 1 & 0 & 1 & 1 & 0 & 0 & 1 & 1 & 1 & 1 & 1 & 1 & 0 & 1 & 1.0 & 1.0 & 1.0 \\
\hline 52 & 1 & 1 & 0 & 1 & 1 & 1 & 0 & 0 & 0 & 1 & 0 & 0 & 1 & 0 & 1.0 & 1.0 & 1.0 \\
\hline 53 & 1 & 1 & 1 & 1 & 0 & 1 & 0 & 0 & 1 & 0 & 1 & 1 & 0 & 1 & 1.0 & 1.0 & 1.0 \\
\hline 54 & 1 & 0 & 0 & 1 & 1 & 1 & 1 & 0 & 1 & 1 & 1 & 1 & 1 & 0 & 1.0 & 1.0 & 0.0 \\
\hline 55 & 1 & 0 & 0 & 1 & 1 & 1 & 1 & 1 & 1 & 0 & 1 & 1 & 0 & & 0.0 & 1.0 & 1.0 \\
\hline 56 & 0 & 1 & 0 & 1 & 1 & 0 & 1 & 0 & 1 & 1 & 1 & 1 & 1 & 1 & 1.0 & 1.0 & 1.0 \\
\hline 57 & 1 & 0 & 0 & 1 & 0 & 1 & 1 & 1 & 1 & 0 & 1 & 1 & 0 & 1 & 1.0 & 1.0 & 1.0 \\
\hline 58 & 1 & 1 & 0 & 1 & 1 & 1 & 0 & 1 & 1 & 1 & 1 & 1 & 1 & 0 & 1.0 & 1.0 & 1.0 \\
\hline 59 & 1 & 1 & 0 & 1 & 0 & 0 & 1 & 0 & 1 & 1 & 1 & 1 & 1 & 1 & 1.0 & 1.0 & 1.0 \\
\hline 60 & 1 & 1 & 1 & 1 & 1 & 1 & 0 & 1 & 1 & 1 & 1 & 1 & 1 & 1 & 1.0 & 1.0 & 1.0 \\
\hline 61 & 1 & 0 & 0 & 1 & 0 & 1 & 0 & 0 & 1 & 0 & 0 & 1 & 0 & 0 & 1.0 & 1.0 & 1.0 \\
\hline 62 & 1 & 1 & 1 & 1 & 1 & 1 & 1 & 1 & 1 & 1 & 1 & 1 & 1 & 0 & 1.0 & 1.0 & 1.0 \\
\hline 63 & 1 & 0 & 0 & 1 & 0 & 0 & 1 & 1 & 1 & 1 & 1 & 1 & 0 & 0 & 1.0 & 1.0 & 1.0 \\
\hline 64 & 0 & 0 & 0 & 1 & 0 & 1 & 1 & 1 & 1 & 1 & 1 & 1 & 1 & 0 & 1.0 & 1.0 & 1.0 \\
\hline 65 & 0 & 1 & 0 & 0 & 1 & 1 & 1 & 0 & 0 & 1 & 0 & 0 & 1 & 1 & 1.0 & 1.0 & 1.0 \\
\hline 66 & 1 & 0 & 1 & 1 & 0 & 1 & 1 & 1 & 1 & 0 & 1 & 1 & 0 & 1 & 1.0 & 1.0 & 1.0 \\
\hline 67 & 0 & 1 & 1 & 0 & 1 & 1 & 0 & 0 & 0 & 1 & 1 & 1 & 1 & 1 & 1.0 & 1.0 & 1.0 \\
\hline 68 & 1 & 0 & 0 & 1 & 0 & 1 & 1 & 1 & 1 & 1 & 1 & 1 & 1 & 1 & 1.0 & 1.0 & 1.0 \\
\hline 69 & 1 & 0 & 0 & 1 & 0 & 0 & 0 & 0 & 1 & 0 & 1 & 1 & 0 & 0 & 1.0 & 1.0 & 1.0 \\
\hline 70 & 1 & 1 & 1 & 0 & 0 & 0 & 0 & 0 & 1 & 0 & 0 & 1 & 0 & 1 & 1.0 & 1.0 & 1.0 \\
\hline 71 & 1 & 0 & 0 & 3 & 0 & 1 & 1 & 1 & 1 & 1 & 1 & 1 & 1 & 0 & 1.0 & 1.0 & 1.0 \\
\hline 72 & 1 & 0 & 0 & 1 & 0 & 0 & 1 & 0 & 0 & 0 & 1 & 1 & 0 & 0 & 0.0 & 1.0 & 1.0 \\
\hline 73 & 1 & 0 & 1 & 1 & 0 & 0 & 0 & 0 & 1 & 0 & 1 & 0 & 0 & 1 & 1.0 & 1.0 & 0.0 \\
\hline 74 & 1 & 1 & 1 & 1 & 1 & 1 & 0 & 0 & 0 & 1 & 0 & 1 & 0 & 1 & 1.0 & 1.0 & 1.0 \\
\hline 75 & 1 & 0 & 1 & 1 & 1 & 0 & 1 & 0 & 0 & 1 & 1 & 1 & 0 & 1 & 1.0 & 1.0 & 1.0 \\
\hline 76 & 0 & 0 & 1 & 1 & 0 & 0 & 0 & 1 & 1 & 1 & 1 & 1 & 1 & & 1.0 & 1.0 & 1.0 \\
\hline 77 & 0 & 1 & 1 & 1 & 1 & 1 & 1 & 1 & 0 & 1 & 1 & 1 & 1 & 1 & 1.0 & 1.0 & 1.0 \\
\hline 78 & 1 & 1 & 1 & 1 & 0 & 0 & 0 & 0 & 1 & 1 & 1 & 1 & 0 & 0 & 1.0 & 1.0 & 1.0 \\
\hline 79 & 0 & 0 & 0 & 1 & 1 & 0 & 0 & 0 & 0 & 0 & 1 & 1 & 1 & 0 & 1.0 & 1.0 & 1.0 \\
\hline 80 & 0 & 1 & 0 & 0 & 1 & 1 & 1 & 1 & 0 & 0 & 1 & 0 & 1 & 0 & 1.0 & 1.0 & 1.0 \\
\hline 81 & 1 & 1 & 0 & 1 & 1 & 0 & 1 & 1 & 1 & 1 & 1 & 1 & 1 & 0 & 1.0 & 1.0 & 1.0 \\
\hline 82 & 1 & 0 & 0 & 1 & 1 & 1 & 1 & 0 & 1 & 1 & 1 & 1 & 1 & 1 & 1.0 & 0.0 & 1.0 \\
\hline 83 & 1 & 0 & 0 & 1 & 0 & 0 & 0 & 1 & 1 & 0 & 0 & 1 & 0 & 0 & 1.0 & 1.0 & 1.0 \\
\hline 84 & & 0 & 1 & & 0 & 0 & 0 & 0 & 0 & 0 & 0 & 0 & 0 & & & & \\
\hline 85 & 1 & 0 & 0 & 1 & 0 & 1 & 1 & 0 & 1 & 0 & 1 & 1 & 1 & 1 & 1.0 & 1.0 & 1.0 \\
\hline 86 & 0 & 1 & 0 & 1 & 1 & 0 & 0 & 0 & 1 & 1 & 0 & 1 & 0 & 1 & 0.0 & 0.0 & 0.0 \\
\hline 87 & 1 & 0 & 0 & 1 & 0 & 0 & 0 & 1 & 1 & 0 & 1 & 1 & 0 & 1 & 1.0 & 1.0 & 1.0 \\
\hline 88 & 0 & 0 & 1 & 1 & 1 & 0 & 1 & 0 & 1 & 0 & 1 & 1 & 0 & 1 & 1.0 & 1.0 & 1.0 \\
\hline 89 & 1 & 0 & 0 & 1 & 0 & 1 & 0 & 1 & 1 & 0 & 1 & 1 & 0 & 1 & 1.0 & 1.0 & 1.0 \\
\hline 90 & 0 & 1 & 1 & 1 & 0 & 0 & 0 & 1 & 0 & 1 & 0 & 1 & 1 & 1 & 1.0 & 1.0 & 1.0 \\
\hline 91 & 1 & 0 & 0 & 1 & 0 & 1 & 1 & 1 & 0 & 0 & 1 & 1 & 0 & 1 & 1.0 & 1.0 & 1.0 \\
\hline 92 & 0 & 1 & 0 & 1 & 1 & 0 & 0 & 1 & 0 & 1 & 0 & 0 & 1 & 0 & 1.0 & 1.0 & 1.0 \\
\hline
\end{tabular}




\begin{tabular}{|c|c|c|c|c|c|c|c|c|c|c|c|c|c|c|c|c|c|}
\hline 93 & 0 & 0 & 0 & 1 & 1 & 1 & 1 & 1 & 1 & 1 & 1 & 1 & 1 & 1 & 1.0 & 1.0 & 1.0 \\
\hline 94 & 0 & 1 & 0 & 0 & 1 & 0 & 1 & 1 & 0 & 1 & 1 & 1 & 1 & 1 & 1.0 & 1.0 & 1.0 \\
\hline 95 & 1 & 0 & 0 & 1 & 0 & 0 & 0 & 0 & 1 & 0 & 1 & 1 & 0 & 1 & 1.0 & 1.0 & 0.0 \\
\hline 96 & 1 & 0 & 0 & 1 & 0 & 0 & 0 & 1 & 1 & 0 & 1 & 1 & 0 & 1 & 1.0 & 0.0 & 1.0 \\
\hline 97 & 1 & 0 & 1 & 1 & 0 & 0 & 0 & 0 & 1 & 0 & 0 & 1 & 0 & 1 & 1.0 & 1.0 & 1.0 \\
\hline
\end{tabular}

LEGENDA

$1=$ positivo

$2=$ negativo

(conforme critérios detalhados nas páginas 37 à 39) 


\section{APÊNDICE 4: DADOS RELATIVOS À SOBREVIVÊNCIA}

\begin{tabular}{|c|c|c|c|c|}
\hline $\mathrm{N}$ & status & Data do óbito & Último Contato & Sobrevivência \\
\hline 1 & 1 & $01 / 12 / 03$ & 01/12/03 & 53,688 \\
\hline 2 & 0 & & 05/05/08 & 83,079 \\
\hline 3 & 1 & 01/06/01 & 01/06/01 & 46,126 \\
\hline 4 & 1 & & 01/02/05 & 71,342 \\
\hline 5 & 0 & & 05/05/08 & 166,59 \\
\hline 6 & 1 & 03/01/97 & 03/01/97 & 14,926 \\
\hline 7 & 0 & & 05/05/08 & 49,479 \\
\hline 8 & 1 & \begin{tabular}{|l|}
$01 / 09 / 04$ \\
\end{tabular} & 01/09/04 & 63,912 \\
\hline 9 & 1 & 01/04/04 & 01/04/04 & 65,819 \\
\hline 10 & 0 & & $17 / 09 / 03$ & 51,123 \\
\hline 11 & & $\mathrm{OIH}$ & 09/06/96 & \\
\hline 12 & 0 & & 05/05/08 & 112,08 \\
\hline 13 & 1 & $01 / 12 / 00$ & $01 / 12 / 00$ & 15,058 \\
\hline 14 & & $\mathrm{OIH}$ & & \\
\hline 15 & & $\mathrm{OIH}$ & & \\
\hline 16 & 0 & & 05/05/08 & 158,7 \\
\hline 17 & 0 & & 08/01/08 & 39,814 \\
\hline 18 & 0 & & 05/05/08 & 84,164 \\
\hline 19 & 1 & 01/06/01 & 01/06/01 & 28,438 \\
\hline 20 & 1 & 01/01/00 & 01/01/00 & 38,729 \\
\hline 21 & 0 & & 05/05/08 & 148,41 \\
\hline 22 & 1 & $11 / 12 / 99$ & $11 / 12 / 99$ & 30,049 \\
\hline 23 & 0 & & 05/05/08 & 82,948 \\
\hline 24 & 0 & & 29/03/06 & 136,67 \\
\hline 25 & 1 & $12 / 12 / 04$ & $12 / 12 / 04$ & 30,115 \\
\hline 26 & 1 & 08/08/00 & 08/08/00 & 20,745 \\
\hline 27 & 1 & 01/05/03 & 05/05/08 & 132,99 \\
\hline 28 & 1 & $12 / 06 / 04$ & $12 / 06 / 04$ & 87,353 \\
\hline 29 & 0 & & 05/05/08 & 123,12 \\
\hline 30 & 0 & & 05/05/08 & 65,326 \\
\hline 31 & 1 & 01/01/00 & 01/01/00 & 12,592 \\
\hline 32 & 0 & & 05/05/08 & 105,4 \\
\hline 33 & 1 & $01 / 02 / 95$ & $01 / 02 / 95$ & 7,2 \\
\hline 34 & 0 & & $11 / 11 / 07$ & 269,03 \\
\hline 35 & 0 & & $12 / 12 / 07$ & 136,08 \\
\hline 36 & 1 & $1 / 11 / 05$ & 01/11/05 & 31,562 \\
\hline 37 & 1 & 01/01/05 & 01/01/05 & 20,745 \\
\hline 38 & 0 & & 05/05/08 & 70,849 \\
\hline 39 & 0 & & $17 / 11 / 06$ & 72,164 \\
\hline 40 & 0 & & 05/05/08 & 88,8 \\
\hline 41 & 0 & & 08/01/08 & 62,597 \\
\hline 42 & 0 & & 08/08/07 & 47,474 \\
\hline 43 & 1 & $13 / 09 / 05$ & $13 / 09 / 05$ & 26,005 \\
\hline 44 & 0 & & $11 / 04 / 07$ & 35,934 \\
\hline
\end{tabular}




\begin{tabular}{|c|c|c|c|c|}
\hline 45 & 0 & & 05/05/08 & 40,932 \\
\hline 46 & 1 & $01 / 02 / 06$ & 01/02/06 & 64,241 \\
\hline 47 & 1 & 01/02/99 & 01/02/99 & 22,093 \\
\hline 48 & 0 & & 05/05/08 & 137,82 \\
\hline 49 & 1 & $12 / 07 / 07$ & $12 / 07 / 07$ & 127,96 \\
\hline 50 & 1 & 01/02/06 & 01/02/06 & 123,39 \\
\hline 51 & 0 & & 07/01/08 & 67,627 \\
\hline 52 & 0 & & 01/11/00 & 19,627 \\
\hline 53 & 1 & 01/02/98 & $01 / 02 / 98$ & 35,901 \\
\hline 54 & 1 & $01 / 07 / 98$ & $01 / 07 / 98$ & 59,441 \\
\hline 55 & 0 & & 08/01/08 & 31,299 \\
\hline 56 & 0 & & $21 / 11 / 03$ & 26,005 \\
\hline 57 & 1 & $10 / 12 / 02$ & $10 / 12 / 02$ & 11,211 \\
\hline 58 & 1 & 01/10/07 & 01/10/07 & 12,164 \\
\hline 59 & 1 & $12 / 04 / 01$ & $12 / 04 / 01$ & 15,748 \\
\hline 60 & 0 & & 05/05/08 & 36,033 \\
\hline 61 & 0 & & 08/01/08 & 175,2 \\
\hline 62 & 0 & & 05/05/08 & 36,789 \\
\hline 63 & 1 & $12 / 12 / 05$ & $12 / 12 / 05$ & 5,4904 \\
\hline 64 & 0 & & $05 / 05 / 08$ & 41,326 \\
\hline 65 & 1 & $01 / 05 / 03$ & $01 / 05 / 03$ & 128,19 \\
\hline 66 & 0 & & 09/09/07 & 32,384 \\
\hline 67 & 0 & & 08/01/08 & 178,16 \\
\hline 68 & 0 & & 04/01/08 & 65,622 \\
\hline 69 & 1 & $15 / 05 / 94$ & $15 / 05 / 94$ & 21,501 \\
\hline 70 & 1 & $01 / 02 / 05$ & $01 / 02 / 05$ & 153,96 \\
\hline 71 & 0 & & 05/05/08 & 23,441 \\
\hline 72 & 1 & $21 / 08 / 86$ & $21 / 08 / 86$ & 44,153 \\
\hline 73 & 1 & $21 / 01 / 03$ & $21 / 01 / 03$ & 156,76 \\
\hline 74 & 1 & $01 / 05 / 91$ & 01/05/91 & 34,06 \\
\hline 75 & 0 & & 01/02/06 & 218,1 \\
\hline 76 & 1 & 01/06/04 & $12 / 04 / 07$ & 19,068 \\
\hline 77 & 0 & & 05/05/08 & 17,918 \\
\hline 78 & 1 & $13 / 07 / 06$ & $13 / 07 / 06$ & 176,38 \\
\hline 79 & 1 & 01/09/98 & $01 / 09 / 98$ & 86,104 \\
\hline 80 & 1 & 06/09/06 & 06/09/06 & 0,9534 \\
\hline 81 & 0 & & 05/05/08 & 27,584 \\
\hline 82 & 1 & 01/02/04 & 01/02/04 & 244,37 \\
\hline 83 & 0 & & 05/05/08 & 25,545 \\
\hline 84 & 0 & & $04 / 08 / 03$ & 134,17 \\
\hline 85 & 1 & 05/05/08 & 05/05/08 & 321,96 \\
\hline 86 & 0 & & $19 / 09 / 07$ & 266,33 \\
\hline 87 & 1 & 02/08/07 & $02 / 08 / 07$ & 12,723 \\
\hline 88 & 1 & 01/11/05 & 01/11/05 & 188,45 \\
\hline 89 & 1 & $03 / 04 / 01$ & 03/04/01 & 9,5671 \\
\hline 90 & 0 & & $05 / 05 / 08$ & 27,814 \\
\hline 91 & 1 & $15 / 11 / 92$ & $15 / 11 / 92$ & 11,145 \\
\hline 92 & 0 & & 03/01/08 & 19,858 \\
\hline
\end{tabular}




\begin{tabular}{|l|r|l|l|r|}
93 & 0 & & $05 / 05 / 08$ & 10,553 \\
\hline 94 & 0 & & $05 / 05 / 08$ & 11,047 \\
\hline 95 & 0 & & $05 / 05 / 08$ & 268,34 \\
\hline 96 & 1 & $01 / 03 / 01$ & $01 / 03 / 01$ & 265,78 \\
\hline 97 & 0 & & $07 / 01 / 08$ & 247,56 \\
\hline
\end{tabular}

\section{LEGENDA}

Status: 0 , vivo; 1 , óbito

OlH: óbito intra-hospitalar 